\title{
All-Photochemical Rotation of Molecular Motors with a Phosphorus Stereoelement
}

Gregory B. Boursalian, Eise R. Nijboer, Ruth Dorel, Lukas Pfeifer, Omer Markovitch, Alex Blokhuis, Ben L. Feringa*

Center for Systems Chemistry, Stratingh Institute for Chemistry, Zernike Institute for Advanced Materials, and Groningen Institute for Evolutionary Life Sciences, University of Groningen, Nijenborgh 4, 9747 AG Groningen, The Netherlands

\section{b.1.feringa@rug.nl}

Table of contents

1. General methods

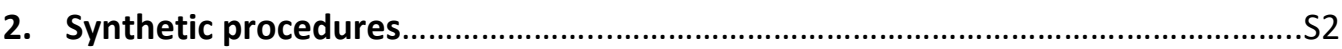

3. Photochemical isomerization studies of motors 1-3 ........................................... 8

4. Kinetic Studies of Thermal Processes..................................................................

5. Transit Through the "Shortcut" Cycle of Motor $\mathbf{1}$ (Figure 5 in the Main Text).....S28

6. Kinetic Modeling and Optimization via Data Fitting .............................................S30

7. Analysis of Fully Constrained Networks for Motor 2 ..........................................S32

8. Single Crystal X-Ray Diffraction Measurements....................................................S32

9. Characterization of New Compounds................................................................

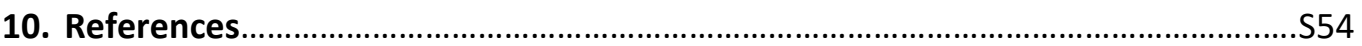




\section{General methods}

All reagents were purchased from commercial sources and used as received without further purification. Dry solvents were obtained from a MBraun solvent purification system. Column chromatography was performed on silica gel (Merck type 9385 230-400 mesh) or on a Reveleris X2 Flash Chromatography system; TLC: silica gel 60, Merck, $0.25 \mathrm{~mm}$. High Resolution Mass spectra (HRMS) were recorded on an LTQ Orbitrap XL. NMR spectra were obtained using a Varian Mercury Plus $\left({ }^{1} \mathrm{H}: 400 \mathrm{MHz},{ }^{13} \mathrm{C}: 100 \mathrm{MHz}\right)$, a Varian Unity Plus $\left({ }^{1} \mathrm{H}: 500 \mathrm{MHz},{ }^{13} \mathrm{C}: 125 \mathrm{MHz}\right)$ or a Bruker Innova $\left({ }^{1} \mathrm{H}: 600 \mathrm{MHz},{ }^{13} \mathrm{C}: 151 \mathrm{MHz}\right)$. Chemical shifts of ${ }^{1} \mathrm{H}$ and ${ }^{13} \mathrm{C}$ nuclei are reported in $\delta$ units (ppm) relative to the residual solvent signal. Chemical shifts of ${ }^{31} \mathrm{P}$ nuclei are reported in $\delta$ units (ppm) downfield of a trimethyl phosphate internal standard (defined as $0.00 \mathrm{ppm}$ ). The splitting patterns are designated as follows: s (singlet), d (doublet), t (triplet), q (quartet), dd (doublet of doublets), dt (doublet of triplets), ddd (doublet of doublets of doublets), dtd (doublet of triplets of doublets), ddt (doublet of doublets of triplets), td (triplet of doublets), and m (multiplet).

Supercritical Fluid Chromatography (SFC) was performed on a TharTechnologies, Inc. (Waters) Investigator II system.

UV-vis absorption spectra were measured on a SPECORD S600 Analytik Jena spectrophotometer, equipped with a QUANTUM Northwest TC-1 temperature controller and fluorescence temperature control cell. CD spectra were measured on a Jasco J-815 CD spectrometer. The solvents used for spectroscopic studies were of spectroscopic grade (UVASOL Merck). Irradiations were performed using LED lamps from ThorLabs, either directly aimed at a reaction solution or coupled to a fiber optic cable inserted into an NMR tube for in situ NMR irradiation experiments; ${ }^{1}$ the particular model used is specified in the experimental procedures. 


\section{Synthetic Procedures}

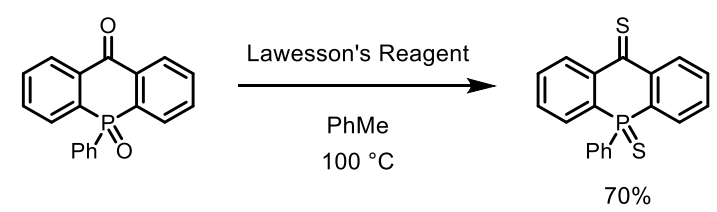

Thioketone phosphine sulfide 4. To an oven-dried $100 \mathrm{~mL}$ round-bottom Schlenk flask equipped with a stirring bar were added $1.00 \mathrm{~g}$ (3.29 mmol, 1.00 equiv) of 5-phenyl-10H-acridophosphin10-one 5-oxide (prepared according to a literature procedure $\left.{ }^{2}\right)$ and $1.66 \mathrm{~g}(4.11 \mathrm{mmol}, 1.25 \mathrm{~mol}$ equiv) of Lawesson's Reagent through a counterflow of nitrogen. The flask was sealed with a glass stopper and evacuated and refilled with nitrogen three times. The stopper was replaced with a rubber septum, through which $25 \mathrm{~mL}$ dry toluene $(0.25 \mathrm{M})$ was added with a syringe. The flask was sealed again with a glass stopper, and the nitrogen inlet was shut. The closed system was heated in an oil bath at $110^{\circ} \mathrm{C}$ for $48 \mathrm{~h}$, after which the opaque emerald green solution was allowed to cool to room temperature. The solvent was removed by rotary evaporation, and the residue was purified by flash column chromatography on silica gel (50:50 pentane/dichloromethane, mixture loaded as a near-saturated solution in dichloromethane). The resulting contaminated product was re-purified through a second round of flash column chromatography (70:30 pentane:dichloromethane, mixture loaded as a near-saturated solution in 50:50 pentane/dichloromethane), yielding 780. $\mathrm{mg}$ (2.32 mmol, $70 \%$ ) of thioketone phosphine sulfide $\mathbf{4}$ as a crystalline turquoise solid.

$\mathbf{R}_{\mathbf{f}}=0.4$ (70:30 pentane:dichloromethane)

${ }^{1} \mathbf{H}$ NMR $\left(500 \mathrm{MHz}, \mathrm{CDCl}_{3}\right) \delta 8.38-8.28(\mathrm{~m}, 4 \mathrm{H}), 7.76(\mathrm{dd}, J=7.5,7.5 \mathrm{~Hz}, 2 \mathrm{H}), 7.60(\mathrm{dd}, J=7.5$, $7.5 \mathrm{~Hz}, 2 \mathrm{H}), 7.48$ (dd, J = 7.5, 14.2 Hz, 2H), $7.33(\mathrm{~m}, 1 \mathrm{H}), 7.26(\mathrm{~m}, 2 \mathrm{H})$.

${ }^{13}$ C NMR $\left(125 \mathrm{MHz}, \mathrm{CDCl}_{3}\right) \delta 225.1(\mathrm{~d}, J=8.5 \mathrm{~Hz}), 144.7(\mathrm{~d}, \mathrm{~J}=4.4 \mathrm{~Hz}), 134.6(\mathrm{~d}, J=85.4 \mathrm{~Hz})$, $132.7(\mathrm{~d}, J=12.5 \mathrm{~Hz}), 132.1(\mathrm{~d}, J=2.5 \mathrm{~Hz}), 131.5(\mathrm{~d}, J=3.3 \mathrm{~Hz}), 131.3(\mathrm{~d}, J=9.9 \mathrm{~Hz}), 130.5(\mathrm{~d}$, $J=11.5 \mathrm{~Hz}), 129.9(\mathrm{~d}, J=7.9 \mathrm{~Hz}), 128.8(\mathrm{~d}, J=13.1 \mathrm{~Hz}), 126.4(\mathrm{~d}, J=81.7 \mathrm{~Hz})$.

${ }^{31}$ P NMR $\left(162 \mathrm{MHz}, \mathrm{CDCl}_{3}\right) \delta 18.5$.

HRMS (ESI+) $m / z$ calc. for $\mathrm{C}_{19} \mathrm{H}_{14} \mathrm{PS}_{2}[\mathrm{M}+\mathrm{H}]^{+}:$337.0269. Found: 337.0274 .

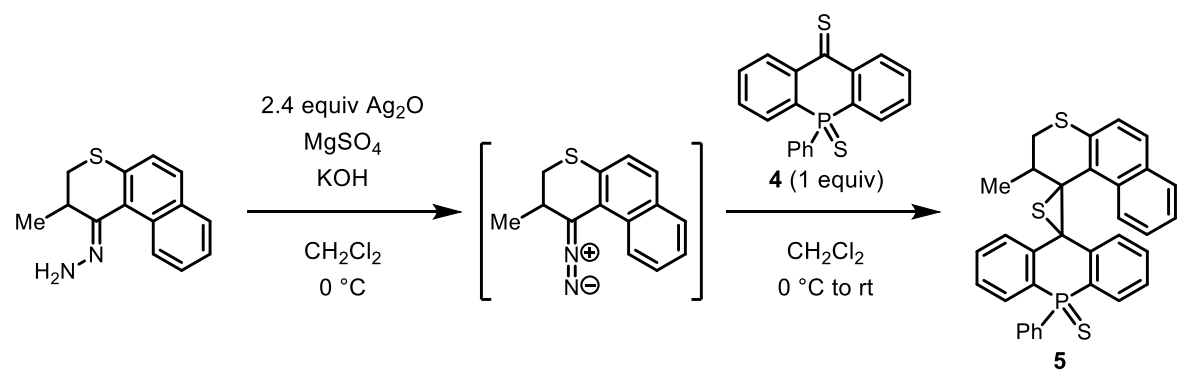

Thiiranes 5. To a $100 \mathrm{~mL}$, oven-dried Schlenk flask equipped with a magnetic stirbar were added 872. mg of (2-methyl-2,3-dihydro-1H-benzo[f]thiochromen-1-ylidene)hydrazone (3.60 mmol, 1.2 equiv) and $1.80 \mathrm{~g}$ anhydrous magnesium sulfate through a counterflow of nitrogen. The flask was sealed with a glass stopper, then evacuated and refilled with nitrogen three times. The stopper was replaced with a rubber septum, through which $48 \mathrm{~mL}$ of dry dichloromethane was added with a syringe. The mixture was stirred to dissolve all of the hydrazone and then cooled to $0{ }^{\circ} \mathrm{C}$ in an ice bath. The septum was removed, and $1.67 \mathrm{~g}$ of silver(I) oxide ( $3.60 \mathrm{mmol}, 2.4$ equiv) and $2.0 \mathrm{~mL}$ of a saturated solution of $\mathrm{KOH}$ in methanol were added quickly through a counterflow of nitrogen. 
The resulting heterogeneous mixture was stirred vigorously at $0{ }^{\circ} \mathrm{C}$ for one hour, after which the supernatant solution was dark red in color. This mixture was then quickly filtered through a sintered glass filter funnel directly into an oven-dried $100 \mathrm{~mL}$ Schlenk flask filled with nitrogen and immersed in an ice bath, and the frit was washed through with $2 \times 1 \mathrm{~mL}$ dry dichloromethane. To the resulting homogeneous dark red diazoalkane solution at $0{ }^{\circ} \mathrm{C}$ was added $1.01 \mathrm{~g}(3.00 \mathrm{mmol}$, 1.00 equiv) thioketone 4 in one portion as a solid, resulting in strong effervescence and instantaneous bleaching of the red color to light yellow. The mixture was allowed to warm to room temperature over $16 \mathrm{~h}$. The reaction mixture was concentrated onto silica gel through rotary evaporation, and the crude product was purified through flash column chromatography, eluting with $40 \rightarrow 80 \%$ DCM in pentane to yield $1.38 \mathrm{~g}$ of thiiranes $\mathbf{5}\left(\mathrm{R}_{\mathrm{f}}=0.13,70: 30\right.$ pentane:dichloromethane) as a light yellow foam. Because the diastereomers of $\mathbf{5}$ could not be separated, the mixture was carried through to the next step without characterization.

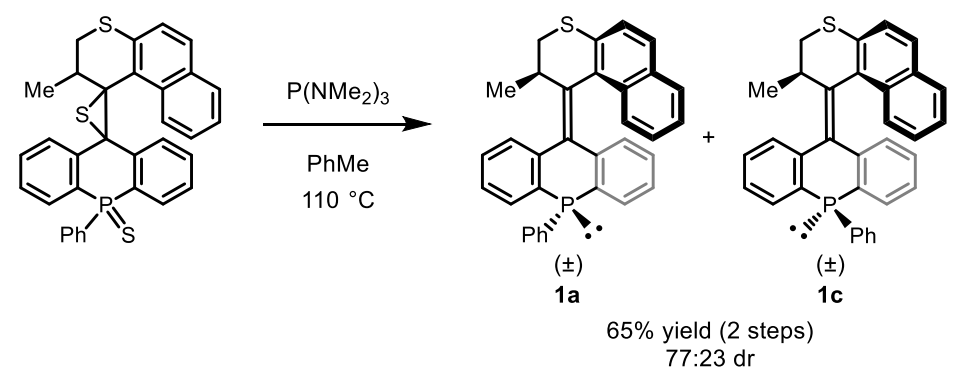

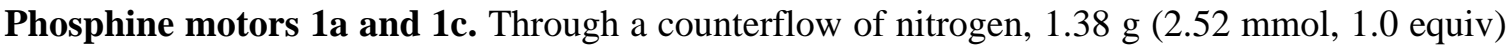
of the thiiranes 5 was added to a dry $40 \mathrm{~mL}$ Schlenk tube. The tube was sealed with a septum, and $7 \mathrm{~mL}$ dry toluene was added via syringe. To the resulting suspension was added $4.5 \mathrm{~mL}$ tris(dimethylamino)phosphine (25. mmol, 10. equiv). The tube was sealed with a stopper, and heated for $16 \mathrm{~h}$ at $110^{\circ} \mathrm{C}$. Upon cooling to room temperature, the reaction mixture was concentrated by rotary evaporation, and the residue was purified by column chromatography on silica gel ( 5 to $10 \%$ dichloromethane in pentane) to yield $1.10 \mathrm{~g}(2.27 \mathrm{mmol}, 65 \%$ yield from thioketone 4$)$ of a mixture of $\mathbf{1 a}$ and $\mathbf{1 c}$ as a colorless solid $(\mathbf{1 a}: \mathbf{1} \mathbf{c}=77: 23)$.

The isomers 1a and 1c were separated by repeated chromatography on silica gel $(10 \%$ dichloromethane in pentane). Isomer 1a was obtained in $>99 \%$ diastereomeric purity, while $\mathbf{2 c}$ could be obtained with $\sim 96 \%$ diastereomeric purity.

Characterization data for 1a:

$\mathbf{R f}=0.5$ (80:20 pentane:dichloromethane) .

${ }^{1} \mathbf{H}$ NMR $\left(400 \mathrm{MHz}, \mathrm{CDCl}_{3}\right) \delta 7.95(\mathrm{dd}, J=12.0,7.0 \mathrm{~Hz}, 1 \mathrm{H}), 7.85-7.75(\mathrm{~m}, 2 \mathrm{H}), 7.62-7.53(\mathrm{~m}$, $2 \mathrm{H}), 7.50-7.44(\mathrm{~m}, 2 \mathrm{H}), 7.44-7.37(\mathrm{~m}, 3 \mathrm{H}), 7.34(\mathrm{dd}, J=7.7,2 \mathrm{H}), 7.21(\mathrm{dd}, J=7.3,7.3 \mathrm{~Hz}, 1 \mathrm{H})$, $6.98(\mathrm{dd}, J=7.5,7.5 \mathrm{~Hz}, 1 \mathrm{H}), 6.84(\mathrm{dd}, J=7.6,7.6 \mathrm{~Hz}, 1 \mathrm{H}), 6.42(\mathrm{~d}, J=8.1 \mathrm{~Hz}, 1 \mathrm{H}), 6.38(\mathrm{~d}, J=$ $8.09 \mathrm{~Hz}, 1 \mathrm{H}), 6.14(\mathrm{~d}, J=7.8 \mathrm{~Hz}, 1 \mathrm{H}), 5.73(\mathrm{~d}, J=8.5 \mathrm{~Hz}, 1 \mathrm{H}), 4.18$ (ddq, $J=8.9,2.9,6.8, \mathrm{~Hz}$, $1 \mathrm{H}), 3.66(\mathrm{dd}, J=11.7,8.9 \mathrm{~Hz}, 1 \mathrm{H}), 2.99$ (dd, $J=11.7 \mathrm{~Hz}, 2.9 \mathrm{~Hz}), 0.59$ (d, $J=6.8 \mathrm{~Hz}, 3 \mathrm{H}$ ).

${ }^{13}$ C NMR $\left(101 \mathrm{MHz}, \mathrm{CDCl}_{3}\right) \delta 142.4(\mathrm{~d}, J=10.3 \mathrm{~Hz}), 139.8(\mathrm{~d}, J=14.3 \mathrm{~Hz}), 139.6(\mathrm{~d}, J=8.3$ $\mathrm{Hz}), 137.8(\mathrm{~d}, J=15.6 \mathrm{~Hz}), 137.5(\mathrm{~d}, J=17.5 \mathrm{~Hz}), 137.1(\mathrm{~d}, J=1.1 \mathrm{~Hz}), 135.9(\mathrm{~d}, J=12.0 \mathrm{~Hz})$, 135.2, 134.4, 134.3, 132.5, 131.6, 131.1, 130.9 (d, $J=1.6 \mathrm{~Hz}), 129.5(\mathrm{~d}, J=9.2 \mathrm{~Hz}), 129.1$ (d, $J=$ $8.8 \mathrm{~Hz}), 128.5(\mathrm{~d}, J=9.6 \mathrm{~Hz}), 128.3(\mathrm{~d}, J=2.9 \mathrm{~Hz}), 127.6(\mathrm{~d}, J=7.0 \mathrm{~Hz}), 127.3(\mathrm{~d}, J=2.7 \mathrm{~Hz})$, $126.7(\mathrm{~d}, J=0.7 \mathrm{~Hz}), 126.2(\mathrm{~d}, J=3.2 \mathrm{~Hz}), 125.9,125.8,125.8,125.4(\mathrm{~d}, J=3.7 \mathrm{~Hz}), 125.3(\mathrm{~d}, J$ $=8.3 \mathrm{~Hz}), 124.6,37.5,33.3,19.9$. 
${ }^{31} \mathbf{P}$ NMR $\left(162 \mathrm{MHz}, \mathrm{CDCl}_{3}\right) \delta-19.5$.

HRMS (ESI+) $m / z$ calc. for $\mathrm{C}_{33} \mathrm{H}_{26} \mathrm{PS}[\mathrm{M}+\mathrm{H}]^{+}$: 485.1487. Found: 485.1481.

Characterization data for $\mathbf{1 c}$ :

$\mathbf{R f}=0.4$ (80:20 pentane:dichloromethane) .

${ }^{1} \mathbf{H}$ NMR $\left(400 \mathrm{MHz}, \mathrm{CDCl}_{3}\right) \delta$ 7.71-7.58 (m br, 4H), $7.55(\mathrm{dd}, J=11.9,7.9 \mathrm{~Hz}, 2 \mathrm{H}), 7.47(\mathrm{dd}, J=$ $7.3 \mathrm{~Hz}, 2 \mathrm{H}), 7.42(\mathrm{~d}, J=8.5 \mathrm{~Hz}, 1 \mathrm{H}), 7.34(\mathrm{dd}, J=7.5 \mathrm{~Hz}, 1 \mathrm{H}), 7.19-7.06(\mathrm{~m}, 3 \mathrm{H}), 7.01$ (dd, $J=$ $6.7 \mathrm{~Hz}, 1 \mathrm{H}), 6.72(\mathrm{dd}, J=6.8,6.8 \mathrm{~Hz}, 1 \mathrm{H}), 6.65-6.58(\mathrm{~m} \mathrm{br}, 1 \mathrm{H}), 6.41(\mathrm{~d}, J=4.5 \mathrm{~Hz}, 2 \mathrm{H}), 4.20$ (ddq, J = 7.6, 3.4, 6.8 Hz, 1H), $3.73(\mathrm{dd}, J=11.5,7.6 \mathrm{~Hz}, 1 \mathrm{H}), 3.05(\mathrm{dd}, J=11.5,3.4 \mathrm{~Hz}, 1 \mathrm{H}), 0.82$ (d, $J=6.8 \mathrm{~Hz}, 3 \mathrm{H})$.

${ }^{13}$ C NMR $\left(101 \mathrm{MHz}, \mathrm{CDCl}_{3}\right) \delta 145.2(\mathrm{~d}, J=2.8 \mathrm{~Hz}), 144.6(\mathrm{~d}, J=4.0 \mathrm{~Hz}), 138.3(\mathrm{~d}, J=17.6 \mathrm{~Hz})$, 138.2, 137.4, 137.0, 135.2, $134.7(\mathrm{~d}, J=22.5 \mathrm{~Hz}), 134.1(\mathrm{~d}, J=17.5 \mathrm{~Hz}), 133.3,133.1(\mathrm{~d}, J=8.5$ $\mathrm{Hz}), 131.8,131.5,131.3,131.1,129.5,129.4(\mathrm{~d}, J=1.2 \mathrm{~Hz}), 128.6,128.5(\mathrm{~d}, J=5.3 \mathrm{~Hz}), 128.0$, $127.9(\mathrm{~d}, J=1.4 \mathrm{~Hz}), 127.5(\mathrm{~d}, J=21.5 \mathrm{~Hz}), 127.3(\mathrm{~d}, J=15.2 \mathrm{~Hz}), 126.5,126.1$ (d, $J=15.2 \mathrm{~Hz})$, $125.9,124.9,124.4,37.3,35.0,20.5$.

${ }^{31} \mathbf{P}$ NMR $\left(162 \mathrm{MHz}, \mathrm{CDCl}_{3}\right) \delta-26.5$.

HRMS (ESI+) $m / z$ calc. for $\mathrm{C}_{33} \mathrm{H}_{26} \mathrm{PS}[\mathrm{M}+\mathrm{H}]^{+}: 485.1487$. Found: 485.1481.

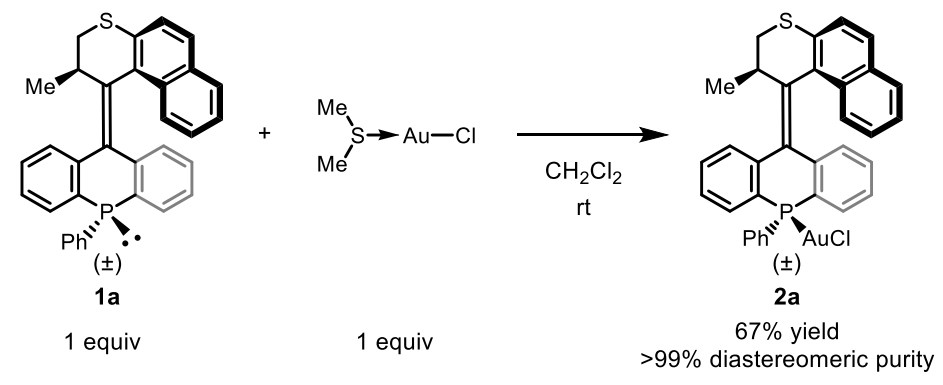

Gold complex 2a. To a heterogeneous mixture consisting of $60.8 \mathrm{mg}$ dimethylsulfide gold(I) chloride $(0.206 \mathrm{mmol}, 1.00$ equiv) partially dissolved in $1.0 \mathrm{~mL}$ dichloromethane in a 1-dram vial was added a solution of $100 \mathrm{mg}$ of phosphine $1 \mathrm{a}$ in $2.0 \mathrm{~mL}$ dichloromethane, which yielded a homogeneous solution. The solution was concentrated by rotary evaporation, and the resulting colorless solid was purified by column chromatography on silica gel (50:50 dichloromethane/pentane, mixture loaded as a near-saturated solution in this solvent system), yielding $98.6 \mathrm{mg}$ of complex $\mathbf{2 a}$ as a colorless solid ( $0.138 \mathrm{mmol}, 67 \%$ yield).

X-Ray quality crystals of $\mathbf{2 a}$ were grown by vapor diffusion of pentane into a solution of $\mathbf{2 a}$ in dichloromethane.

$\mathbf{R}_{\mathbf{f}}=0.32$ (50:50 pentane:dichloromethane).

${ }^{1} \mathbf{H}$ NMR $\left(400 \mathrm{MHz}, \mathrm{CDCl}_{3}\right) \delta 8.13(\mathrm{~d}, J=8.5 \mathrm{~Hz}, 1 \mathrm{H}), 7.83(\mathrm{dd}, J=7.8,4.0 \mathrm{~Hz}, 1 \mathrm{H}), 7.74-7.39$ (m, 7H), 7.30 (ddd, $J=7.6,2.4 \mathrm{~Hz}, 1 \mathrm{H}), 7.28-7.21(\mathrm{~m}, 1 \mathrm{H}), 7.15(\mathrm{dd}, J=8.1,6.8 \mathrm{~Hz}, 1 \mathrm{H}), 7.06$ $(\mathrm{dd}, J=12.4,7.6 \mathrm{~Hz}, 1 \mathrm{H}), 6.84-6.69(\mathrm{~m}, 2 \mathrm{H}), 6.52(\mathrm{ddd}, J=9.0,6.7,2.0 \mathrm{~Hz}, 1 \mathrm{H}), 6.42(\mathrm{dd}, J=$ $8.0,4.1 \mathrm{~Hz}, 1 \mathrm{H}), 4.22(\mathrm{ddq}, J=8.5,6.8,4.1 \mathrm{~Hz}, 1 \mathrm{H}), 3.60(\mathrm{dd}, J=11.8,8.5 \mathrm{~Hz}, 1 \mathrm{H}), 2.96(\mathrm{dd}, J=$ $11.8,4.1 \mathrm{~Hz}, 1 \mathrm{H}), 0.91(\mathrm{~d}, J=6.8 \mathrm{~Hz}, 3 \mathrm{H})$. 
Note: the ${ }^{1} \mathrm{H}$ NMR data for $\mathbf{2 a}$ tabulated above was acquired at room temperature, at which some aromatic signals are invisible due to a dynamic process (likely rotation of the phenyl group) with a coalescence temperature near room temperature. These signals become sharp as the temperature is reduced; see page S46 for spectra at various temperatures.

${ }^{13}$ C NMR $\left(151 \mathrm{MHz}, \mathrm{CDCl}_{3}\right) \delta 142.3(\mathrm{~d}, J=6.7 \mathrm{~Hz}), 142.0,140.7(\mathrm{~d}, J=7.7 \mathrm{~Hz}), 135.5,133.6(\mathrm{~d}$, $J=2.7 \mathrm{~Hz}), 132.9,131.8,131.2(\mathrm{~d}, J=60.0 \mathrm{~Hz}), 130.9,130.8(\mathrm{~d}, J=9.2 \mathrm{~Hz}), 130.7(\mathrm{~d}, J=10.8$ $\mathrm{Hz}), 130.2(\mathrm{~d}, J=2.5 \mathrm{~Hz}), 129.9(\mathrm{~d}, J=9.4 \mathrm{~Hz}), 129.6(\mathrm{~d}, J=10.5 \mathrm{~Hz}), 129.2(\mathrm{~d}, J=2.6 \mathrm{~Hz}), 129.0$ $(\mathrm{d}, J=4.6 \mathrm{~Hz}), 128.9$ (d, $J=4.8 \mathrm{~Hz}), 128.3(\mathrm{~d}, J=60.8 \mathrm{~Hz}), 128.0,127.6,127.4(\mathrm{~d}, J=10.9 \mathrm{~Hz})$, 127.4, 127.0, 126.9, 126.5 (d, $J=11.0 \mathrm{~Hz}), 126.2,125.8(\mathrm{~d}, J=2.4 \mathrm{~Hz}), 125.3,37.1,35.5,21.1$.

${ }^{31} \mathbf{P}$ NMR $\left(162 \mathrm{MHz}, \mathrm{CDCl}_{3}\right) \delta 6.9$.

HRMS (ESI+) $m / z$ calc. for $\mathrm{C}_{33} \mathrm{H}_{25} \mathrm{PSAu}[\mathrm{M}-\mathrm{Cl}]^{+}:$681.1075. Found: 681.1077 .

X-Ray Crystallography see page S36.
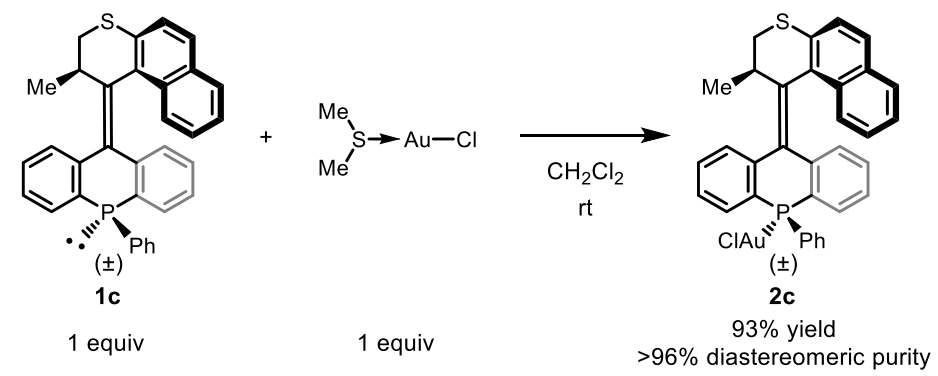

Gold complex 2c. A solution of $24.2 \mathrm{mg}$ phosphine 1 c $(0.0499 \mathrm{mmol}, 1.00$ equiv) in $0.7 \mathrm{~mL}$ dichloromethane was added to a 1-dram vial containing of $14.7 \mathrm{mg}$ dimethylsulfide gold(I) chloride (0.0499 mmol, 1.00 equiv), resulting in a homogeneous solution upon mixing. The solution was concentrated by rotary evaporation, and the resulting colorless solid was purified by column chromatography on silica gel (50:50 dichloromethane/pentane, mixture loaded as a near-saturated solution in this solvent system), yielding $33.4 \mathrm{mg}$ of complex $\mathbf{2 c}$ as a colorless solid (0.0466 mmol, 93\% yield).

X-Ray quality crystals of $\mathbf{2 c}$ were grown by vapor diffusion of pentane into a solution of $\mathbf{2 c}$ in dichloromethane.

$\mathbf{R}_{\mathbf{f}}=0.32$ (50:50 pentane:dichloromethane).

${ }^{1}$ H NMR $\left(600 \mathrm{MHz}, \mathrm{CDCl}_{3}\right) \delta 8.34$ (ddd, $\left.J=16.8,7.5,1.4 \mathrm{~Hz}, 1 \mathrm{H}\right), 8.13$ (ddd, $J=16.9,7.6,1.3$ $\mathrm{Hz}, 1 \mathrm{H}$ ), 7.89 (ddd, $J=7.8,3.5,1.2 \mathrm{~Hz}, 1 \mathrm{H}), 7.74$ (tt, $J=7.6,1.5 \mathrm{~Hz}, 1 \mathrm{H}), 7.66-7.59(\mathrm{~m}, 2 \mathrm{H})$, 7.59-7.53 (m, 2H), 7.50 (m, 3H), 7.47-7.40 (m, 2H), 7.03-6.96 (m, 2H), $6.54(\mathrm{dd}, J=7.7,7.7 \mathrm{~Hz}$, $1 \mathrm{H}), 6.35$ (ddd, $J=8.3,6.8,1.3 \mathrm{~Hz}, 1 \mathrm{H}), 6.21(\mathrm{ddd}, J=7.9,3.7,1.1 \mathrm{~Hz}, 1 \mathrm{H}), 5.57$ (dd, $J=8.4,1.1$ $\mathrm{Hz}, 1 \mathrm{H}), 4.16(\mathrm{ddq}, J=13.7,6.8,3.1 \mathrm{~Hz}, 1 \mathrm{H}), 3.63(\mathrm{dd}, J=11.8,8.9 \mathrm{~Hz}, 1 \mathrm{H}), 2.98(\mathrm{dd}, J=11.8$, $3.1 \mathrm{~Hz}, 1 \mathrm{H}), 0.61(\mathrm{~d}, J=6.8 \mathrm{~Hz}, 3 \mathrm{H})$.

${ }^{13}$ C NMR $\left(151 \mathrm{MHz}, \mathrm{CDCl}_{3}\right) \delta 143.7,143.2,141.7,137.6(\mathrm{~d}, J=22.3 \mathrm{~Hz}), 135.6(\mathrm{~d}, J=22.7 \mathrm{~Hz})$, 135.1, 132.9, $132.0(\mathrm{~d}, J=10.8 \mathrm{~Hz}), 132.0,131.8,131.7(\mathrm{~d}, J=2.7 \mathrm{~Hz}), 131.2(\mathrm{~d}, J=7.8 \mathrm{~Hz})$, 130.7, 130.4 (d, $J=2.6 \mathrm{~Hz}), 130.1$ (d, $J=57.4 \mathrm{~Hz}), 130.0$ (d, $J=6.5 \mathrm{~Hz}), 129.3$ (d, $J=11.8 \mathrm{~Hz})$, $129.3(\mathrm{~d}, J=6.6 \mathrm{~Hz}), 128.2,128.1(\mathrm{~d}, J=15.0 \mathrm{~Hz}), 127.8,126.9(\mathrm{~d}, J=15.1 \mathrm{~Hz}), 126.6,126.1$, $125.7(\mathrm{~d}, J=61.5 \mathrm{~Hz}), 125.1(\mathrm{~d}, J=64.8 \mathrm{~Hz}), 124.7,123.7,36.9,35.6,20.5$.

${ }^{31} \mathbf{P}$ NMR $\left(243 \mathrm{MHz}, \mathrm{CDCl}_{3}\right) \delta 15.3$. 
HRMS (ESI+) $m / z$ calc. for $\mathrm{C}_{33} \mathrm{H}_{25} \mathrm{PSAu}[\mathrm{M}-\mathrm{Cl}]^{+}: 681.1075$. Found: 681.1077 .

X-Ray Crystallography see page S37.

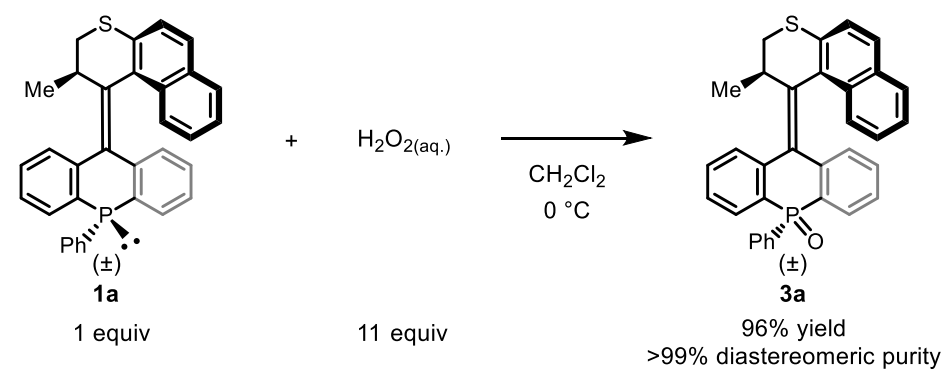

Phosphine oxide 3a. To a rapidly stirred solution of $49 . \mathrm{mg}$ phosphine $1 \mathrm{a}(0.10 \mathrm{mmol}, 1.0$ equiv) in $3.0 \mathrm{~mL}$ dichloromethane in a 1-dram vial immersed in an ice bath was added $0.11 \mathrm{~mL}$ of $30 \mathrm{wt} \%$ aqueous hydrogen peroxide (1.08 mmol, 11. equiv) via syringe. After $1 \mathrm{~h}$, the cloudy reaction mixture was diluted with $10 \mathrm{~mL}$ dichloromethane, transferred to a separatory funnel, and extracted with $10 . \mathrm{mL}$ water. The organic layer was separated, and the aqueous layer was extracted with $5 \mathrm{x}$ $5 \mathrm{~mL}$ dichloromethane. The combined organic layers were washed with brine, dried over anhydrous sodium sulfate, and concentrated to yield $48.3 \mathrm{mg}$ of $\mathbf{3 a}$ as a colorless solid $(0.096 \mathrm{mmol}, 96 \%$ yield).

The enantiomers $(\boldsymbol{R})$-3a and $(\boldsymbol{S})$-3a were separated by supercritical fluid chromatography (Chiralpak IA, $70 \% \mathrm{CO}_{2} / 30 \% \mathrm{MeOH}, 4 \mathrm{~mL} / \mathrm{min}$ ), with repeated $15 \mu \mathrm{L}$ injections of a solution of $25 \mathrm{mg}$ racemic 3a in $0.6 \mathrm{~mL}$ chloroform. The retention time of the $(S)$-enantiomer was $3.4 \mathrm{~min}$, and the $(R)$-enantiomer eluted at 4.8 minutes. The configuration of the $(S)$-enantiomer was assigned by $\mathrm{X}$-Ray diffraction.

$\mathrm{X}$-Ray quality crystals of $(\boldsymbol{S})-\mathbf{3 a}$ were grown by vapor diffusion of pentane into a solution in dichloromethane.

$\mathbf{R}_{\mathbf{f}}=0.22$ (95:5 dichloromethane:ethyl acetate).

${ }^{1} \mathbf{H}$ NMR $\left(400 \mathrm{MHz}, \mathrm{CDCl}_{3}\right) \delta{ }^{1} \mathrm{H}$ NMR $\left(400 \mathrm{MHz}, \mathrm{CDCl}_{3}\right) \delta 8.10(\mathrm{~d}, J=8.5 \mathrm{~Hz}, 1 \mathrm{H}), 7.77(\mathrm{dd}, J$ = 7.9, 4.2 Hz, 1H), $7.65(\mathrm{~m}, 2 \mathrm{H}), 7.58-7.48(\mathrm{~m}, 3 \mathrm{H}), 7.42(\mathrm{~d}, J=8.5 \mathrm{~Hz}, 1 \mathrm{H}), 7.33-7.19(\mathrm{~m}, 3 \mathrm{H})$, $7.12(\mathrm{dd}, J=7.5 \mathrm{~Hz}, 1 \mathrm{H}), 7.01(\mathrm{dd}, J=12.7,7.8 \mathrm{~Hz}, 1 \mathrm{H}), 6.74(\mathrm{dd}, J=7.5 \mathrm{~Hz}, 1 \mathrm{H}), 6.54(\mathrm{dd}, J=$ $7.6 \mathrm{~Hz}, 1 \mathrm{H}), 6.50-6.42(\mathrm{~m}, 1 \mathrm{H}), 4.23(\mathrm{ddq}, J=8.0,3.3,6.7 \mathrm{~Hz}, 1 \mathrm{H}), 3.67(\mathrm{dd}, J=11.3,8.0 \mathrm{~Hz}$, $1 \mathrm{H}), 3.06$ (dd, $J=11.3,3.3 \mathrm{~Hz}, 1 \mathrm{H}), 0.87$ (d, $J=6.7 \mathrm{~Hz}, 3 \mathrm{H})$.

Note: the ${ }^{1} \mathrm{H}$ NMR data for $\mathbf{3 a}$ tabulated above was acquired at room temperature, at which some aromatic signals are invisible due to a dynamic process (likely rotation of the phenyl group) with a coalescence temperature near room temperature. These signals become sharp as the temperature is reduced; see page S50 for spectra at various temperatures.

${ }^{13}$ C NMR $\left(151 \mathrm{MHz}, \mathrm{CDCl}_{3}\right) \delta 146.0(\mathrm{~d}, J=5.3 \mathrm{~Hz}), 144.2(\mathrm{~d}, J=5.2 \mathrm{~Hz}), 141.3,134.9,133.5$, $133.4(\mathrm{~d}, J=101.3 \mathrm{~Hz}), 132.5,132.4(\mathrm{~d}, J=2.8 \mathrm{~Hz}), 131.5(\mathrm{~d}, J=10.1 \mathrm{~Hz}), 131.5,131.3,130.9$ $(\mathrm{d}, J=11.1 \mathrm{~Hz}), 130.84(\mathrm{~d}, J=102.6 \mathrm{~Hz}), 130.4,130.1(\mathrm{~d}, J=10.0 \mathrm{~Hz}), 129.4,128.8,128.8,128.3$, 128.1, 128.0, 127.1, 127.0 (d, $J=12.3 \mathrm{~Hz}), 126.9,126.1$ (d, $J=12.2 \mathrm{~Hz}), 126.1,125.6,124.8,37.1$, $34.2,19.7$.

${ }^{31} \mathbf{P}$ NMR $\left(243 \mathrm{MHz}, \mathrm{CDCl}_{3}\right) \delta 14.8$. 
HRMS (ESI+) $m / z$ calc. for $\mathrm{C}_{33} \mathrm{H}_{26} \mathrm{OPS}[\mathrm{M}+\mathrm{H}]^{+}:$501.1437. Found: 501.1433.

X-Ray Crystallography see page S38.

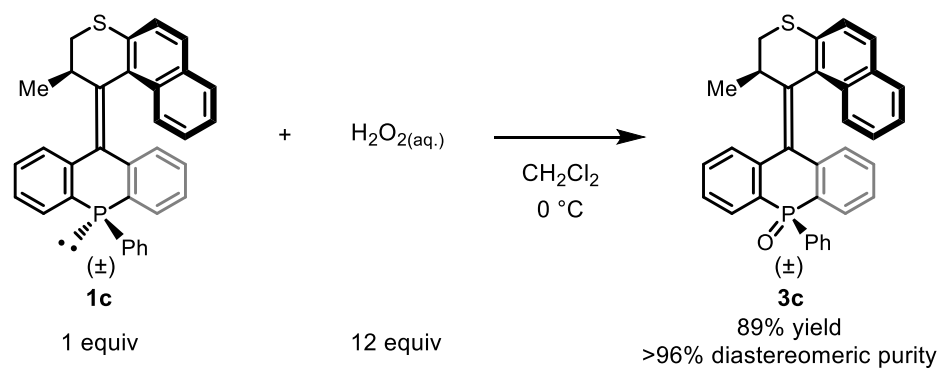

Phosphine oxide 3c. To a rapidly stirred solution of $24.2 \mathrm{mg}$ phosphine $1 \mathbf{c}(0.0500 \mathrm{mmol}, 1.0$ equiv) in $1.5 \mathrm{~mL}$ dichloromethane in a 1-dram vial immersed in an ice bath was added $0.060 \mathrm{~mL}$ of $30 \mathrm{wt} \%$ aqueous hydrogen peroxide $(0.59 \mathrm{mmol}, 12$. equiv) via syringe. After $1.5 \mathrm{~h}$, the cloudy reaction mixture was diluted with $8 . \mathrm{mL}$ dichloromethane, transferred to a separatory funnel, and extracted with $10 . \mathrm{mL}$ water. The organic layer was separated, and the aqueous layer was extracted with $3 \times 5 \mathrm{~mL}$ dichloromethane. The combined organic layers were washed with brine, dried over anhydrous sodium sulfate, and concentrated to yield $22.4 \mathrm{mg}$ of $\mathbf{3 c}$ as a colorless solid ( 0.0447 mmol, $89 \%$ yield).

$\mathrm{X}$-Ray quality crystals of $\mathbf{3 c}$ were grown by vapor diffusion of pentane into a solution of $\mathbf{3 c}$ in dichloromethane.

$\mathbf{R}_{\mathbf{f}}=0.16$ (90:10 dichloromethane:ethyl acetate)

${ }^{1} \mathbf{H}$ NMR $\left(500 \mathrm{MHz}, \mathrm{CDCl}_{3}\right) \delta 8.38(\mathrm{ddd}, J=12.1,7.3,1.4 \mathrm{~Hz}, 1 \mathrm{H}), 8.17$ (ddd, $J=12.0,7.6,1.4$ $\mathrm{Hz}, 1 \mathrm{H}), 7.90-7.78(\mathrm{~m}, 3 \mathrm{H}), 7.74(\mathrm{dd}, J=7.6 \mathrm{~Hz}, 1 \mathrm{H}), 7.66(\mathrm{dd}, J=6.9 \mathrm{~Hz}, 1 \mathrm{H}), 7.62(\mathrm{~d}, J=8.5$ $\mathrm{Hz}, 1 \mathrm{H}), 7.57-7.49(\mathrm{~m}, 4 \mathrm{H}), 7.44(\mathrm{~d}, J=8.5 \mathrm{~Hz}, 1 \mathrm{H}), 7.08-6.97(\mathrm{~m}, 2 \mathrm{H}), 6.57(\mathrm{dd}, J=7.6 \mathrm{~Hz}$, $1 \mathrm{H}), 6.34(\mathrm{ddd}, J=8.4,6.8,1.4 \mathrm{~Hz}, 1 \mathrm{H}), 6.25(\mathrm{dd}, J=7.8,4.9 \mathrm{~Hz}, 1 \mathrm{H}), 5.70(\mathrm{~d}, J=8.5 \mathrm{~Hz}, 1 \mathrm{H})$, $4.29-4.19$ (ddq, $J=8.8,3.1,6.8 \mathrm{~Hz} 1 \mathrm{H}), 3.68(\mathrm{dd}, J=11.8,8.8 \mathrm{~Hz}, 1 \mathrm{H}), 3.02(\mathrm{dd}, J=11.8,3.1$ $\mathrm{Hz}, 1 \mathrm{H}), 0.67(\mathrm{~d}, J=6.8 \mathrm{~Hz}, 3 \mathrm{H})$.

${ }^{13}$ C NMR $\left(126 \mathrm{MHz}, \mathrm{CDCl}_{3}\right) \delta 141.8(\mathrm{~d}, J=8.1 \mathrm{~Hz}), 141.2(\mathrm{~d}, J=8.5 \mathrm{~Hz}), 140.5,135.0,134.5$, 133.7, 133.0, $132.4(\mathrm{~d}, J=2.8 \mathrm{~Hz}), 132.1(\mathrm{~d}, J=5.8 \mathrm{~Hz}), 131.8,131.5(\mathrm{~d}, J=11.0 \mathrm{~Hz}), 131.5(\mathrm{~d}, J$ $=3.1 \mathrm{~Hz}), 130.8,130.8(\mathrm{~d}, J=51.6 \mathrm{~Hz}), 129.9(\mathrm{~d}, J=2.6 \mathrm{~Hz}), 129.9,129.6(\mathrm{~d}, J=5.7 \mathrm{~Hz}), 129.1$, $128.9(\mathrm{~d}, J=12.4 \mathrm{~Hz}), 128.7(\mathrm{~d}, J=9.7 \mathrm{~Hz}), 128.5(\mathrm{~d}, J=9.9 \mathrm{~Hz}), 128.0(\mathrm{~d}, J=11.2 \mathrm{~Hz}), 127.9$ (d, $J=42.4 \mathrm{~Hz}), 126.8$ (d, $J=11.3 \mathrm{~Hz}), 126.5,125.9,124.6,124.0,36.9,35.2,20.5$.

${ }^{31} \mathbf{P}$ NMR $\left(162 \mathrm{MHz}, \mathrm{CDCl}_{3}\right) \delta 11.0$.

HRMS (ESI+) $m / z$ calc. for $\mathrm{C}_{33} \mathrm{H}_{26} \mathrm{OPS}[\mathrm{M}+\mathrm{H}]^{+}:$501.1437. Found: 501.1436.

X-Ray Crystallography see page S39. 


\section{Photochemical isomerization studies of motors 1-3}

\subsection{Determination of PSS ratios}

PSS ratios of motor 2 starting from 2a at $340 \mathrm{~nm}$. An NMR tube containing a solution of motor 2a $(1.7 \mathrm{mg}, 2.4 \mu \mathrm{mol})$ in $0.50 \mathrm{~mL}$ of $d_{8}$-THF $(4.8 \mathrm{mM})$ was fitted with a glass fiberoptic cable nested inside a coaxial tube for in situ irradiation. The tube was inserted into a Varian Unity Plus $500 \mathrm{MHz}$ NMR spectrometer and cooled to $-20{ }^{\circ} \mathrm{C}$. After initial ${ }^{1} \mathrm{H}$ and ${ }^{31} \mathrm{P}$ NMR spectra were recorded, the sample was irradiated through the fiberoptic cable while still inserted, using a ThorLabs M340F3 (340 nm) LED, set to maximum power. The ratio of $\mathbf{2 a - d}$ was followed by ${ }^{31} \mathrm{P}$ NMR, and irradiation was continued until this ratio settled on a constant value (approximately 90 $\min ): \mathbf{2 a}: \mathbf{2 b}: \mathbf{2 c}: \mathbf{2 d}=27: 51: 8: 14$.

PSS ratios of motor 2 starting from $2 \mathrm{a}$ at $365 \mathrm{~nm}$ and $395 \mathrm{~nm}$. An NMR tube containing a solution of motor $2 \mathrm{a}(1.9 \mathrm{mg}, 2.6 \mu \mathrm{mol})$ in $0.50 \mathrm{~mL}$ of $d_{8}$-THF $(5.2 \mathrm{mM})$ was fitted with a glass fiberoptic cable nested inside a coaxial tube for in situ irradiation. The tube was inserted into a Varian Unity Plus $500 \mathrm{MHz}$ NMR spectrometer and cooled to $-20{ }^{\circ} \mathrm{C}$. After initial ${ }^{1} \mathrm{H}$ and ${ }^{31} \mathrm{P}$ NMR spectra were recorded, the sample was irradiated through the fiberoptic cable while still inserted, using a ThorLabs M365FP1 (365 nm) LED, set to maximum power. The ratio of 2a-d was followed by ${ }^{31} \mathrm{P}$ NMR, and irradiation was continued until this ratio settled on a constant value

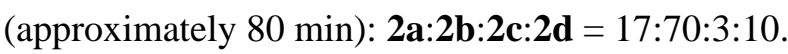

The LED was then swapped for a ThorLabs M395F2 (395 nm), and irradiation continued until the ratio of $\mathbf{2 a - d}$ settled on a constant value (approximately $80 \mathrm{~min}$ ): $\mathbf{2 a}: \mathbf{2 b}: \mathbf{2 c}: \mathbf{2 d}=17: 70: 3: 10$.

PSS ratios of motor 3 starting from 3a at $365 \mathrm{~nm}$ and $385 \mathrm{~nm}$. An NMR tube containing a solution of motor $3 \mathbf{a}(1.7 \mathrm{mg}, 3.4 \mu \mathrm{mol})$ in $0.50 \mathrm{~mL}$ of $d_{8}$-THF $(6.8 \mathrm{mM})$ was fitted with a glass fiberoptic cable nested inside a coaxial tube for in situ irradiation. The tube was inserted into a Varian Unity Plus $500 \mathrm{MHz}$ NMR spectrometer and cooled to $-50{ }^{\circ} \mathrm{C}$. After initial ${ }^{1} \mathrm{H}$ and ${ }^{31} \mathrm{P}$ NMR spectra were recorded, the sample was irradiated through the fiberoptic cable while still inserted, using a ThorLabs M365FP1 (365 nm) LED, set to maximum power. The ratio of 3a-d was followed by ${ }^{31} \mathrm{P}$ NMR, and irradiation was continued until this ratio settled on a constant value (approximately $60 \mathrm{~min}$ ): $\mathbf{3 a}: 3 \mathbf{b}: \mathbf{3 c}: \mathbf{3 d}=13: 75: 5: 7$.

The LED was then swapped for a ThorLabs M385F1 $(385 \mathrm{~nm})$, and irradiation continued until the ratio of $\mathbf{3 a}-\mathbf{d}$ settled on a constant value: $\mathbf{3 a}: \mathbf{3 b} \mathbf{3} \mathbf{3 c}: \mathbf{3 d}=4: 85: 3: 8$.

The PSS ratios at $405 \mathrm{~nm}$ were taken from the end point of the photokinetic study starting from $\mathbf{3 a}$ (see next section, Figure S3).

\subsection{Photokinetic studies of isomerization}

Approach to PSS at $395 \mathrm{~nm}$ starting from 2a. An NMR tube containing a solution of motor 2a $(1.8 \mathrm{mg}, 2.5 \mu \mathrm{mol})$ in $0.50 \mathrm{~mL}$ of $d_{8}$-THF $(5.0 \mathrm{mM})$ was fitted with a glass fiberoptic cable nested inside a coaxial tube for in situ irradiation. The tube was inserted into a Varian Unity Plus $500 \mathrm{MHz}$ NMR spectrometer and cooled to $-20{ }^{\circ} \mathrm{C}$. After an initial ${ }^{31} \mathrm{P}$ NMR spectrum was recorded, the sample was irradiated through the fiberoptic cable while still inserted, using a ThorLabs M395F2 (395 nm) LED, set to maximum power. The approach was followed by ${ }^{31} \mathrm{P}$ NMR, with 64 scans for each time point, $2 \mathrm{sec}$ relaxation delay, and an acquisition time of $0.675 \mathrm{sec}$, for a total measurement time of $171.2 \mathrm{sec}$. These acquisitions were carried out every $10 \mathrm{~min}$. 

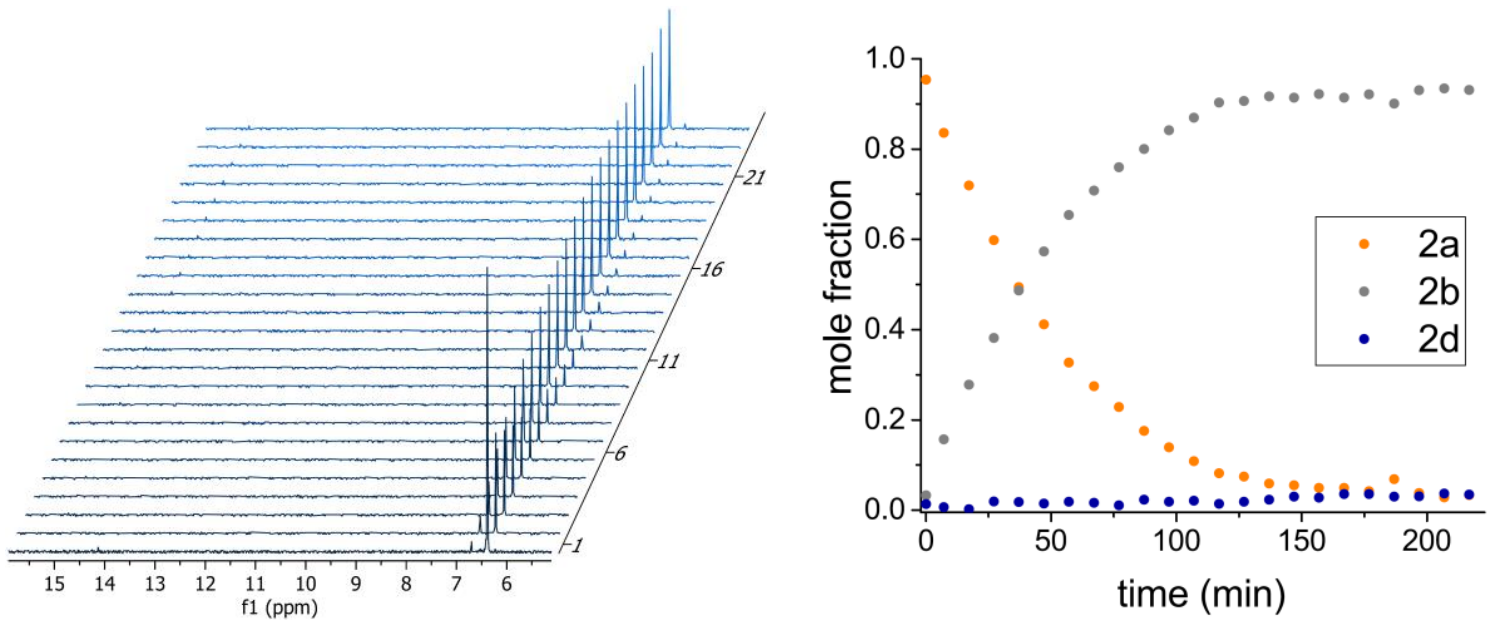

Figure S1. Approach to PSS of motor 2a irradiated at $395 \mathrm{~nm}$, followed by ${ }^{31} \mathrm{P}$ NMR: ${ }^{31} \mathrm{P}$ NMR traces (left) and plot of mole fraction vs. time (right).

Approach to PSS at $395 \mathbf{~ n m}$ starting from 2c. An NMR tube containing a solution of motor 2c $(1.9 \mathrm{mg}, 2.6 \mu \mathrm{mol})$ in $0.50 \mathrm{~mL}$ of $d_{8}$-THF $(5.2 \mathrm{mM})$ was fitted with a glass fiberoptic cable nested inside a coaxial tube for in situ irradiation. The tube was inserted into a Varian Unity Plus $500 \mathrm{MHz}$ NMR spectrometer and cooled to $-20{ }^{\circ} \mathrm{C}$. After an initial ${ }^{31} \mathrm{P}$ NMR spectrum was recorded, the sample was irradiated through the fiberoptic cable while still inserted, using a ThorLabs M395F2 (395 nm) LED, set to maximum power. The approach was followed by ${ }^{31} \mathrm{P}$ NMR, with 64 scans for each time point, $2 \mathrm{sec}$ relaxation delay, and an acquisition time of $0.675 \mathrm{sec}$, for a total measurement time of $171.2 \mathrm{sec}$. These acquisitions were carried out every $10 \mathrm{~min}$.
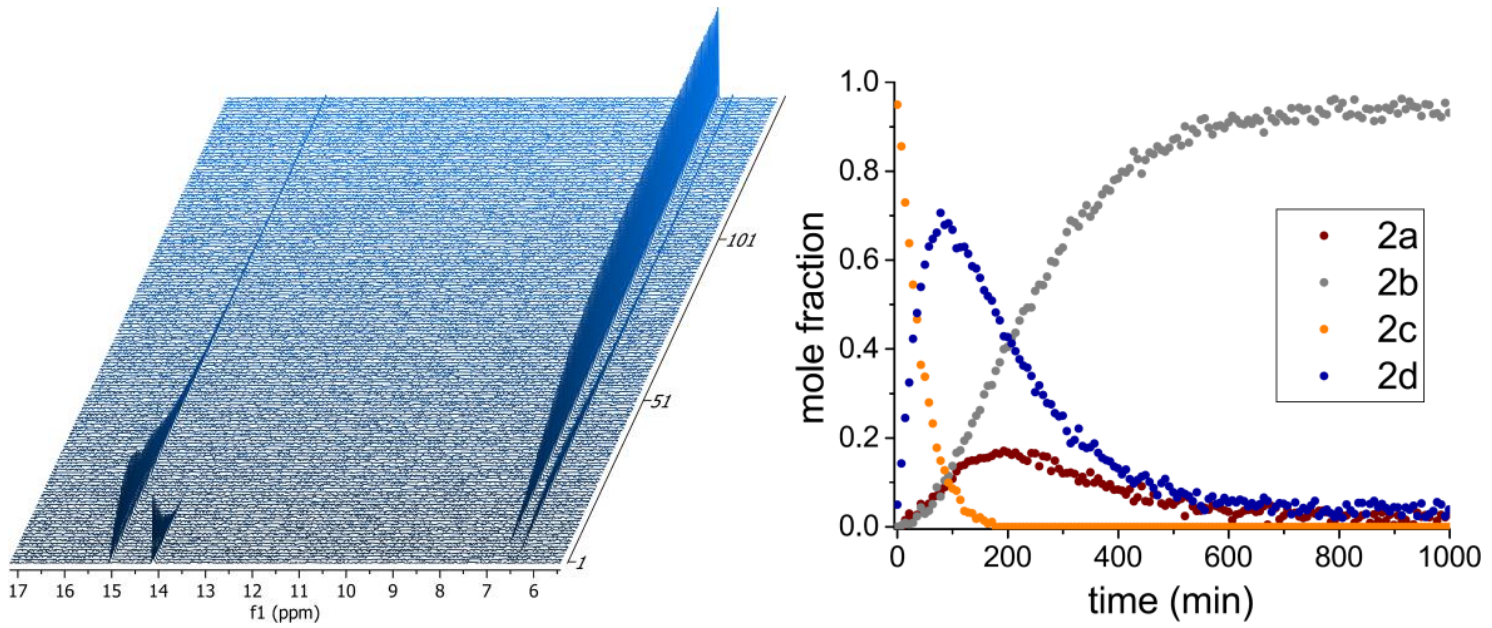

Figure S2. Approach to PSS of motor $2 \mathrm{c}$ irradiated at $395 \mathrm{~nm}$, followed by ${ }^{31} \mathrm{P}$ NMR: ${ }^{31} \mathrm{P}$ NMR traces (left) and plot of mole fraction vs. time (right).

Approach to PSS at $\mathbf{4 0 5} \mathbf{~ n m}$ starting from 3a. An NMR tube containing a solution of motor 3a (1.5 mg, $2.5 \mu \mathrm{mol})$ in $0.50 \mathrm{~mL}$ of $d_{8}$-THF $(5.0 \mathrm{mM})$ was fitted with a glass fiberoptic cable nested inside a coaxial tube for in situ irradiation. The tube was inserted into a Bruker AVANCE III 600 NMR spectrometer and cooled to $-50{ }^{\circ} \mathrm{C}$. After an initial ${ }^{31} \mathrm{P}$ NMR spectrum was recorded, the sample was irradiated through the fiberoptic cable while still inserted, using a ThorLabs M395F2 (395 nm) LED, set to maximum power. The approach was followed by ${ }^{31} \mathrm{P}$ NMR, with 32 scans for each time point, $2 \mathrm{sec}$ relaxation delay, and an acquisition time of $2.2282 \mathrm{sec}$. These acquisitions were carried out every $10 \mathrm{~min}$. 

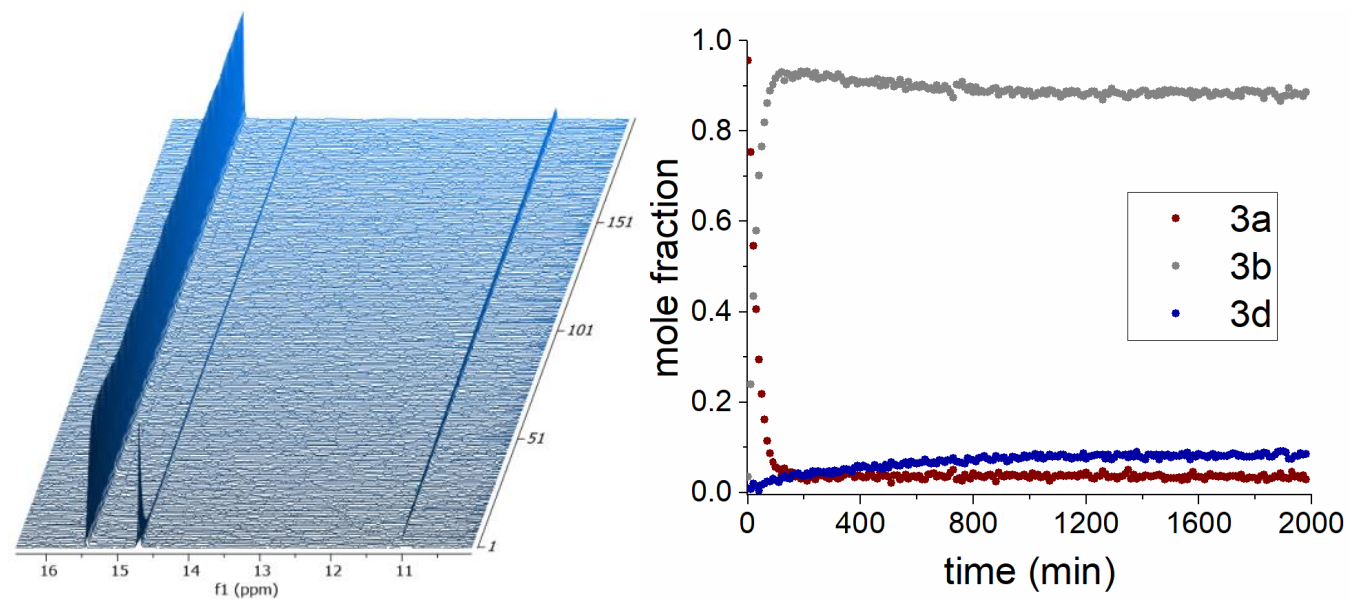

Figure S3. Approach to PSS of motor 3a irradiated at $405 \mathrm{~nm}$, followed by ${ }^{31} \mathrm{P}$ NMR: ${ }^{31} \mathrm{P}$ NMR traces (left) and plot of mole fraction vs. time (right).

Approach to PSS at $405 \mathrm{~nm}$ starting from 3c. An NMR tube containing a solution of motor 3c $(1.5 \mathrm{mg}, 2.5 \mu \mathrm{mol})$ in $0.50 \mathrm{~mL}$ of $d_{8}$-THF $(5.0 \mathrm{mM})$ was fitted with a glass fiberoptic cable nested inside a coaxial tube for in situ irradiation. The tube was inserted into a Varian Unity Plus $500 \mathrm{MHz}$ NMR spectrometer and cooled to $-50{ }^{\circ} \mathrm{C}$. After an initial ${ }^{31} \mathrm{P}$ NMR spectrum was recorded, the sample was irradiated through the fiberoptic cable while still inserted, using a ThorLabs M405FP1 $(405 \mathrm{~nm}) \mathrm{LED}$, set to maximum power. The approach was followed by ${ }^{31} \mathrm{P}$ NMR, with 64 scans for each time point, $2 \mathrm{sec}$ relaxation delay, and an acquisition time of $0.675 \mathrm{sec}$, for a total measurement time of $171.2 \mathrm{sec}$. These acquisitions were carried out every $10 \mathrm{~min}$.
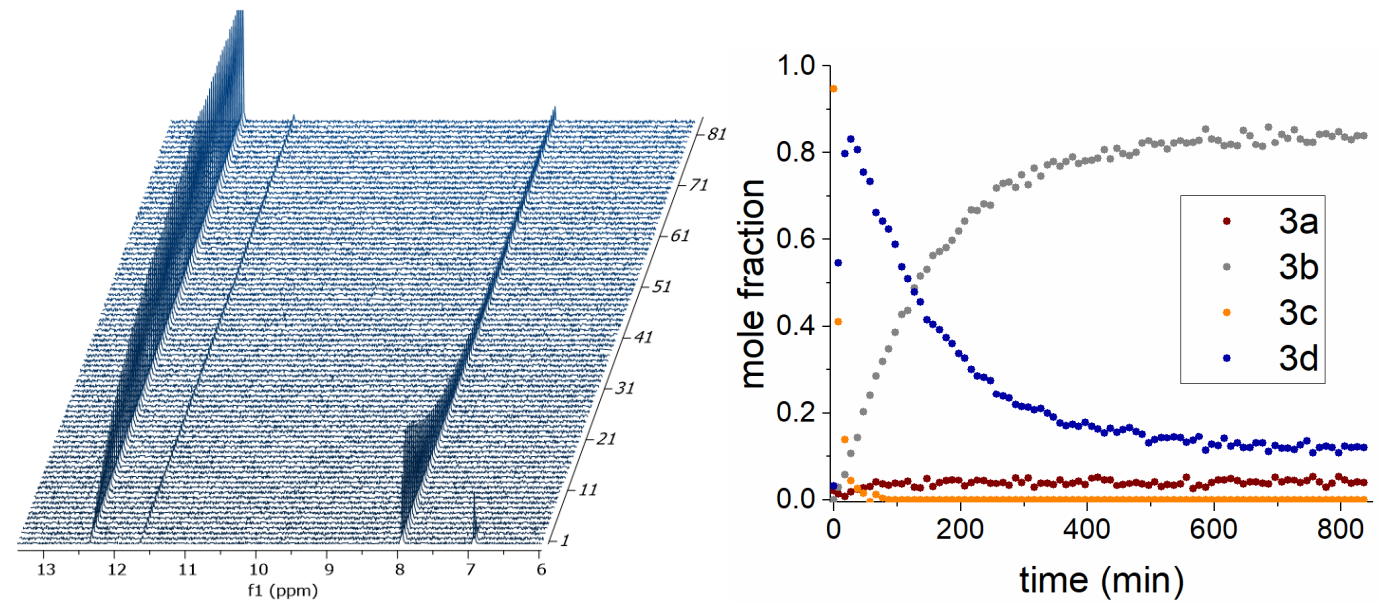

Figure S4. Approach to PSS of motor 3c irradiated at $405 \mathrm{~nm}$, followed by ${ }^{31} \mathrm{P}$ NMR: ${ }^{31} \mathrm{P}$ NMR traces (left) and plot of mole fraction vs. time (right). 


\section{Kinetic Studies of Thermal Processes}

\subsection{General Comments}

Most commonly, kinetic studies of the thermal helix inversion process of molecular motors are conducted by monitoring the reaction through optical spectroscopy, for example UV/vis or Circular Dichroism spectroscopy. This is possible because most molecular motors exhibit clean-cut photochemical isomerization behavior: irradiation of a stable state of the motor yields just one metastable diastereomer through $E / Z$ isomerization. Conversion of this metastable diastereomer to a new stable diastereomer at a higher temperature can be conveniently followed by optical spectroscopy because it is a one-to-one process. The more complex photochemical behavior of phosphine-based motors 1-3 precludes such straightforward monitoring, because both metastable diastereomers can be significantly represented in the photostationary state, so both thermal helix inversion processes occur in parallel.

Therefore, ${ }^{1} \mathrm{H}$ and ${ }^{31} \mathrm{P}$ NMR spectroscopy were used to follow the thermal helix inversion processes of unstable compounds $\mathbf{1 b}, \mathbf{2} \mathbf{b}, \mathbf{2 d}, \mathbf{3} \mathbf{b}$, and $\mathbf{3 d}$. The high inherent resolution of NMR spectroscopy permits simultaneous measurement of the concentrations of all species in the mixture, so that their individual reactions can be readily monitored. Mixtures enriched in the desired metastable isomer(s) were prepared through irradiation until the photostationary state was reached (for $\mathbf{1 b}, \mathbf{2} \mathbf{b}$, $\mathbf{3 b}, \mathbf{3 d}$ ), or through timed irradiation of an appropriate stable diastereomer (for $\mathbf{2 d}$ ). The samples were then warmed to the desired temperature in the NMR probe to induce the thermal helix inversion(s). The precise temperature within the NMR probe was measured prior to the run by the ethylene glycol thermometer method. ${ }^{3}$

The kinetics of the processes were analyzed in terms of the mole fraction of the metastable diastereomer in a pair with its corresponding helix inversion product; for example, for the conversion of $\mathbf{2 b}$ to $\mathbf{2 c}$, the mole fraction of $\mathbf{2 b}$ is given as $[\mathbf{2 b}] /([\mathbf{2 b}]+[\mathbf{2 c}])$. This ratio was determined through integration of the ${ }^{1} \mathrm{H}$ or ${ }^{31} \mathrm{P}$ NMR signals corresponding to each species, and the results were fit to a first-order exponential decay function using the OriginPro software package to extract the rate constant. ${ }^{4}$

In all cases, the sum of the integrals for each metastable isomer and its stable product was constant throughout the run, consistent with clean thermal helix inversion of each metastable diastereomer without side reactions. No evidence of any byproducts was found in any time point or in ${ }^{1} \mathrm{H}$ NMR analysis of the reaction mixture at the end of the run, and the mixture was inspected at the end of each run to confirm homogeneity. In nearly all runs, the reaction was followed through at least two half-lives, and for every process at least one run was taken to full conversion ( $\geq 5$ half-lives). All Eyring and Arrhenius plots thus derived showed excellent linear correlation $\left(\mathrm{R}^{2}>0.99\right)$.

\subsection{Kinetic Studies of Thermal Helix Inversion of $2 b$}
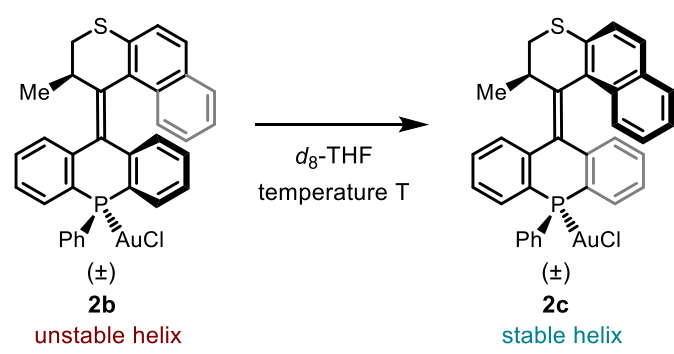
General Procedure. A solution of $3.6 \mathrm{mg}(5.0 \mu \mathrm{mol})$ of motor $2 \mathrm{a}$ in $0.50 \mathrm{~mL} d_{8}$-THF $(10 . \mathrm{mM})$ in an NMR tube was irradiated for one hour with a $395 \mathrm{~nm}$ LED lamp in a refrigerator at $6{ }^{\circ} \mathrm{C}$, in order to generate the photostationary state consisting of $>90 \% \mathbf{2 b}$. The sample was then inserted into an NMR probe pre-warmed to the appropriate temperature. After the instrument was tuned, locked, and shimmed, it was set to acquire a ${ }^{31} \mathrm{P}$ NMR spectrum every $15 \mathrm{~min}$. The progress of the reaction was followed by integration of the signals from $\mathbf{2 b}$ and $\mathbf{2 c}$, and converting the raw integral values to a mole fraction of $\mathbf{2} \mathbf{b}$ relative to the sum of the concentrations of the two compounds. The data was analyzed in terms of first order kinetics.

\section{Eyring analysis.}

$\begin{array}{cccccccc}\mathbf{T}\left({ }^{\circ} \mathbf{C}\right) & \mathbf{T}(\mathbf{K}) & \mathbf{t}_{\mathbf{1}}(\mathbf{s}) & \mathbf{k}\left(=\mathbf{t}_{\mathbf{1}}{ }^{-1}\right) & \mathbf{1 / T} & \mathbf{I n}(\mathbf{k} / \mathbf{T}) & \ln (\mathbf{k}) & \mathbf{t}_{\mathbf{1 / 2}}(\mathbf{h}) \\ 35.0 & 308 & 45528.1 & 2.20 \mathrm{E}-05 & 0.003247 & -1.65 \mathrm{E}+01 & -10.7261 & 8.77 \\ 40.0 & 313 & 26836.2 & 3.73 \mathrm{E}-05 & 0.003195 & -1.59 \mathrm{E}+01 & -10.1975 & 5.17 \\ 45.0 & 318 & 15513.9 & 6.45 \mathrm{E}-05 & 0.003145 & -1.54 \mathrm{E}+01 & -9.64949 & 2.99 \\ 55.0 & 328 & 4919.6 & 2.03 \mathrm{E}-04 & 0.003049 & -1.43 \mathrm{E}+01 & -8.50098 & 0.95 \\ 60.0 & 333 & 3166.2 & 3.16 \mathrm{E}-04 & 0.003003 & -1.39 \mathrm{E}+01 & -8.06029 & 0.61\end{array}$

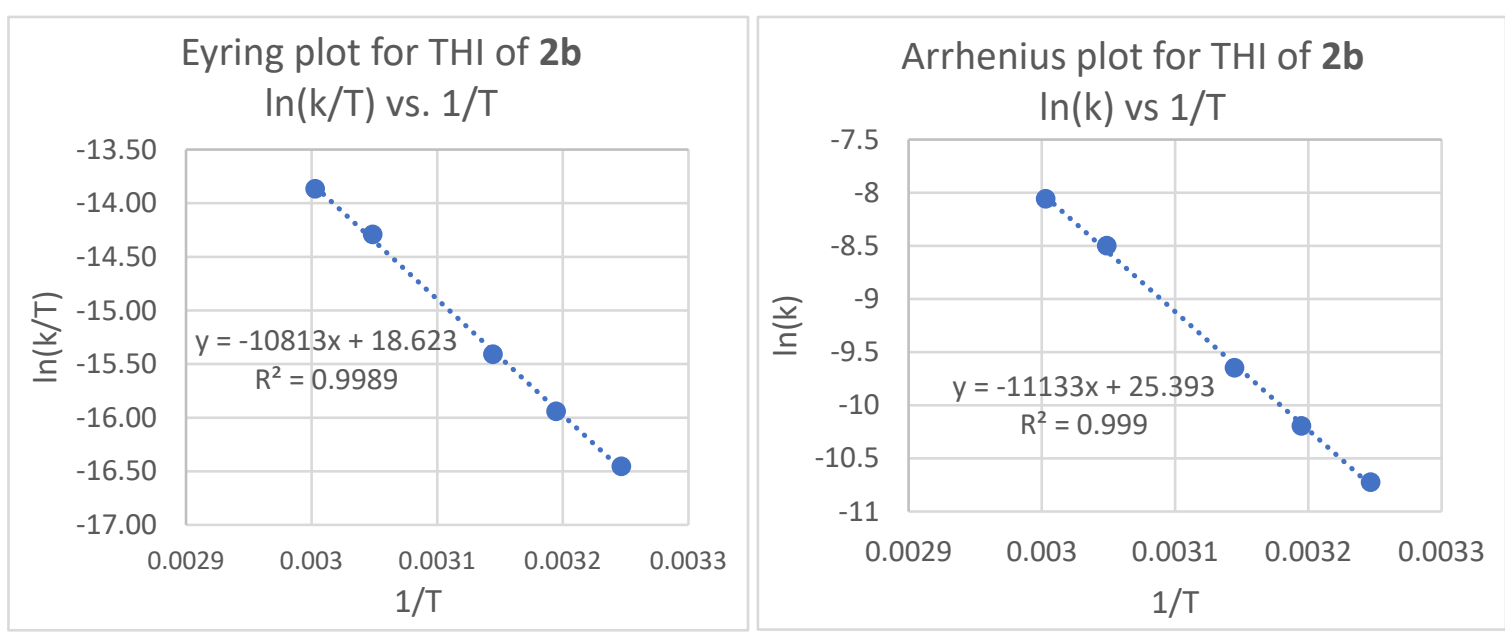

\begin{tabular}{|c|c|c|}
\hline$\Delta \mathrm{G}^{\ddagger}\left(25^{\circ} \mathrm{C}\right)$ & Uncertainty $(95 \%$ conf. $)$ & $\mathrm{t}_{1 / 2}\left(25^{\circ} \mathrm{C}\right)$ \\
\hline $24.542 \mathrm{kcal} / \mathrm{mol}$ & $0.095 \mathrm{kcal} / \mathrm{mol}$ & $30.3 \mathrm{~h}$ \\
\hline
\end{tabular}




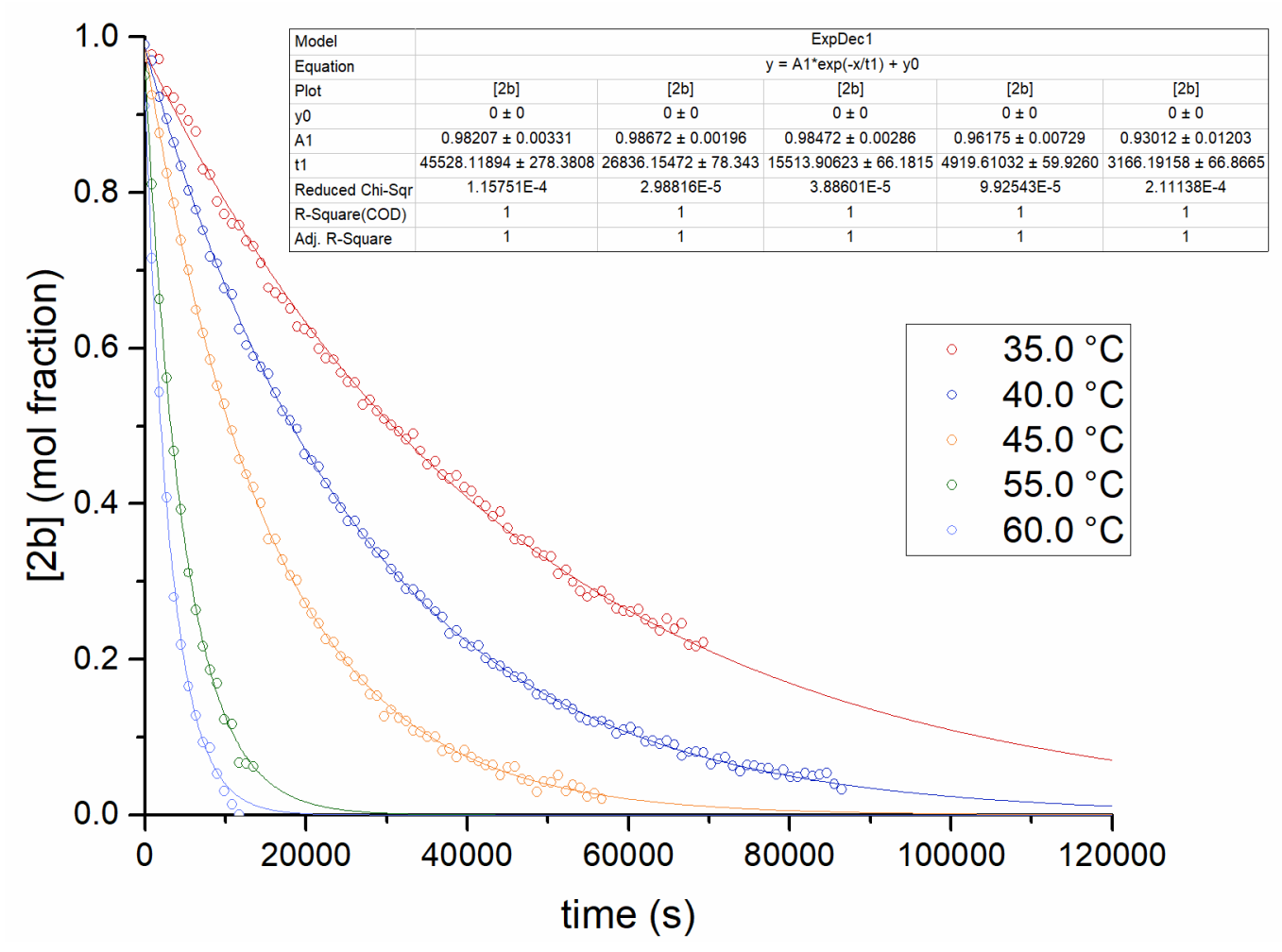

Figure S5. Decay curves for thermal helix inversion of $\mathbf{2 b}$.

${ }^{31}$ P NMR Traces of Kinetic Runs.

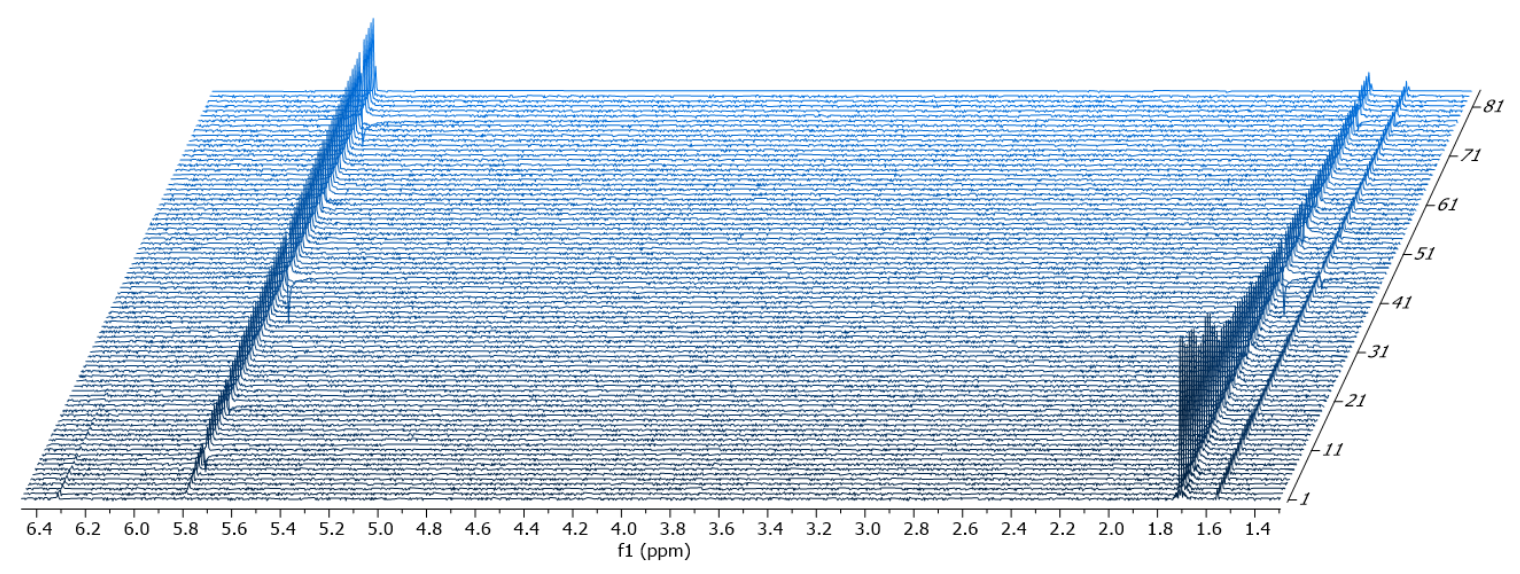

$\mathrm{T}=35.0{ }^{\circ} \mathrm{C}$

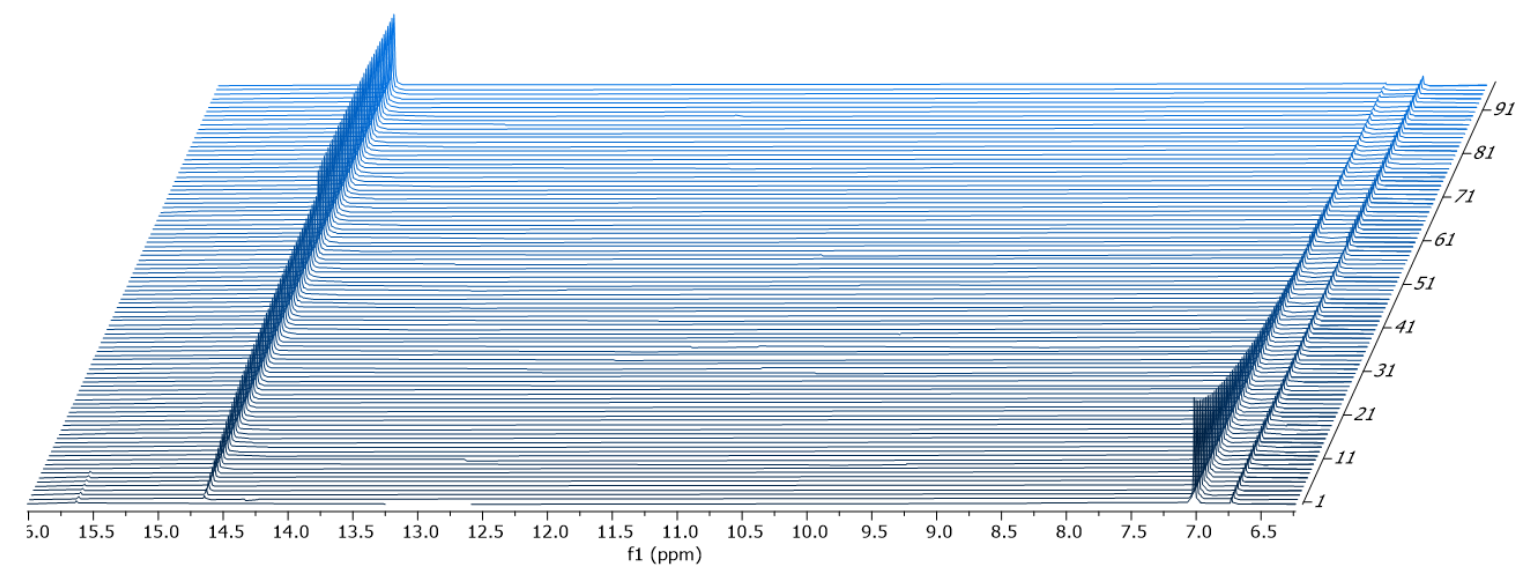




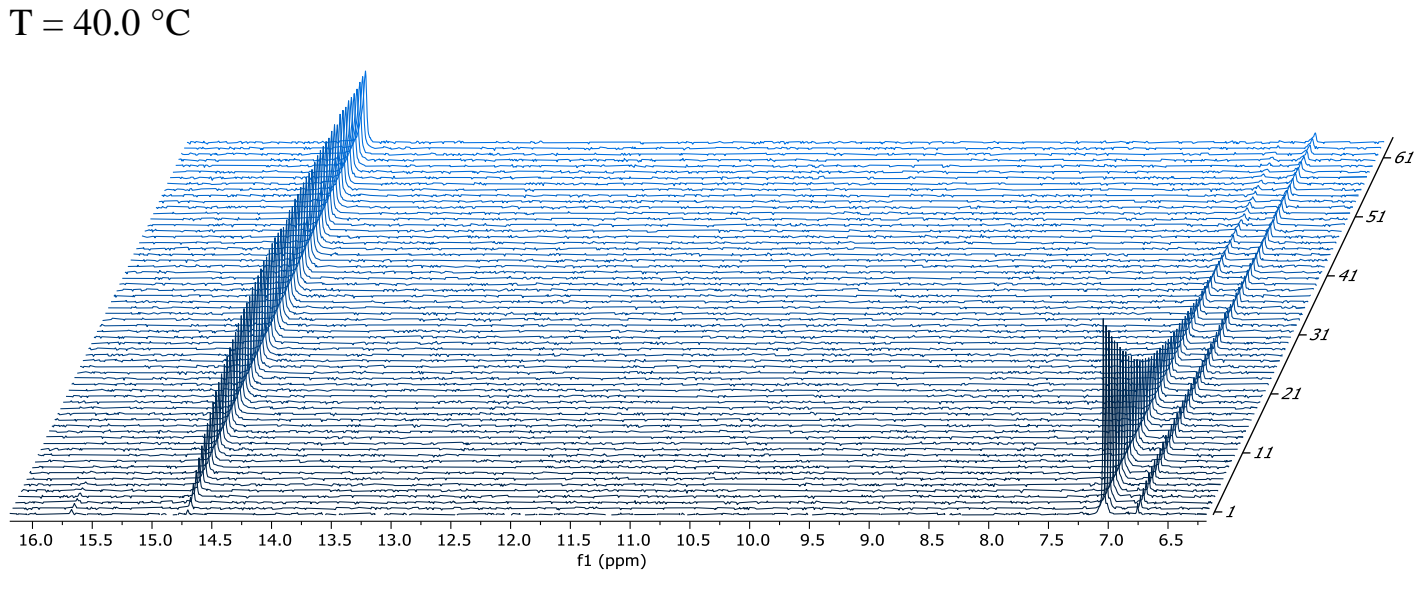

$\mathrm{T}=45.0{ }^{\circ} \mathrm{C}$

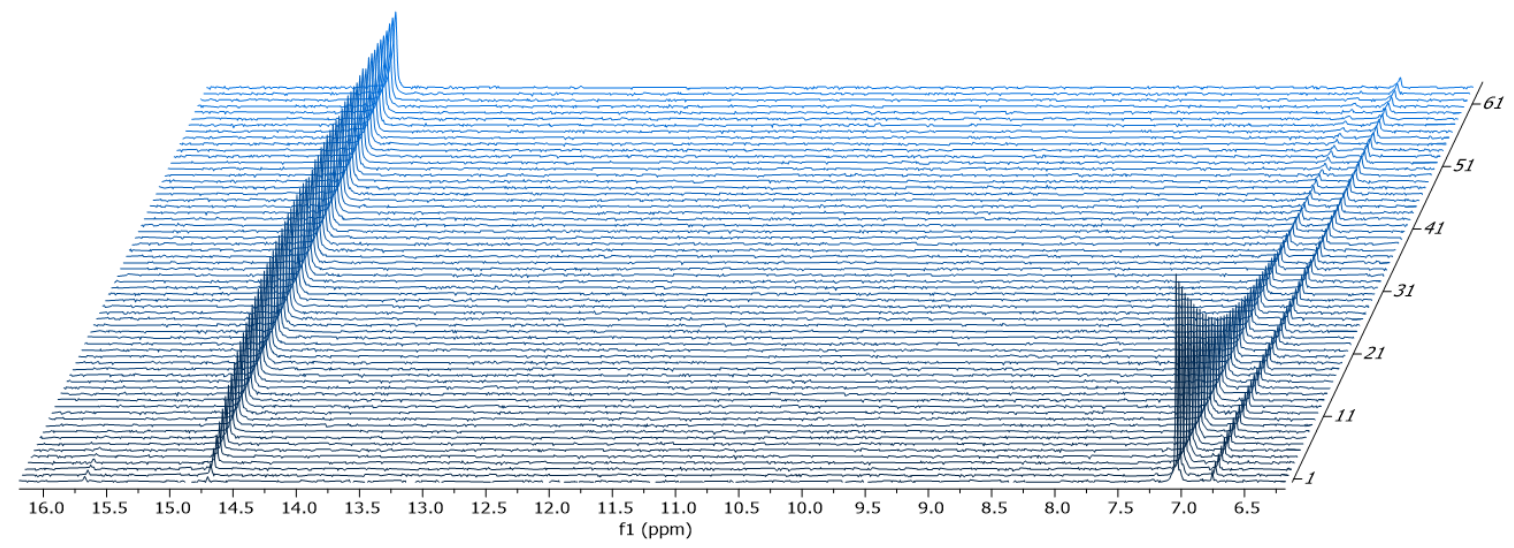

$\mathrm{T}=55.0{ }^{\circ} \mathrm{C}$

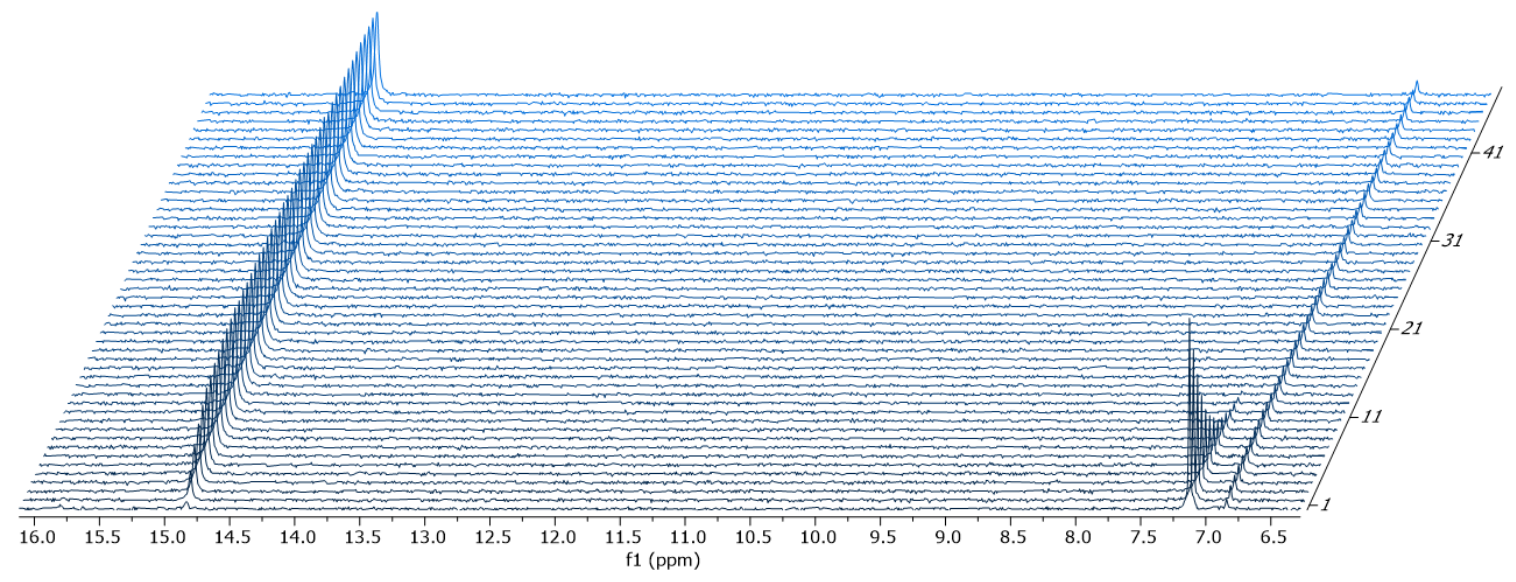

$\mathrm{T}=60.0{ }^{\circ} \mathrm{C}$ 

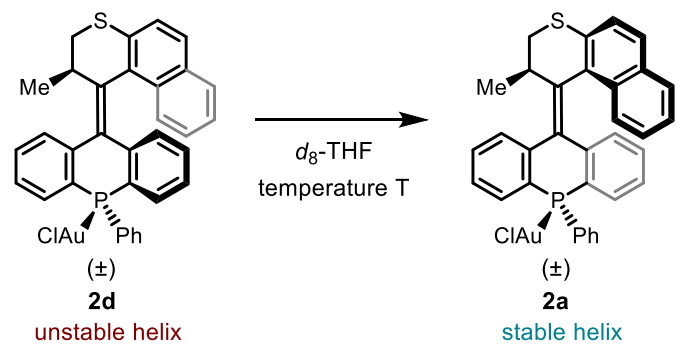

General Procedure. A solution of $3.6 \mathrm{mg}(5.0 \mu \mathrm{mol})$ of motor $\mathbf{2 c}$ in $0.50 \mathrm{~mL} \mathrm{~d}_{8}$-THF $(10 . \mathrm{mM})$ in an NMR tube was affixed to a fiber optic in situ irradiation system and inserted into an NMR spectrometer. The sample was irradiated through the cable with a $395 \mathrm{~nm}$ LED lamp while the reaction progress was monitored by ${ }^{1} \mathrm{H}$ NMR spectroscopy. Irradiation was suspended once the concentration of $\mathbf{2 d}$ had reached its peak ( $70 \%$ of the mixture), and the sample was then removed and inserted into a separate NMR spectrometer pre-warmed to the appropriate temperature. After the instrument was tuned, locked, and shimmed, it was set to acquire a ${ }^{31} \mathrm{P}$ NMR spectrum every $15 \mathrm{~min}$. The progress of the reaction was followed by integration of the signals from $\mathbf{2 d}$ and $\mathbf{2 a}$, and converting the raw integral values to a mole fraction of $\mathbf{2 d}$ relative to the sum of the concentrations of the two compounds. The data was analyzed in terms of first order kinetics. Because of unexpected technical problems, the run at the lowest temperature $\left(23.6{ }^{\circ} \mathrm{C}\right)$ was followed by ${ }^{1} \mathrm{H}$ NMR spectroscopy instead of ${ }^{31} \mathrm{P}$ NMR spectroscopy.

\section{Eyring Analysis.}

$\begin{array}{cccccccc}\mathbf{T}\left({ }^{\circ} \mathbf{C}\right) & \mathbf{T}(\mathbf{K}) & \mathbf{t}_{\mathbf{1}}(\mathbf{s}) & \mathbf{k}\left(=\mathbf{t}_{\mathbf{1}}{ }^{-1}\right) & \mathbf{1 / T} & \mathbf{I n}(\mathbf{k} / \mathbf{T}) & \mathbf{I n}(\mathbf{k}) & \mathbf{t}_{1 / 2}(\mathbf{h}) \\ 23.6 & 296.6 & 79321.44 & 1.26 \mathrm{E}-05 & 0.0033557 & -1.70 \mathrm{E}+01 & -11.2813 & 15.27 \\ 30.0 & 303.0 & 30174.46 & 3.31 \mathrm{E}-05 & 0.00330033 & -1.60 \mathrm{E}+01 & -10.3148 & 5.81 \\ 35.0 & 308.0 & 15876.28 & 6.30 \mathrm{E}-05 & 0.00324675 & -1.54 \mathrm{E}+01 & -9.67258 & 3.06 \\ 40.0 & 313.0 & 9189.431 & 1.09 \mathrm{E}-04 & 0.00319489 & -1.49 \mathrm{E}+01 & -9.12581 & 1.77 \\ 45.0 & 318.0 & 4705.388 & 2.13 \mathrm{E}-04 & 0.00314465 & -1.42 \mathrm{E}+01 & -8.45646 & 0.91\end{array}$

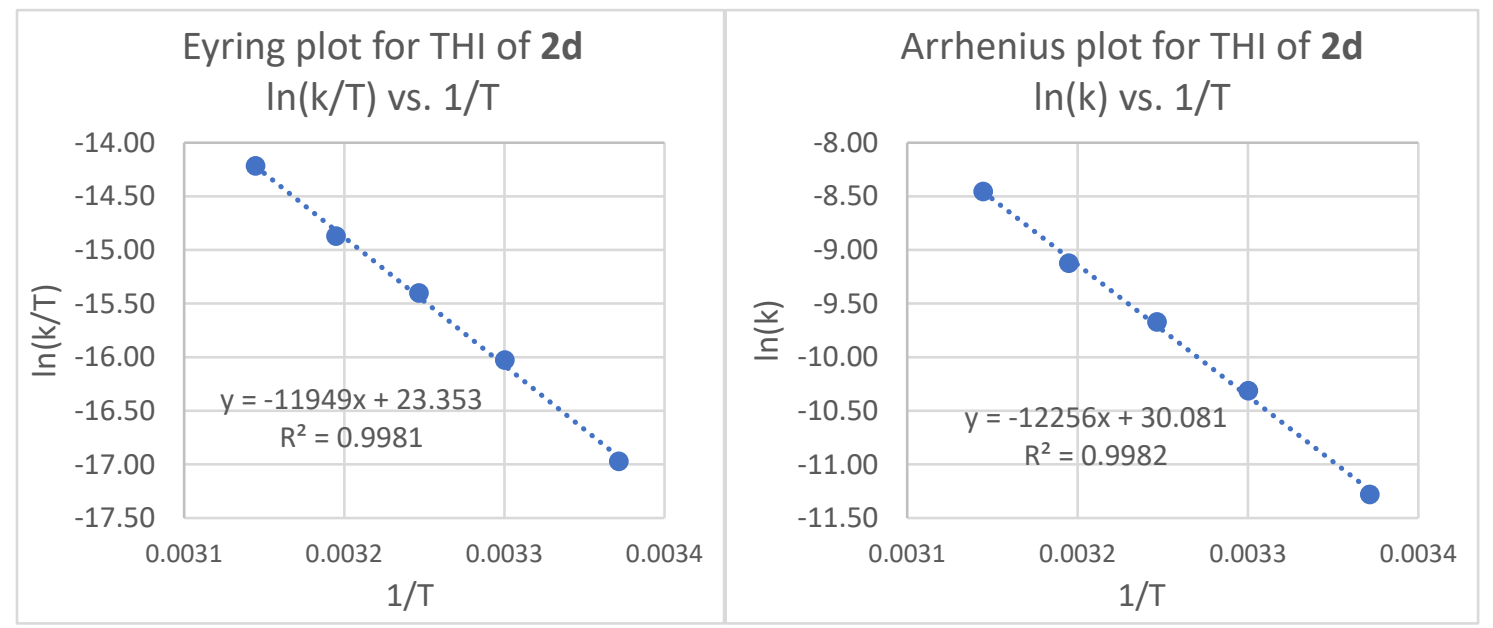

\begin{tabular}{|c|c|c|}
\hline$\Delta \mathrm{G}^{\ddagger}\left(25^{\circ} \mathrm{C}\right)$ & Uncertainty $(95 \%$ conf. $)$ & $\mathrm{t}_{1 / 2}\left(25^{\circ} \mathrm{C}\right)$ \\
\hline $23.998 \mathrm{kcal} / \mathrm{mol}$ & $0.075 \mathrm{kcal} / \mathrm{mol}$ & $12.1 \mathrm{~h}$ \\
\hline
\end{tabular}




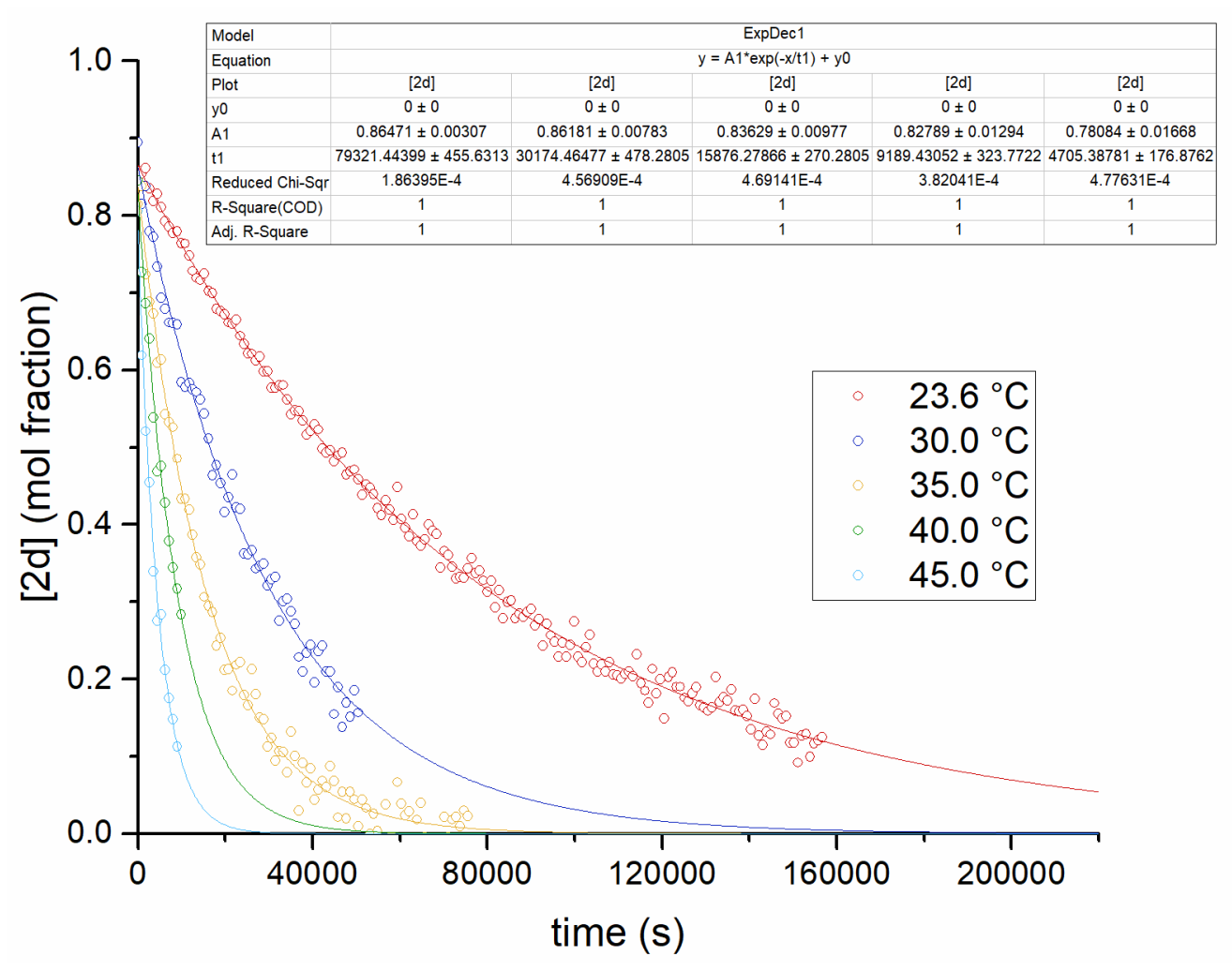

Figure S6. Decay curves for thermal helix inversion of $\mathbf{2 d}$.

${ }^{1} \mathrm{H}\left(25^{\circ} \mathrm{C}\right)$ and ${ }^{31} \mathbf{P}$ (all other temperatures) NMR Traces of Kinetic Runs.

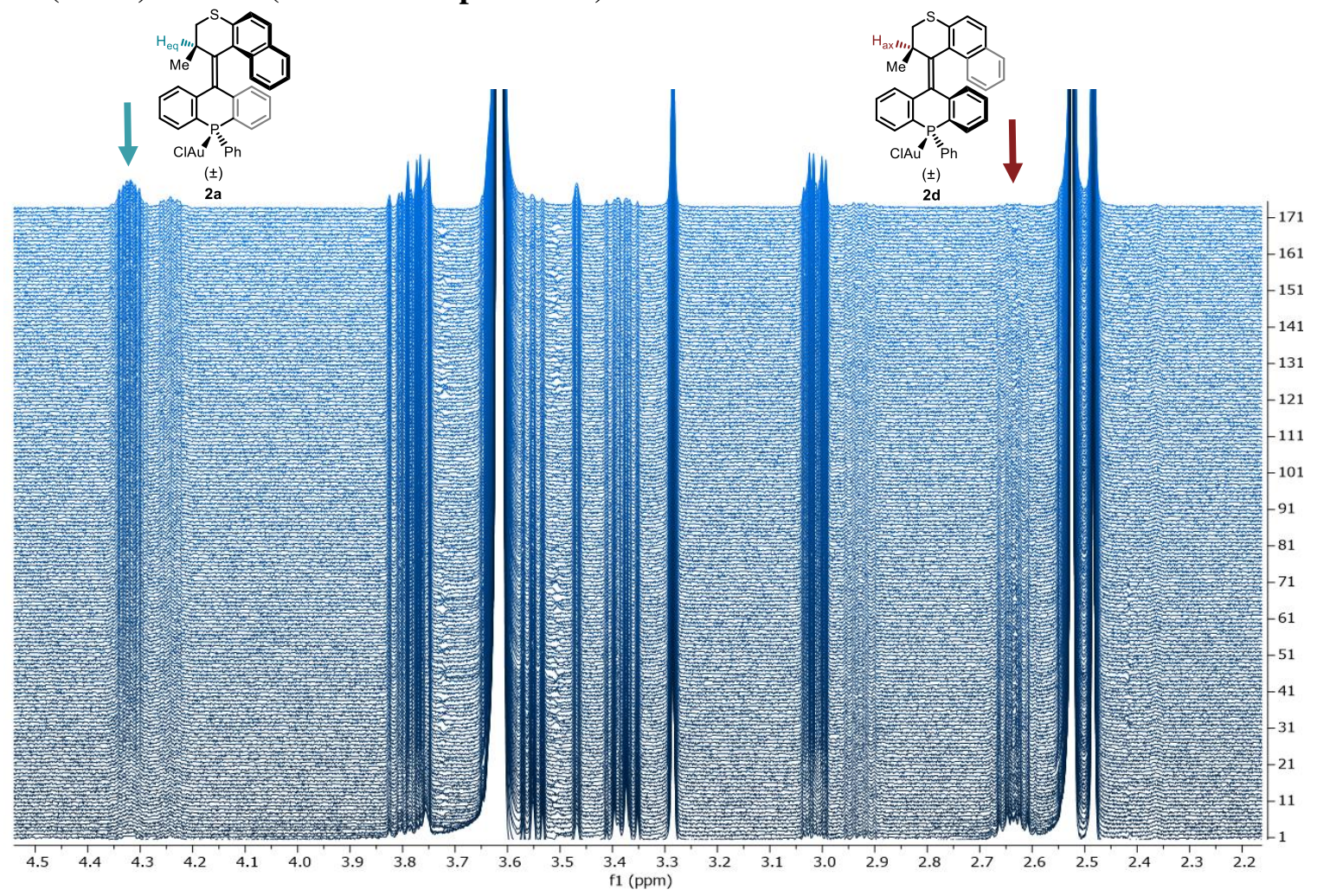

$\mathrm{T}=23.6^{\circ} \mathrm{C}$ 


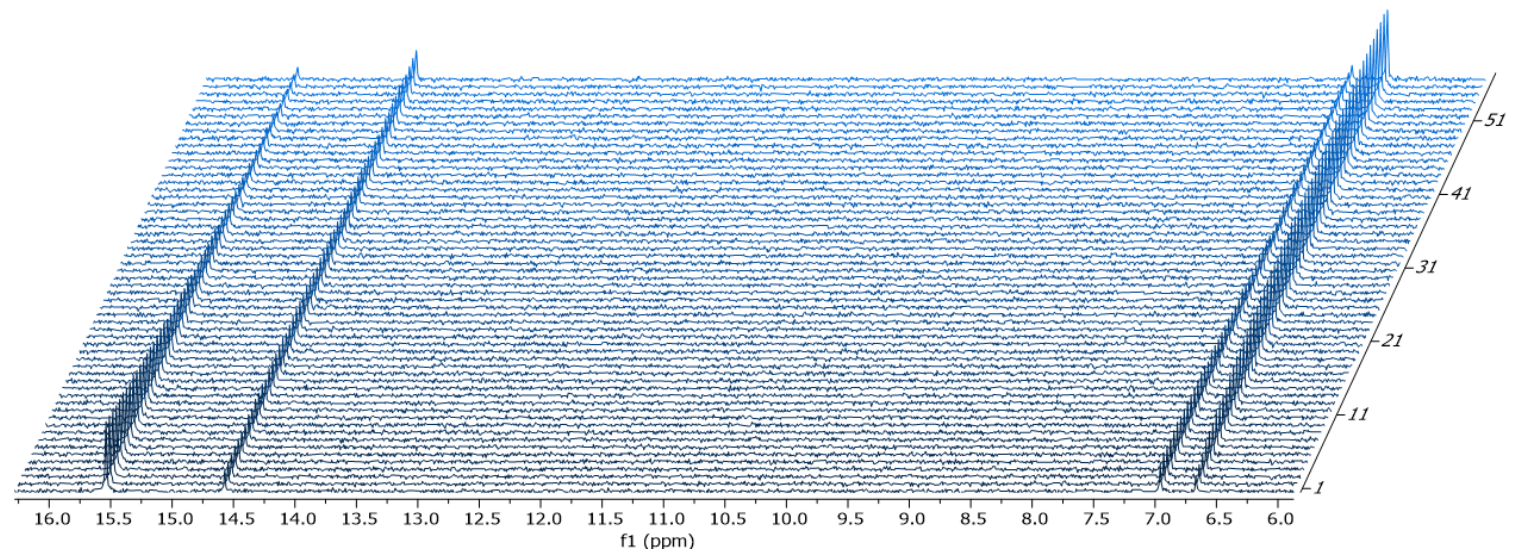

$\mathrm{T}=30.0{ }^{\circ} \mathrm{C}$

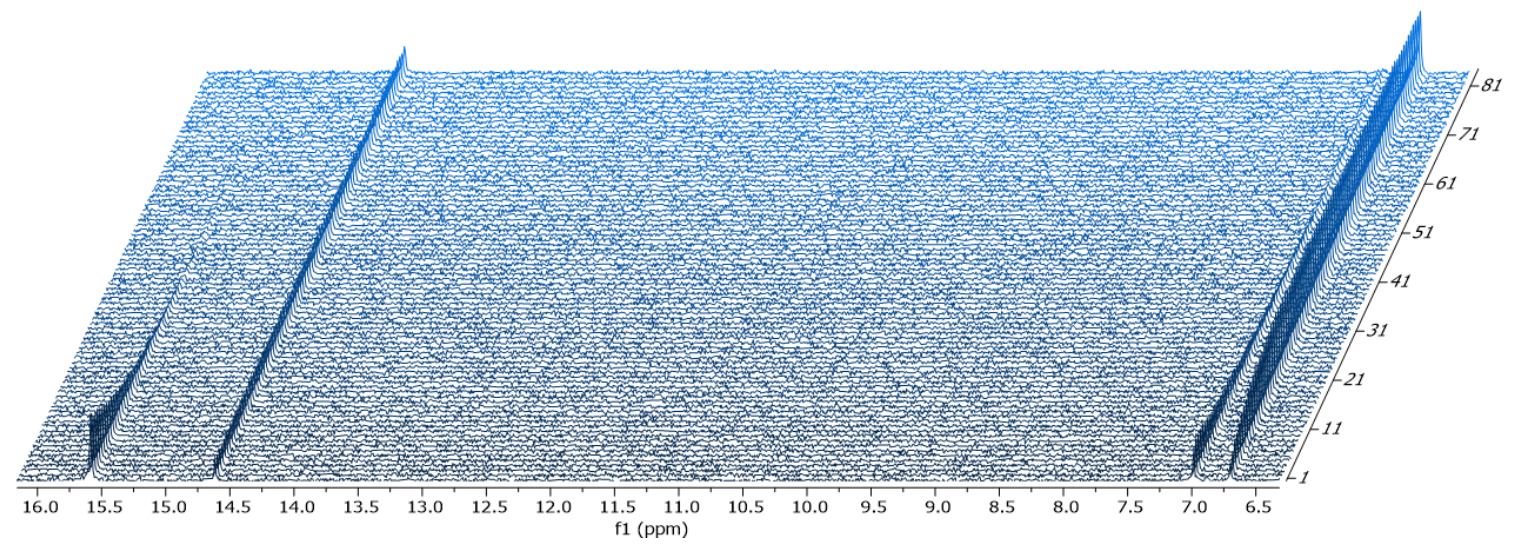

$\mathrm{T}=35.0{ }^{\circ} \mathrm{C}$

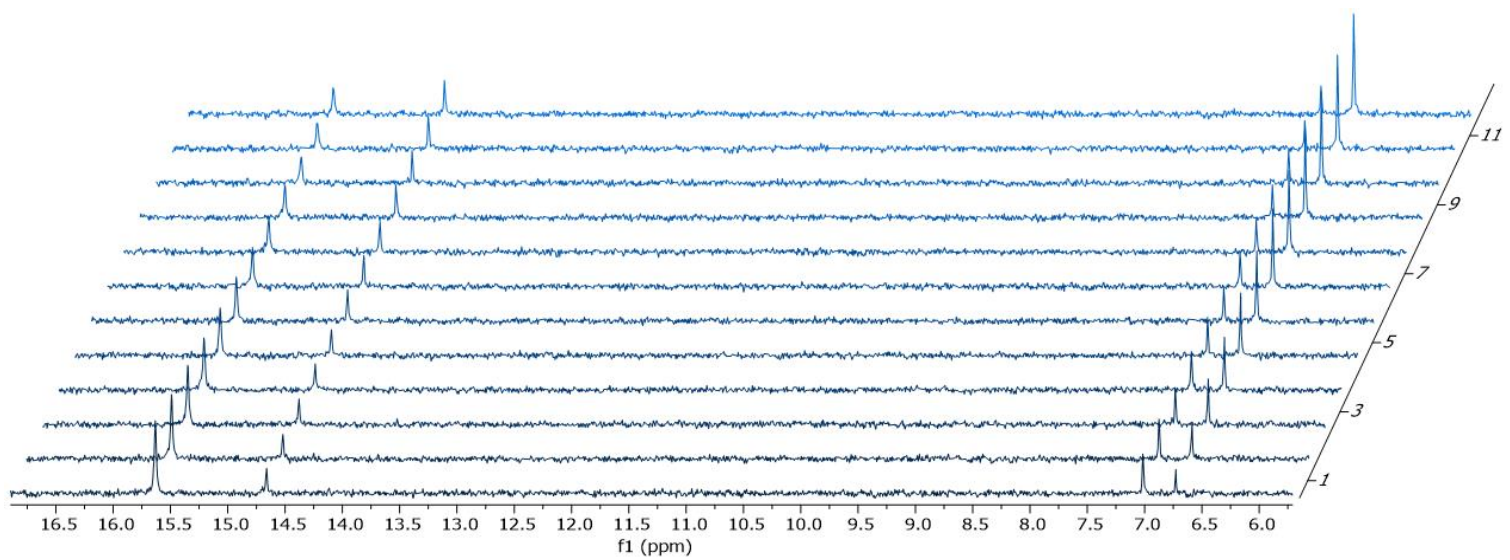

$\mathrm{T}=40.0{ }^{\circ} \mathrm{C}$ 


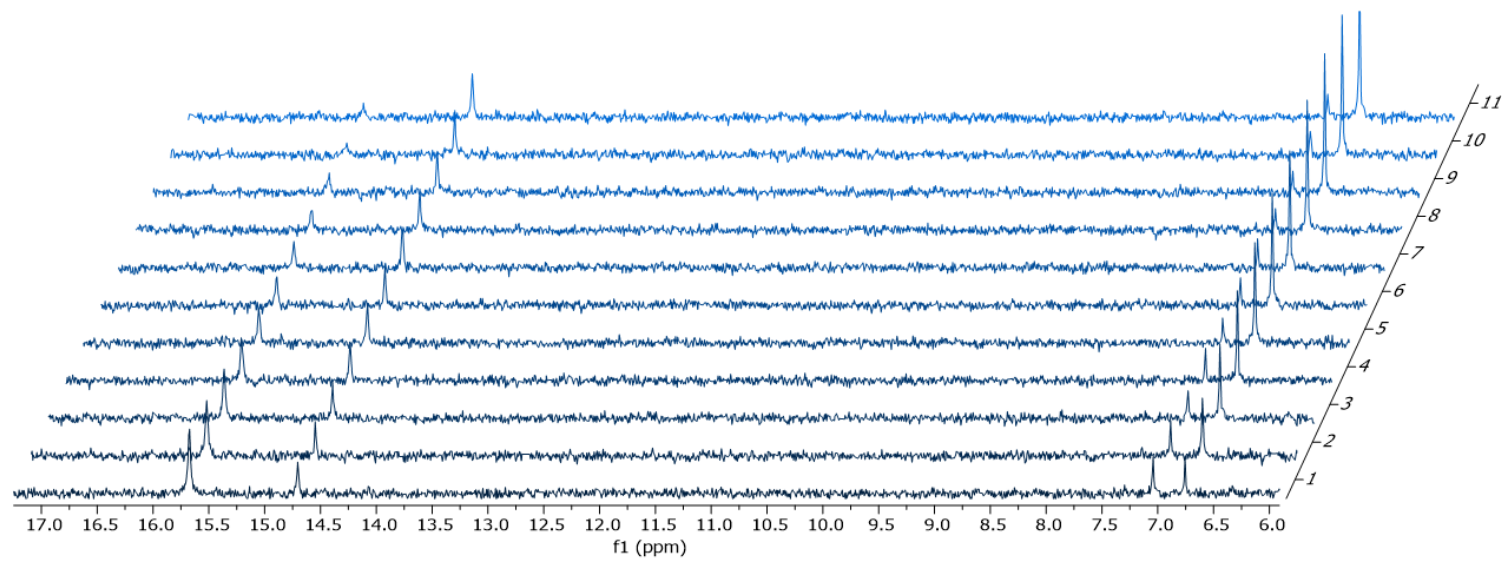

$\mathrm{T}=45.0{ }^{\circ} \mathrm{C}$

\subsection{Kinetic Studies of Thermal Helix Inversion of $3 b$ and $3 d$}

Because both compounds $\mathbf{3 b}$ and $\mathbf{3 d}$ are significantly represented in the photostationary state at 405 $\mathrm{nm}$, the thermal helix inversion of both compounds could be adequately followed within one data set.

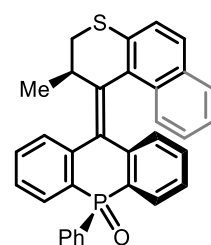

$( \pm)$

unstable helix

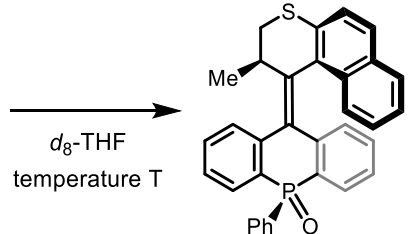

$( \pm)$

3c
table helix<smiles>C[C@H]1CSc2ccc3ccccc3c2C1=C1c2ccccc2P(=O)(c2ccccc2)c2ccccc21</smiles>

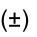

3d

unstable helix

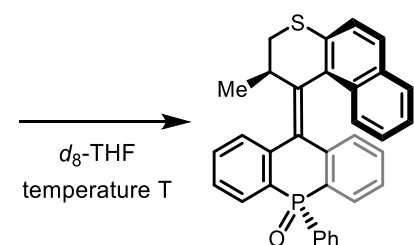

$( \pm)$

$3 a$

stable helix

General Procedure. A solution of $3.6 \mathrm{mg}(5.0 \mu \mathrm{mol})$ of motor $3 \mathrm{a}$ in $0.50 \mathrm{~mL} d_{8}$-THF $(10 . \mathrm{mM})$ in an NMR tube was irradiated for one hour with a $405 \mathrm{~nm}$ LED lamp in a refrigerator at $6{ }^{\circ} \mathrm{C}$, in order to generate the photostationary state consisting of $84 \% \mathbf{3 b}$ and $12 \% \mathbf{3 d}$. The sample was then inserted into an NMR probe pre-warmed to the appropriate temperature. After the instrument was tuned, locked, and shimmed, it was set to acquire a ${ }^{31} \mathrm{P}$ NMR spectrum every $15 \mathrm{~min}$. The progress of the reaction was followed by integration of the appropriate signals from $\mathbf{3 a} \mathbf{a}-\mathbf{d}$. The data was processed by converting the raw integral values to a mole fraction of $\mathbf{3 b}$ relative to the sum of the concentrations of $\mathbf{3 b}$ and $\mathbf{3 c}$, and a mole fraction of $\mathbf{3 d}$ relative to the sum of the concentrations of $\mathbf{3 d}$ and $\mathbf{3 a}$. These mole fractions of $\mathbf{3 b}$ and $\mathbf{3 d}$ were analyzed in terms of first order kinetics.

\section{Eyring Analysis for THI of $\mathbf{3 b}$.}

$\begin{array}{cccccccc}\mathbf{T}\left({ }^{\circ} \mathbf{C}\right) & \mathbf{T}(\mathbf{K}) & \mathbf{t}_{\mathbf{1}}(\mathbf{s}) & \mathbf{k}\left(=\mathbf{t}_{\mathbf{1}}{ }^{-1}\right) & \mathbf{1 / T} & \mathbf{I n}(\mathbf{k} / \mathbf{T}) & \ln (\mathbf{k}) & \mathbf{t}_{\mathbf{1} / \mathbf{2}}(\mathbf{h}) \\ 25.0 & 298.0 & 27882.3 & 3.59 \mathrm{E}-05 & 0.003356 & -1.59 \mathrm{E}+01 & -10.2357 & 5.37 \\ 30.0 & 303.0 & 15367.39 & 6.51 \mathrm{E}-05 & 0.0033 & -1.54 \mathrm{E}+01 & -9.64 & 2.96 \\ 33.0 & 306.0 & 10675.92 & 9.37 \mathrm{E}-05 & 0.003268 & -1.50 \mathrm{E}+01 & -9.27575 & 2.06 \\ 36.0 & 309.0 & 7495.09 & 1.33 \mathrm{E}-04 & 0.003236 & -1.46 \mathrm{E}+01 & -8.91171 & 1.43 \\ 39.0 & 312.0 & 5178.743 & 1.93 \mathrm{E}-04 & 0.003205 & -1.43 \mathrm{E}+01 & -8.55232 & 1.00\end{array}$



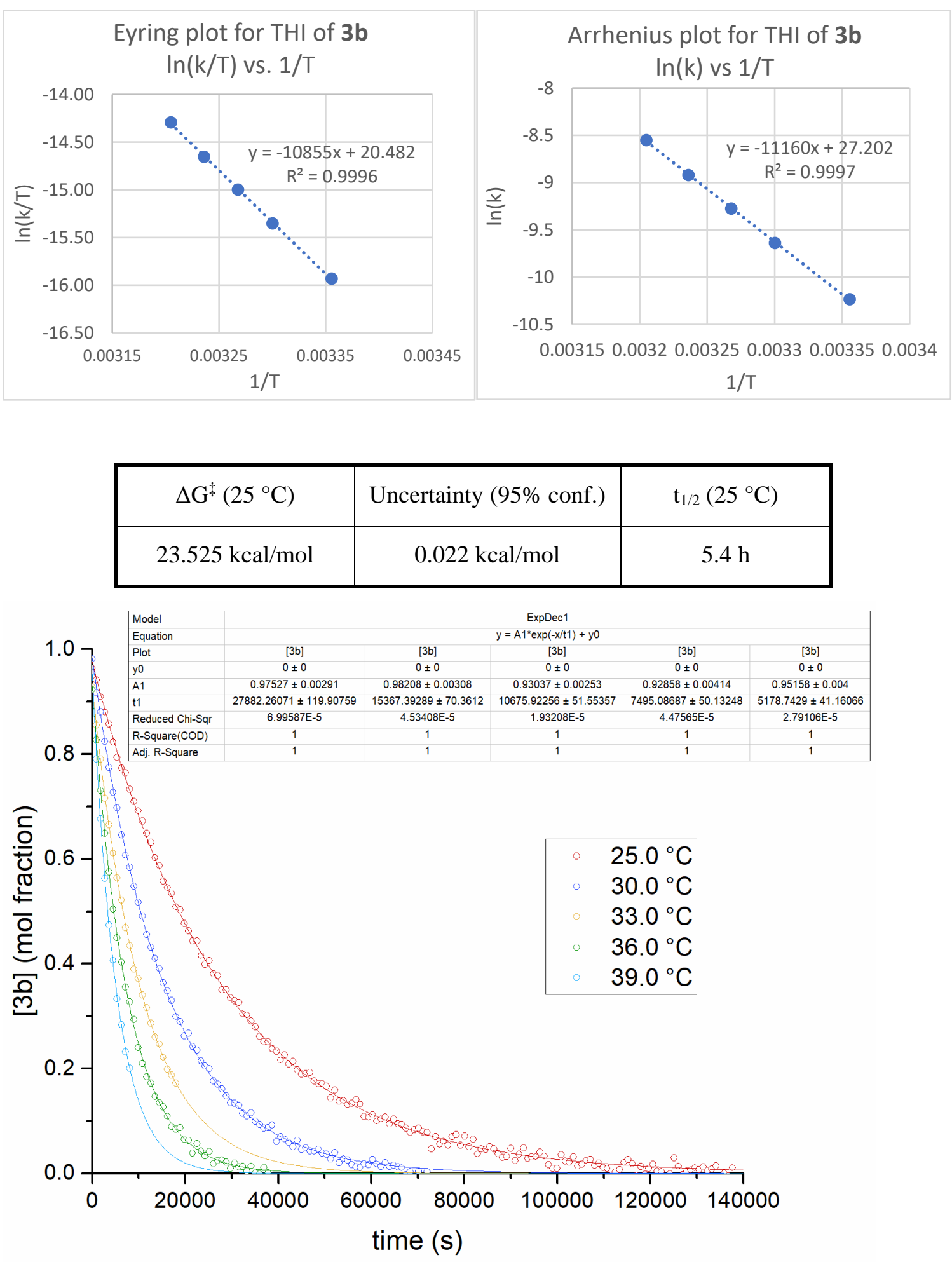

Figure S7. Decay curves for thermal helix inversion of $\mathbf{3 b}$.

Eyring Analysis for THI of 3d.

$\begin{array}{cccccccc}\mathbf{T}\left({ }^{\circ} \mathbf{C}\right) & \mathbf{T}(\mathbf{K}) & \mathbf{t}_{\mathbf{1}}(\mathbf{s}) & \mathbf{k}\left(=\mathbf{t}_{\mathbf{1}}{ }^{-1}\right) & \mathbf{1 / T} & \mathbf{I n}(\mathbf{k} / \mathbf{T}) & \mathbf{I n}(\mathbf{k}) & \mathbf{t}_{1 / 2}(\mathbf{h}) \\ 25.0 & 298.0 & 76410.98 & 1.31 \mathrm{E}-05 & 0.003356 & -1.69 \mathrm{E}+01 & -11.2439 & 14.71 \\ 30.0 & 303.0 & 41237.02 & 2.43 \mathrm{E}-05 & 0.0033 & -1.63 \mathrm{E}+01 & -10.6271 & 7.94 \\ 33.0 & 306.0 & 28676.67 & 3.49 \mathrm{E}-05 & 0.003268 & -1.60 \mathrm{E}+01 & -10.2638 & 5.52 \\ 36.0 & 309.0 & 19492.55 & 5.13 \mathrm{E}-05 & 0.003236 & -1.56 \mathrm{E}+01 & -9.87779 & 3.75\end{array}$




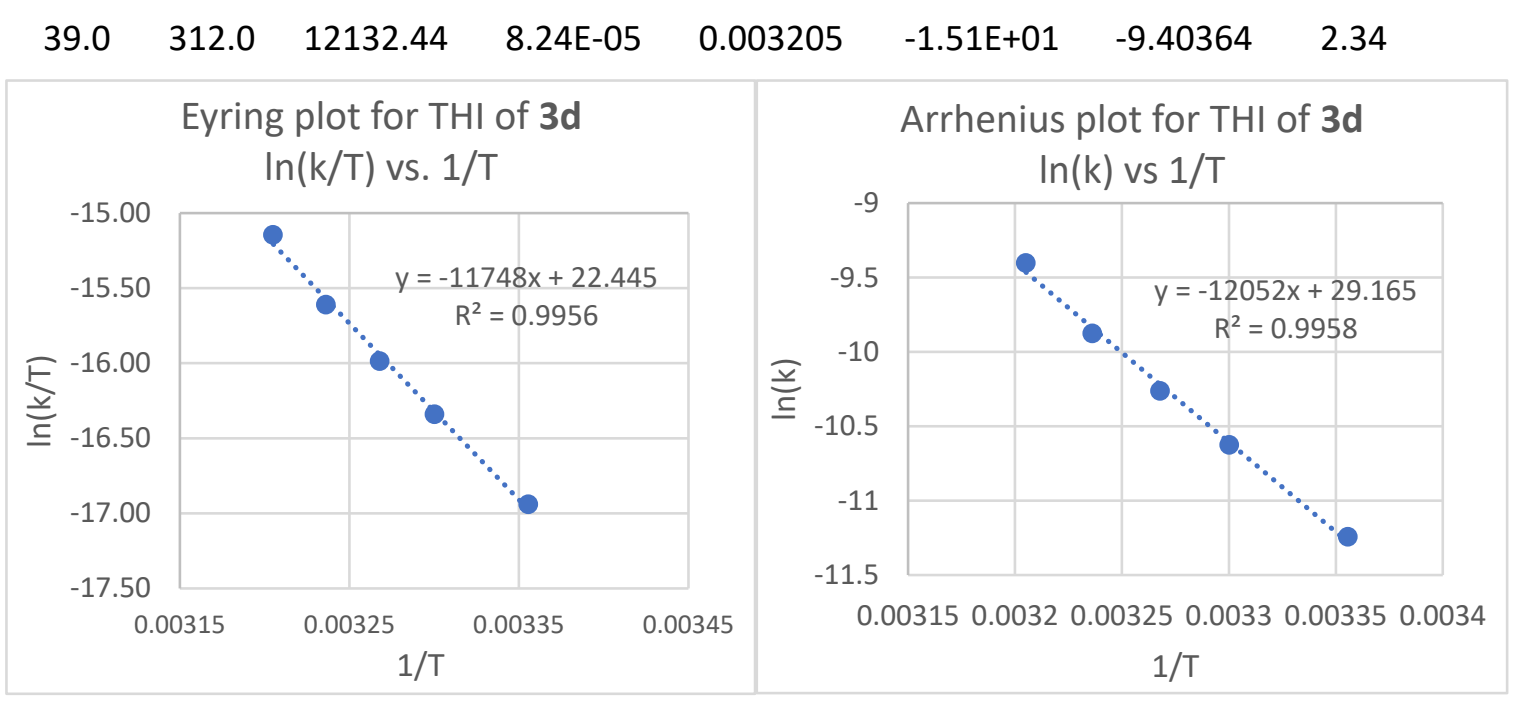

\begin{tabular}{|c|c|c|}
\hline$\Delta \mathrm{G}^{\ddagger}\left(25^{\circ} \mathrm{C}\right)$ & Uncertainty $(95 \%$ conf. $)$ & $\mathrm{t}_{1 / 2}\left(25^{\circ} \mathrm{C}\right)$ \\
\hline $24.136 \mathrm{kcal} / \mathrm{mol}$ & $0.084 \mathrm{kcal} / \mathrm{mol}$ & $15.2 \mathrm{~h}$ \\
\hline
\end{tabular}

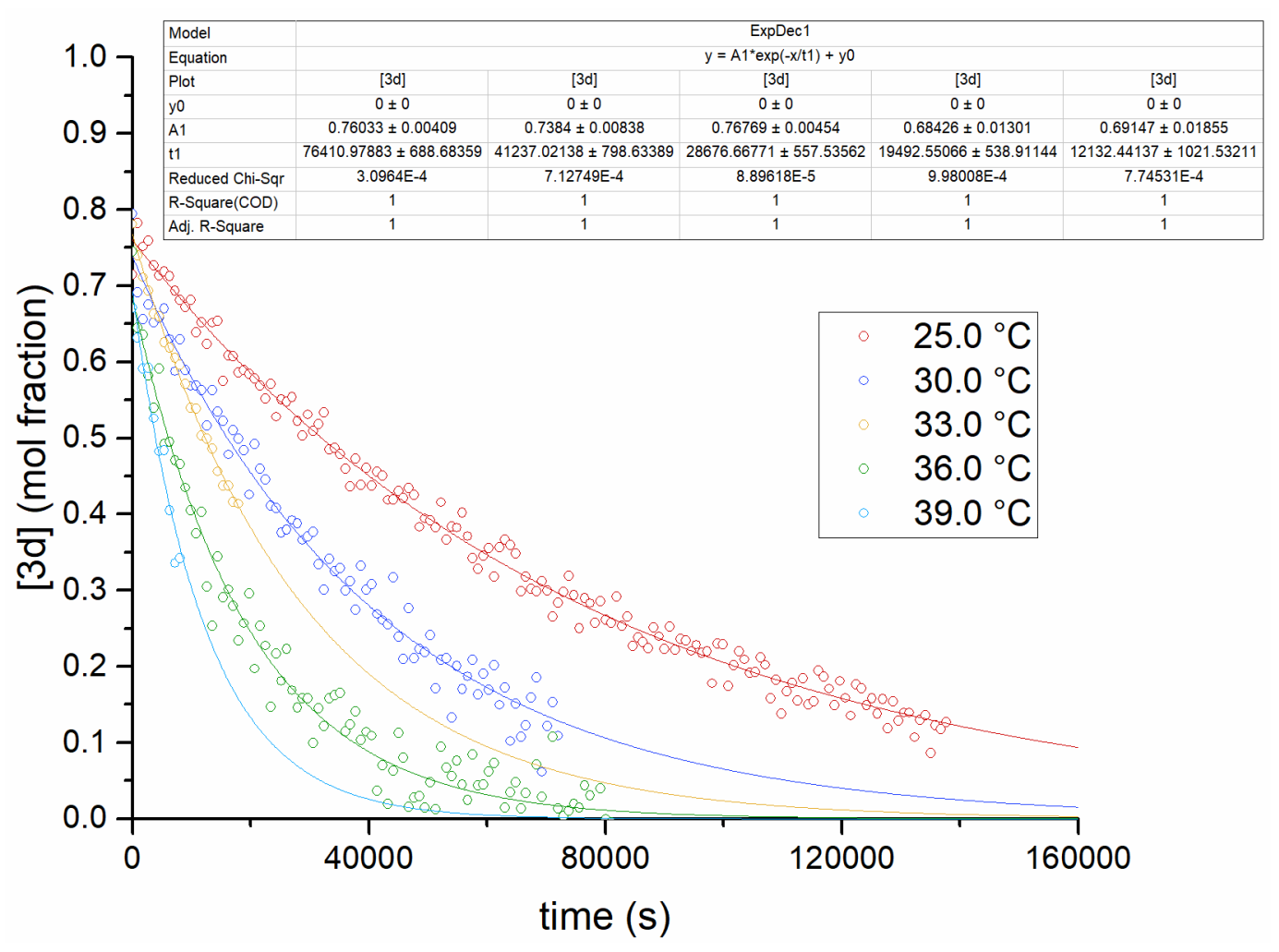

Figure S8. Decay curves for thermal helix inversion of 3d. 
${ }^{31}$ P NMR Traces of Kinetic Runs.

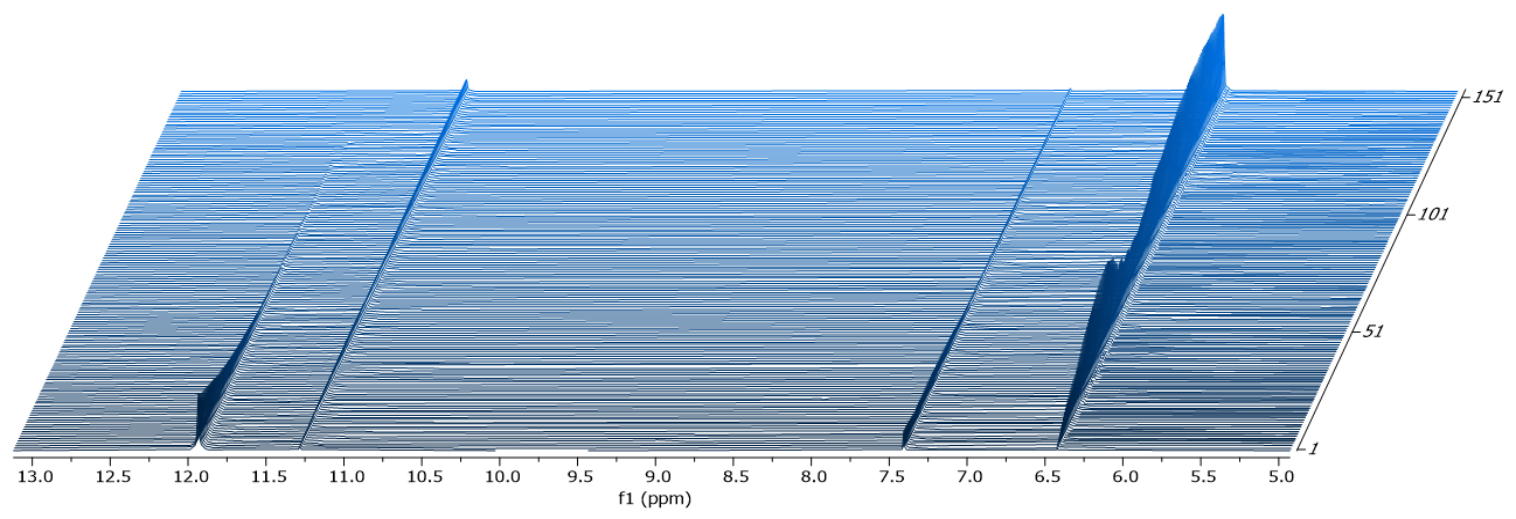

$\mathrm{T}=25.0^{\circ} \mathrm{C}$

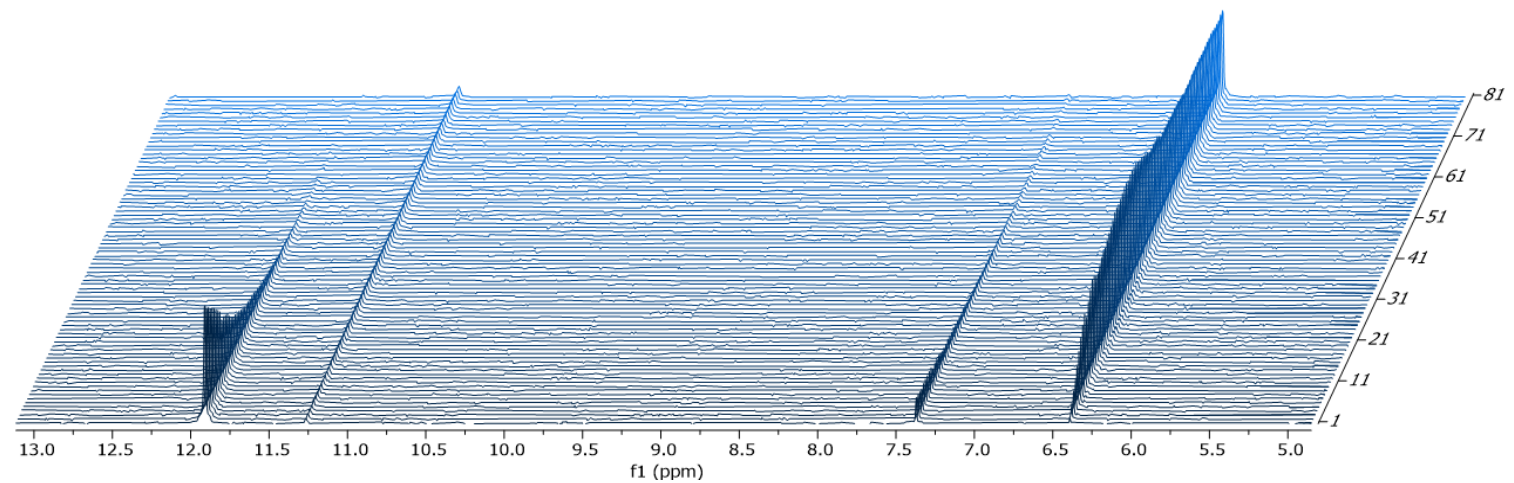

$\mathrm{T}=30.0{ }^{\circ} \mathrm{C}$

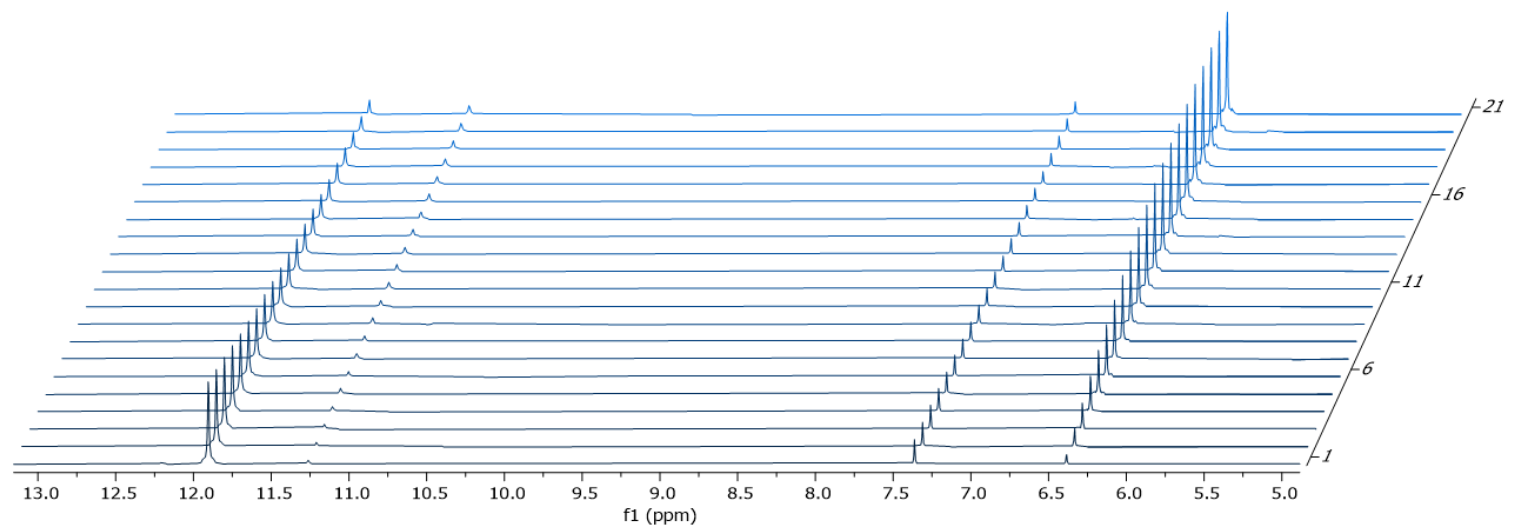

$\mathrm{T}=33.0{ }^{\circ} \mathrm{C}$

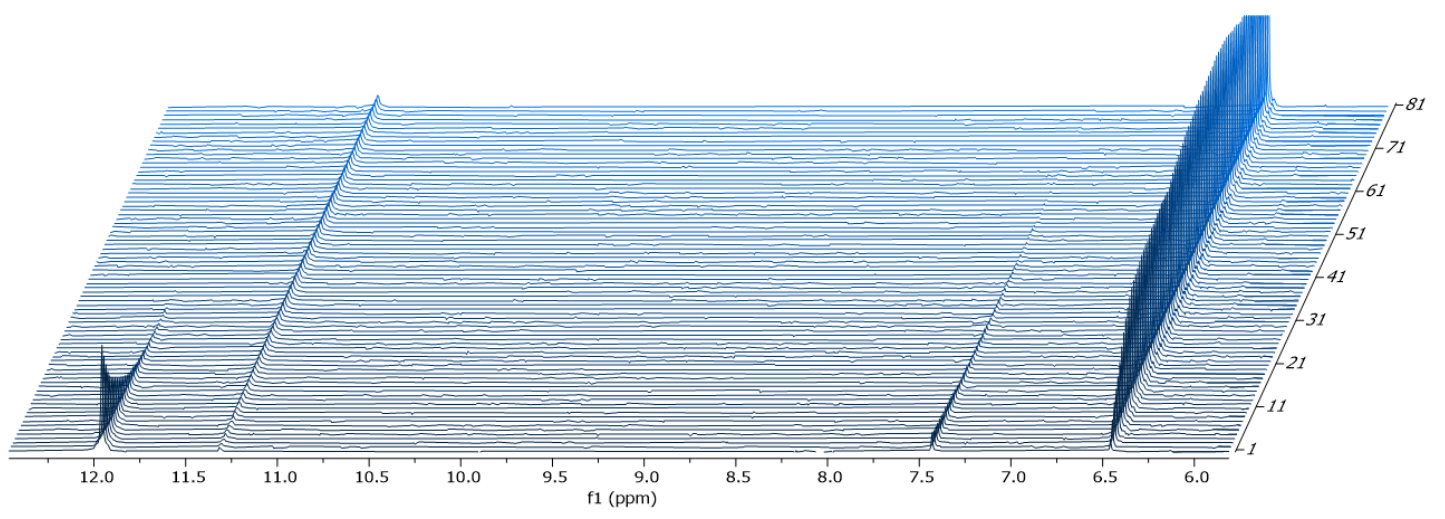




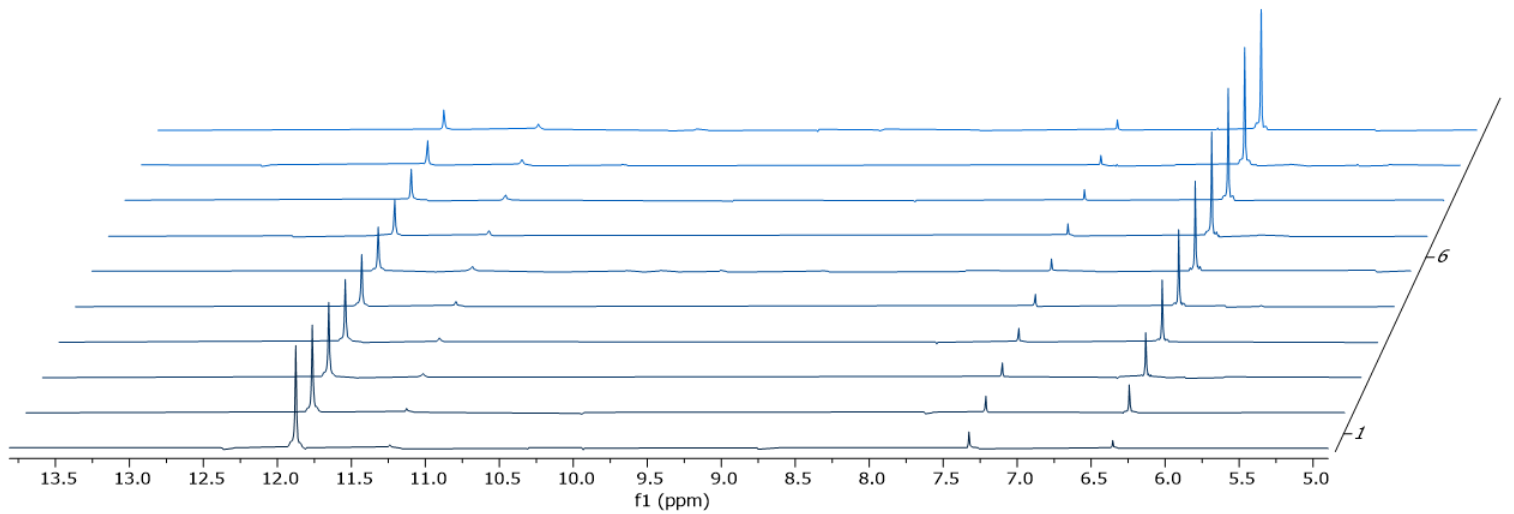

$\mathrm{T}=39.0{ }^{\circ} \mathrm{C}$

\subsection{Kinetic Studies of Thermal Helix Inversion of $1 b$}<smiles>C[C@H]1CSc2ccc3ccccc3c2C1=C1c2ccccc2P(C)(C)(c2ccccc2)c2ccccc21</smiles>

$( \pm)$

unstable helix

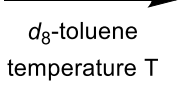

temperature $T$

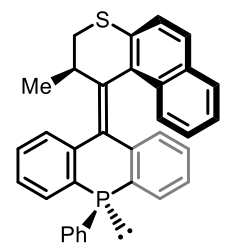

$( \pm)$

1c

stable helix

General Procedure. A solution of $2.5 \mathrm{mg}(5.0 \mu \mathrm{mol})$ of motor $1 \mathrm{a}$ in $0.50 \mathrm{~mL} d_{8}$-toluene $(10 . \mathrm{mM})$ in a J-Young NMR tube was thoroughly degassed through 5 freeze-pump-thaw cycles (Caution: the solution should be frozen at $-115{ }^{\circ} \mathrm{C}$ in a liquid nitrogen/ethanol bath, because there is a high risk of the tube breaking if frozen in liquid nitrogen directly). The solution was irradiated at 365 $\mathrm{nm}$ for $10 \mathrm{~min}$ at room temperature in order to generate the photostationary state consisting almost entirely of $\mathbf{1 b}$. The sample was then inserted into an NMR probe pre-warmed to the appropriate temperature. After the instrument was tuned, locked, and shimmed, it was set to acquire a ${ }^{1} \mathrm{H}$ NMR spectrum every $15 \mathrm{~min}$. The progress of the reaction was followed by integration of the signals from $\mathbf{1 b}$ and $\mathbf{1 c}$, and converting the raw integral values to a mole fraction of $\mathbf{1 b}$ relative to the sum of the concentrations of the two compounds. The data was analyzed in terms of first order kinetics.

After growing slightly initially (probably from thermal helix inversion of the small amount of $\mathbf{1 d}$ formed in the PSS), the signal for 1a remained constant throughout the course of each run, indicating that the rate of pyramidal inversion of $\mathbf{1 c}$ is negligible within the range of temperatures employed in this study.

\section{Eyring Analysis.}

$\begin{array}{cccccccc}\mathbf{T}\left({ }^{\circ} \mathbf{C}\right) & \mathbf{T}(\mathbf{K}) & \mathbf{t}_{\mathbf{1}}(\mathbf{s}) & \mathbf{k}\left(=\mathbf{t}_{\mathbf{1}}{ }^{-1}\right) & \mathbf{1 / T} & \ln (\mathbf{k} / \mathbf{T}) & \mathbf{I n}(\mathbf{k}) & \mathbf{t}_{1 / 2}(\mathbf{h}) \\ 29.44 & 302.44 & 107635.5 & 9.29 \mathrm{E}-06 & 0.003306 & -1.73 \mathrm{E}+01 & -11.5865 & 20.72 \\ 32.5 & 305.5 & 70359.5 & 1.42 \mathrm{E}-05 & 0.003273 & -1.69 \mathrm{E}+01 & -11.1614 & 13.55 \\ 35.62 & 308.62 & 49413.9 & 2.02 \mathrm{E}-05 & 0.00324 & -1.65 \mathrm{E}+01 & -10.808 & 9.51 \\ 38.71 & 311.71 & 31619.9 & 3.16 \mathrm{E}-05 & 0.003208 & -1.61 \mathrm{E}+01 & -10.3615 & 6.09 \\ 41.8 & 314.8 & 21702.3 & 4.61 \mathrm{E}-05 & 0.003177 & -1.57 \mathrm{E}+01 & -9.98517 & 4.18\end{array}$




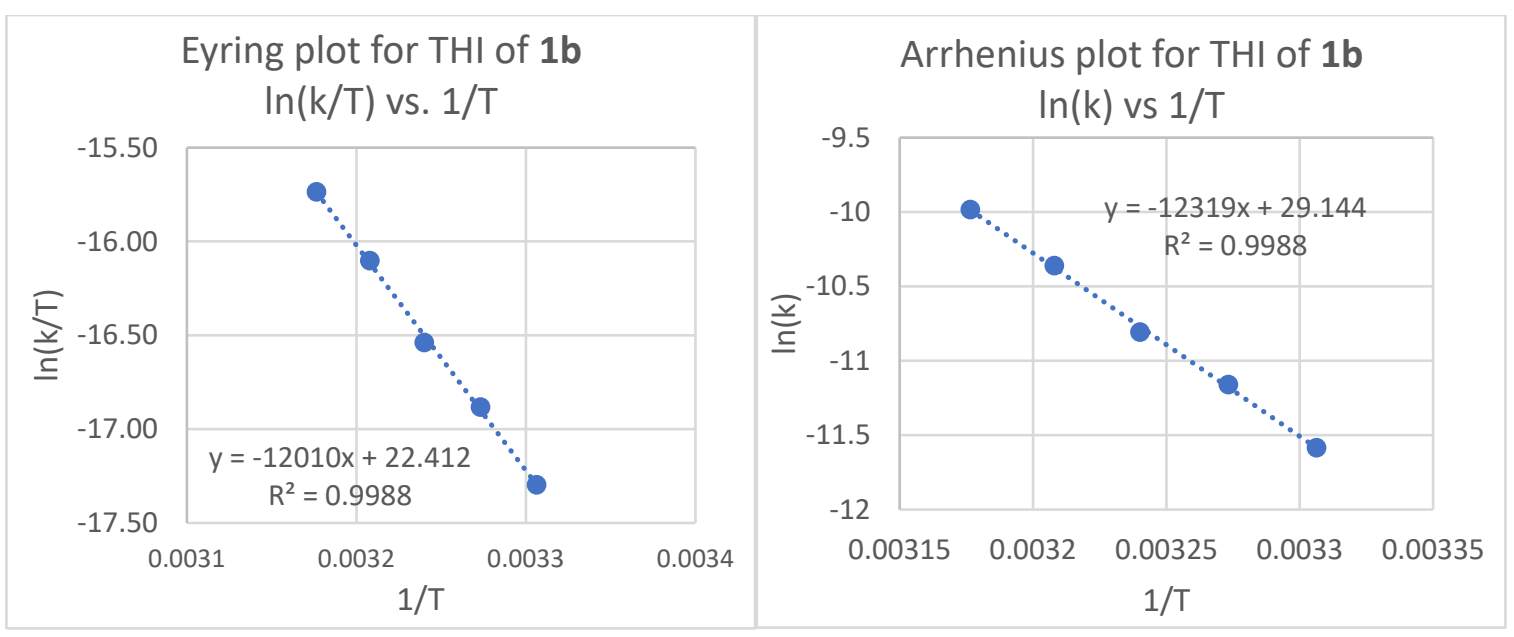

\begin{tabular}{|c|c|c|}
\hline$\Delta \mathrm{G}^{\ddagger}\left(25^{\circ} \mathrm{C}\right)$ & Uncertainty $(95 \%$ conf. $)$ & $\mathrm{t}_{1 / 2}\left(25^{\circ} \mathrm{C}\right)$ \\
\hline $24.675 \mathrm{kcal} / \mathrm{mol}$ & $0.054 \mathrm{kcal} / \mathrm{mol}$ & $37.9 \mathrm{~h}$ \\
\hline
\end{tabular}

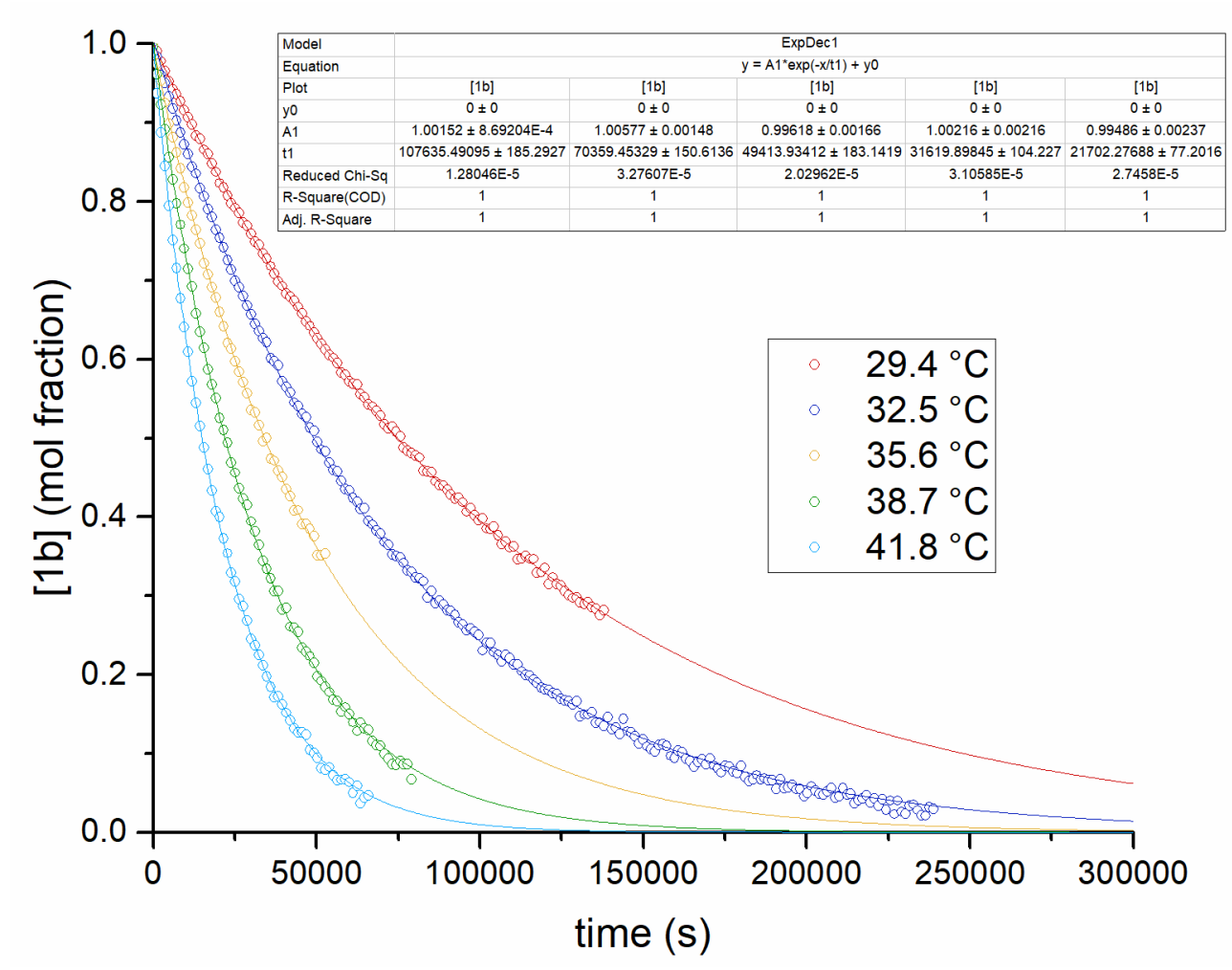

Figure S9. Decay curves for thermal helix inversion of $\mathbf{1 b}$. 
${ }^{1}$ H NMR Traces of Kinetic Runs

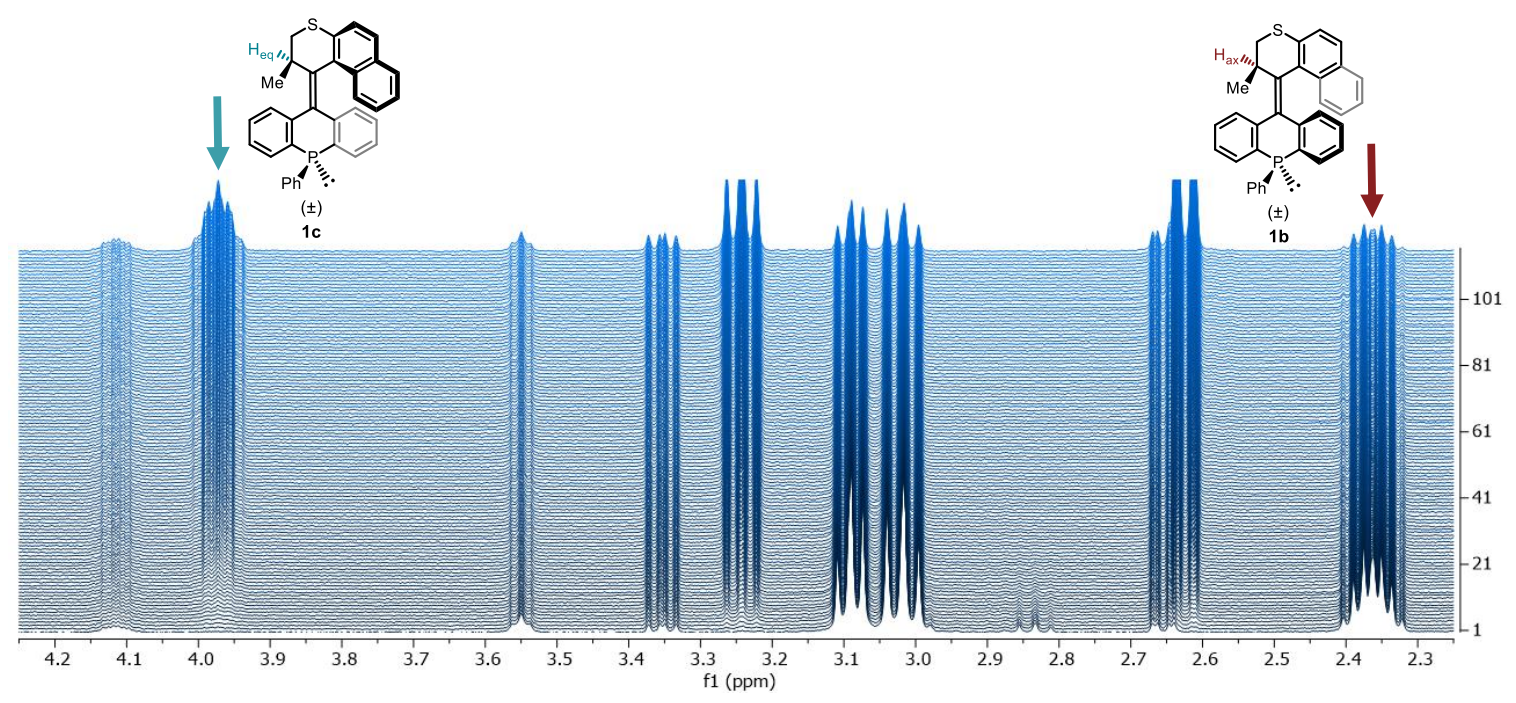

$\mathrm{T}=29.4{ }^{\circ} \mathrm{C}$

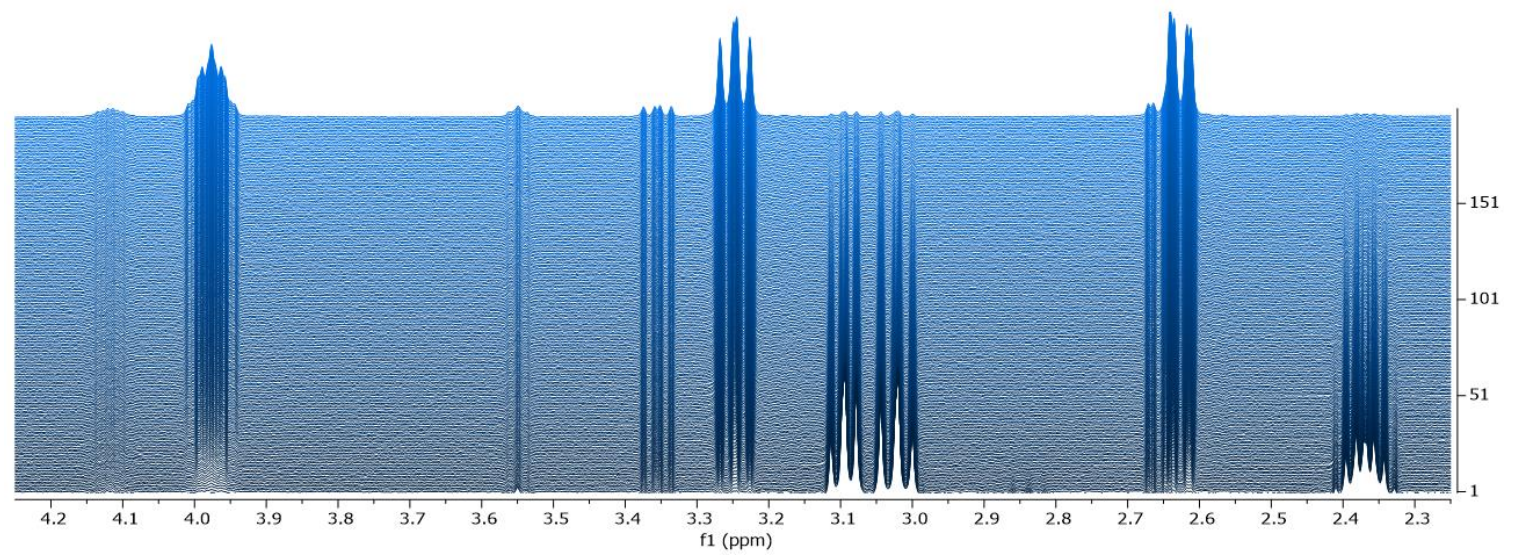

$\mathrm{T}=32.5^{\circ} \mathrm{C}$

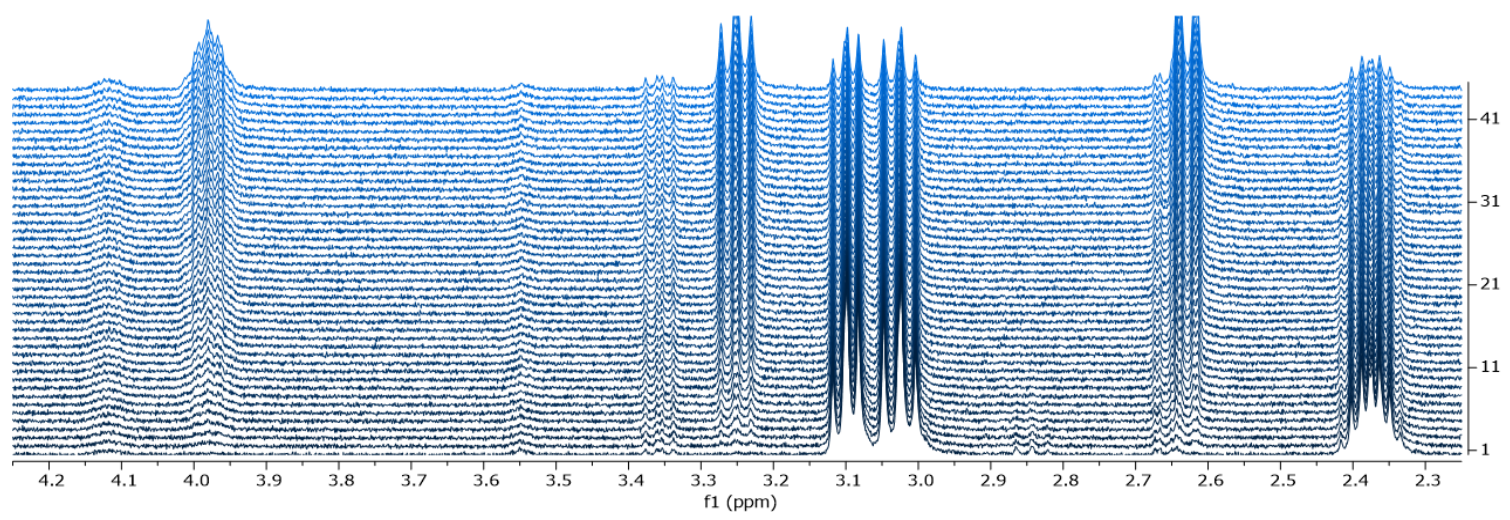

$\mathrm{T}=35.6{ }^{\circ} \mathrm{C}$ 


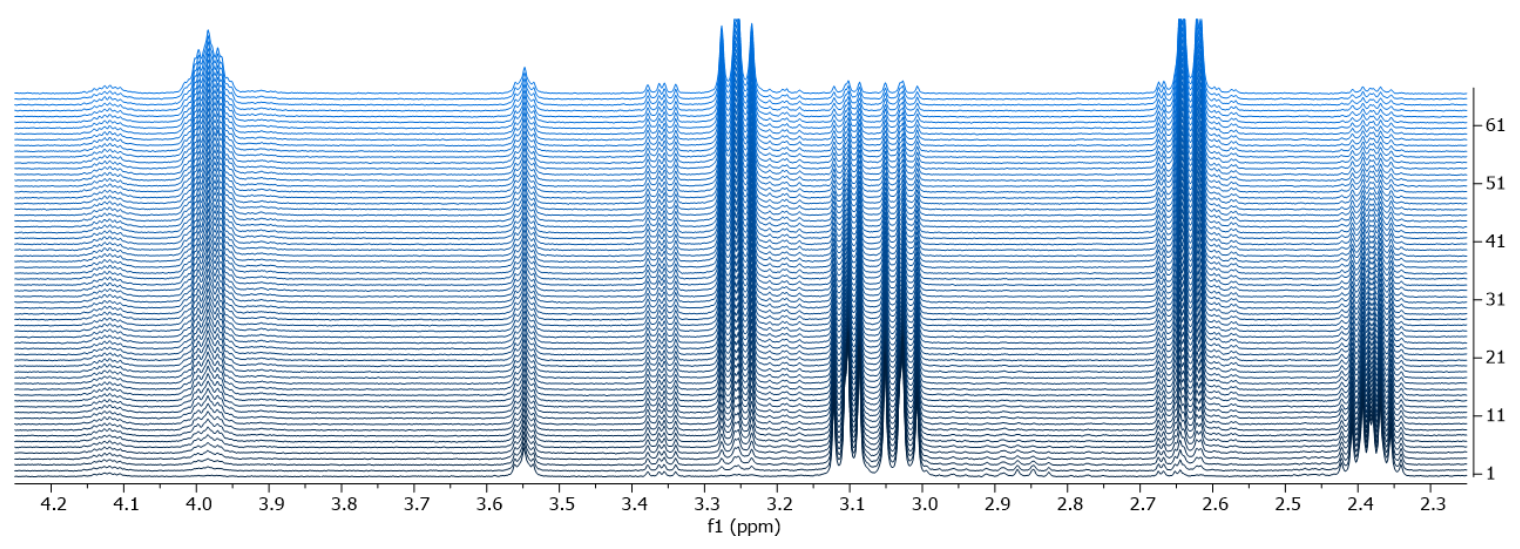

$\mathrm{T}=38.7^{\circ} \mathrm{C}$

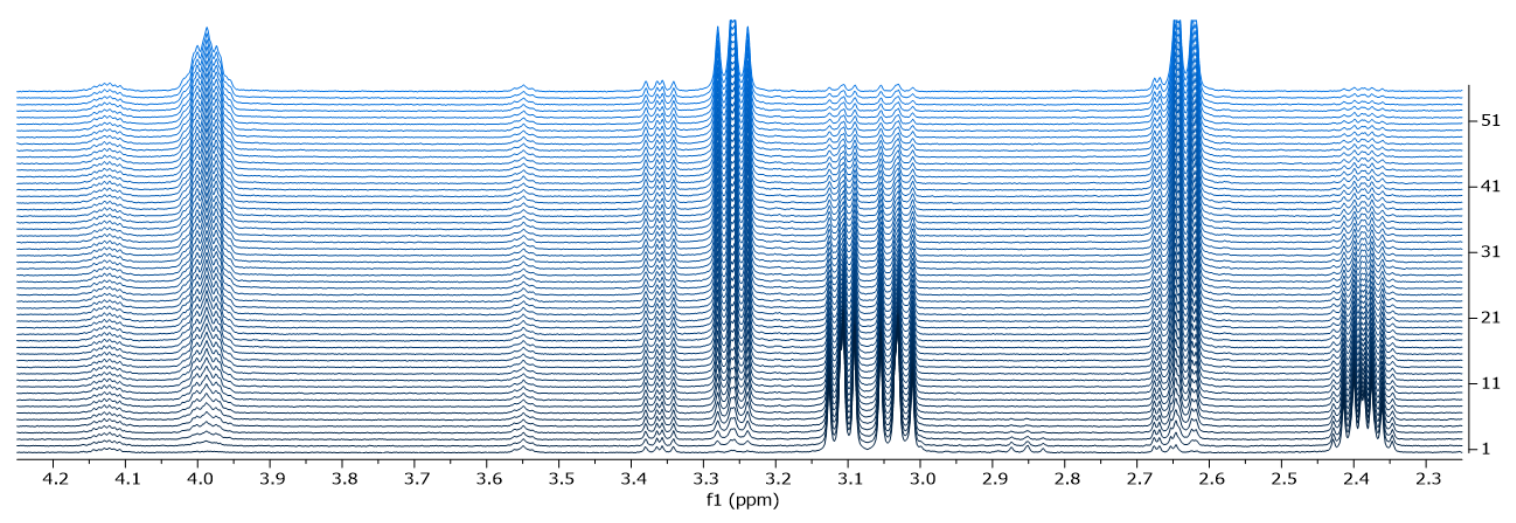

$\mathrm{T}=41.8^{\circ} \mathrm{C}$

\subsection{Kinetic Studies of Pyramidal Inversion of 1c}

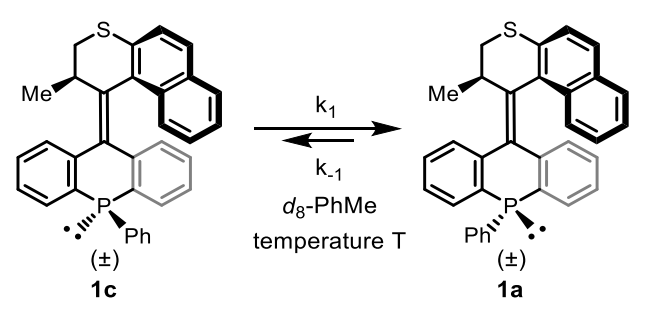

General Procedure. A solution of $2.5 \mathrm{mg}(5.0 \mu \mathrm{mol})$ of motor $1 \mathrm{c}$ in $0.50 \mathrm{~mL} d_{8}$-toluene $(10 . \mathrm{mM})$ in a J-Young NMR tube was thoroughly degassed through 5 freeze-pump-thaw cycles (Caution: the solution should be frozen at $-115{ }^{\circ} \mathrm{C}$ in a liquid nitrogen/ethanol bath, because there is a high risk of the tube breaking if frozen in liquid nitrogen directly), and the sample was inserted into an NMR probe pre-warmed to the appropriate temperature. After the instrument was tuned, locked, and shimmed, it was set to acquire a ${ }^{1} \mathrm{H}$ NMR spectrum regular intervals. The approach to equilibrium was monitored by integration of the signals from 1c $(3.31 \mathrm{ppm})$ and 1a $(3.39 \mathrm{ppm})$, corresponding to the methylene proton adjacent to sulfur. The data was processed by converting the raw integral values to a mole fraction of $1 \mathrm{c}$ relative to the sum of the concentrations of the two compounds.

\section{Eyring Analysis.}

$\begin{array}{cccccccccc}\mathbf{T}\left({ }^{\circ} \mathbf{C}\right) & \mathbf{T}(\mathbf{K}) & \mathbf{t}_{\mathbf{1}}(\mathbf{s}) & \mathbf{k}_{\text {eq }}\left(=\mathbf{t}_{1}{ }^{-1}\right) & \mathbf{K}_{\text {eq }} & \mathbf{k}_{1} & \mathbf{1} / \mathbf{T} & \ln (\mathbf{k} / \mathbf{T}) & \ln (\mathbf{k}) & \mathbf{t}_{1 / 2}(\mathbf{h}) \\ 91.6 & 364.6 & 29194.4 & 3.43 \mathrm{E}-05 & 0.294 & 2.65 \mathrm{E}-05 & 0.002743 & -1.64 \mathrm{E}+01 & -10.2817 & 5.62 \\ 96.9 & 369.9 & 21700.5 & 4.61 \mathrm{E}-05 & 0.27 & 3.63 \mathrm{E}-05 & 0.002703 & -1.61 \mathrm{E}+01 & -9.98509 & 4.18\end{array}$




$\begin{array}{llllllllll}101.9 & 374.9 & 10188.4 & 9.82 \mathrm{E}-05 & 0.272 & 7.72 \mathrm{E}-05 & 0.002667 & -1.54 \mathrm{E}+01 & -9.22901 & 1.96 \\ 106.8 & 379.8 & 8443.69 & 1.18 \mathrm{E}-04 & 0.265 & 9.36 \mathrm{E}-05 & 0.002633 & -1.52 \mathrm{E}+01 & -9.04117 & 1.63 \\ 111.8 & 384.8 & 4807.28 & 2.08 \mathrm{E}-04 & 0.274 & 1.63 \mathrm{E}-04 & 0.002599 & -1.47 \mathrm{E}+01 & -8.47789 & 0.93\end{array}$

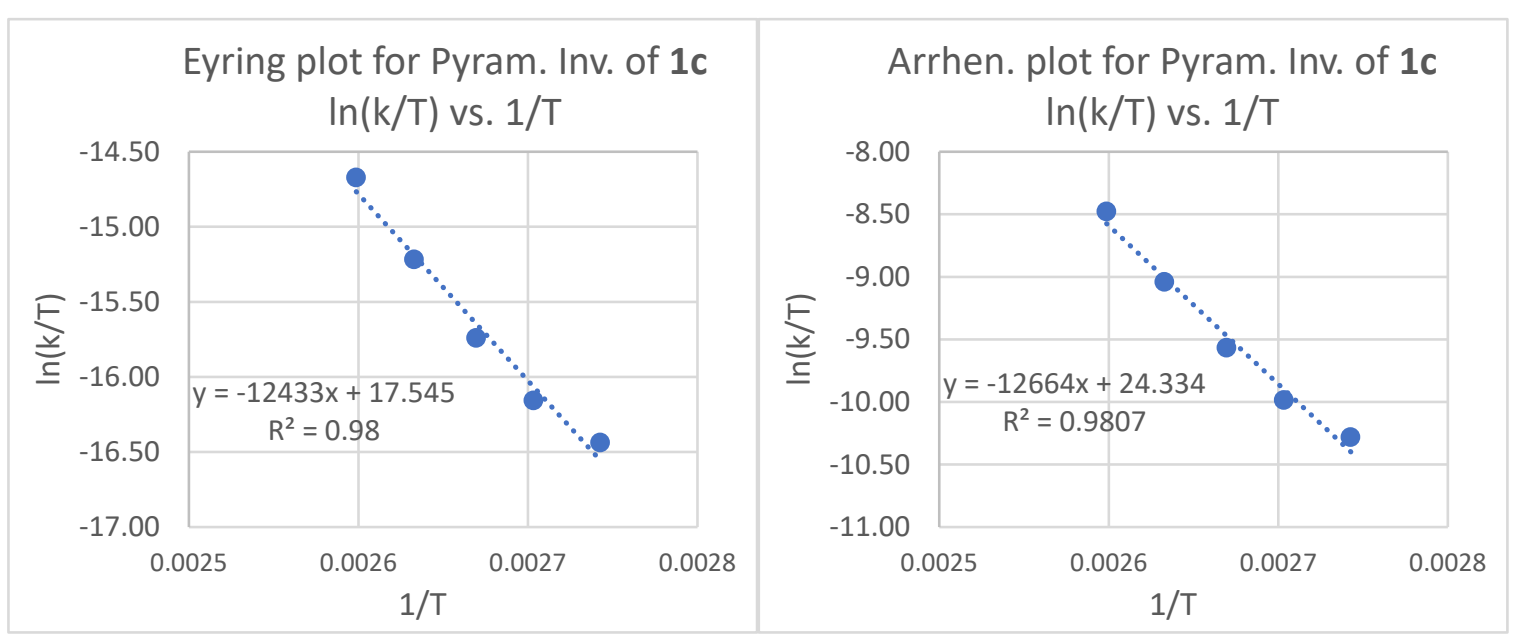

\begin{tabular}{|c|c|c|}
\hline$\Delta \mathrm{G}^{\ddagger}\left(25^{\circ} \mathrm{C}\right)$ & Uncertainty $(95 \%$ conf. $)$ & $\mathrm{t}_{1 / 2}\left(25^{\circ} \mathrm{C}\right)$ \\
\hline $28.2 \mathrm{kcal} / \mathrm{mol}$ & $1.3 \mathrm{kcal} / \mathrm{mol}$ & 1.7 years \\
\hline
\end{tabular}

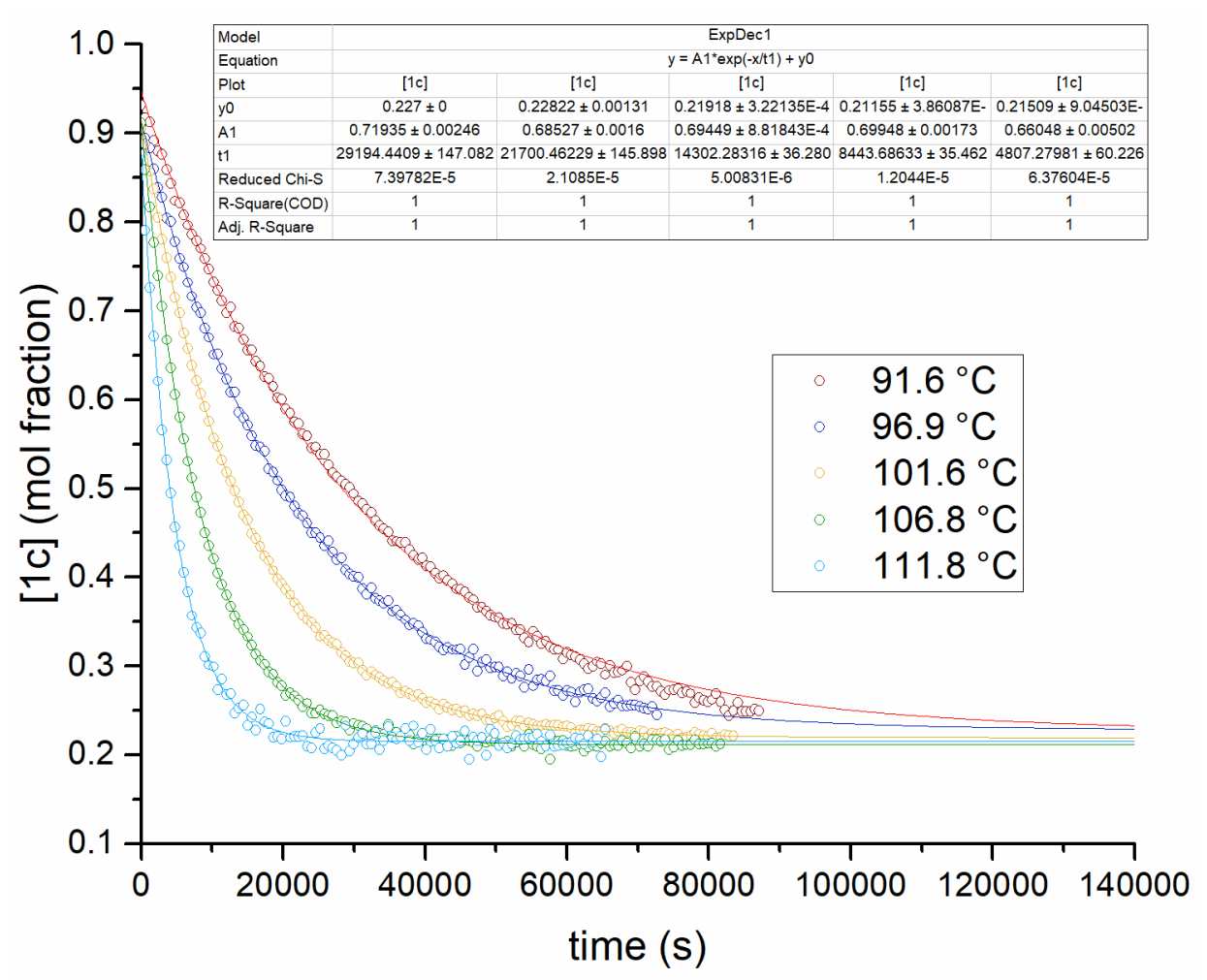

Figure S10. Decay curves for phosphorus inversion of $1 \mathrm{c}$. 

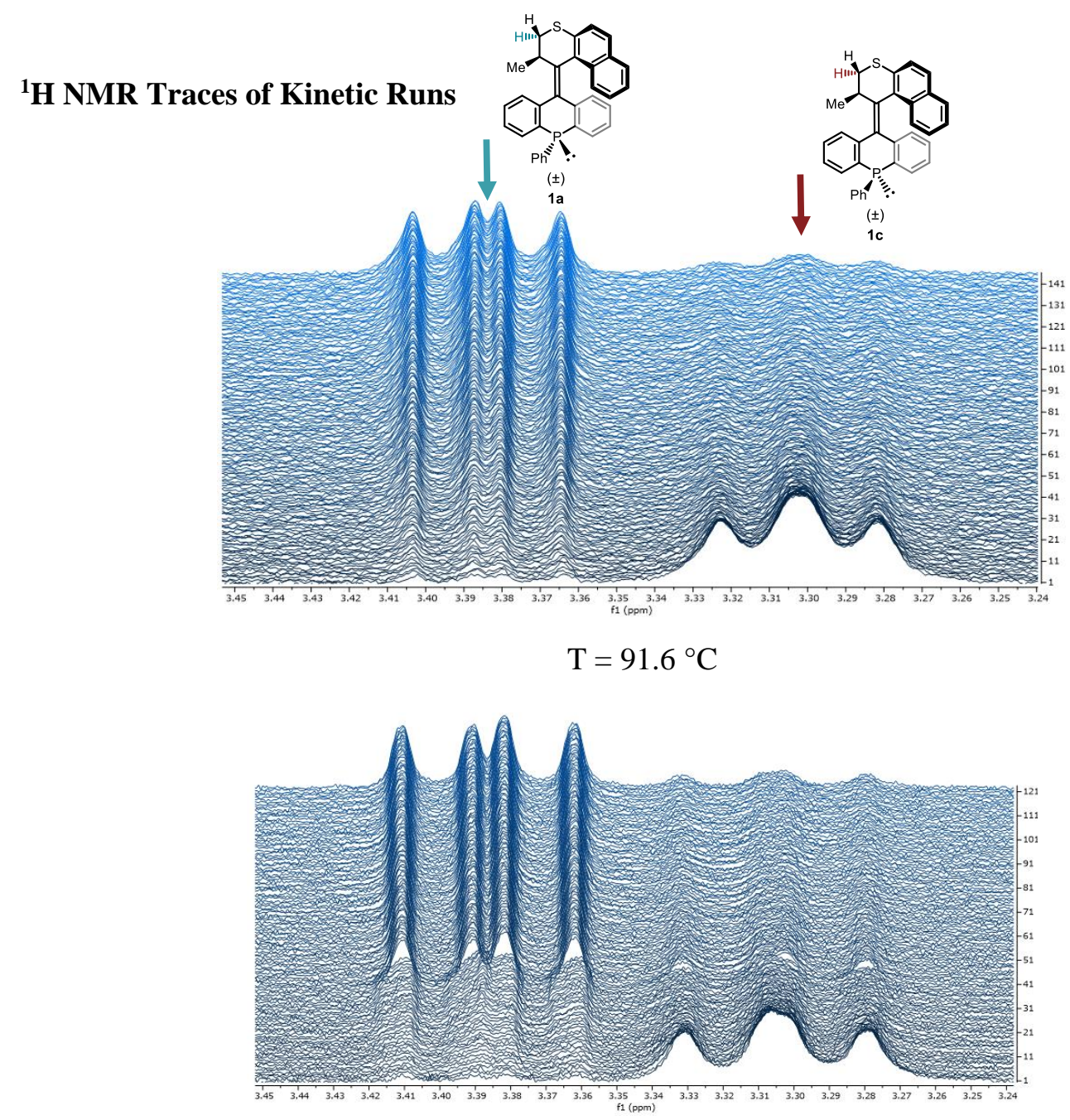

$\mathrm{T}=96.9^{\circ} \mathrm{C}$

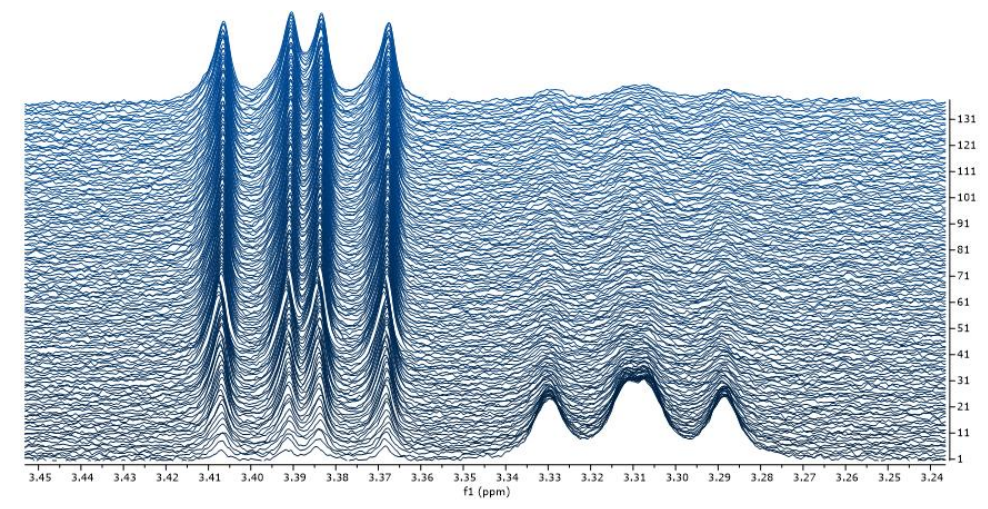

$\mathrm{T}=101.9^{\circ} \mathrm{C}$ 


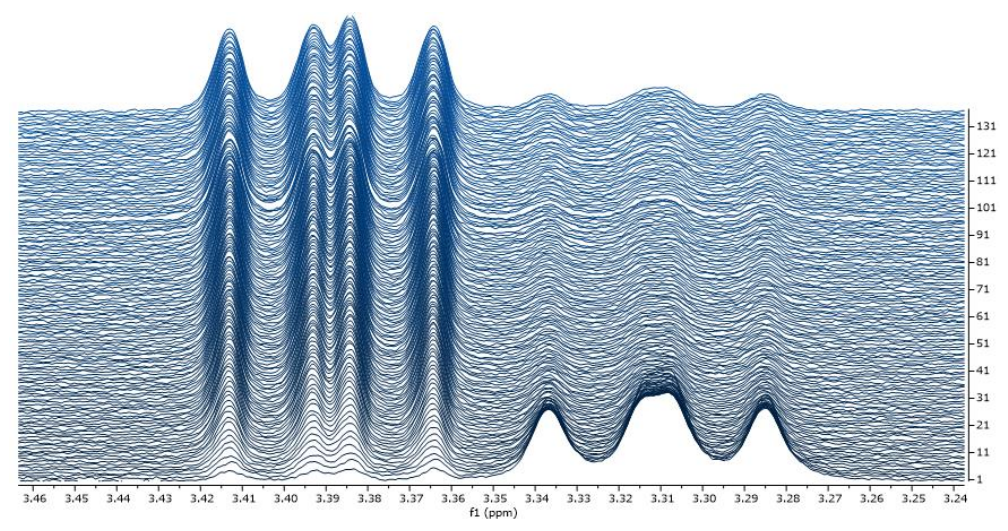

$$
\mathrm{T}=106.8^{\circ} \mathrm{C}
$$

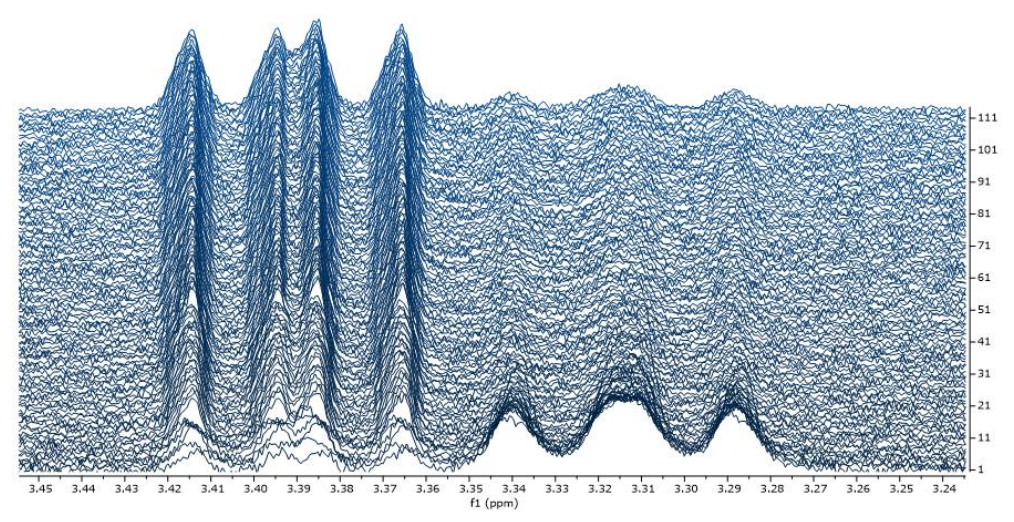

$$
\mathrm{T}=111.8^{\circ} \mathrm{C}
$$

\section{Transit Through the "Shortcut" Cycle of Motor 1 (Figure 5 in the Main Text)}<smiles>CC(C)P1(=O)c2ccccc2C(=C2[CH]CSc3ccc4ccccc4c32)c2ccccc21</smiles>

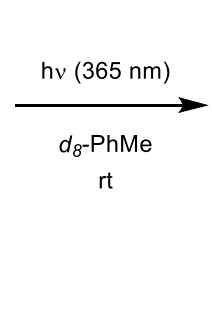

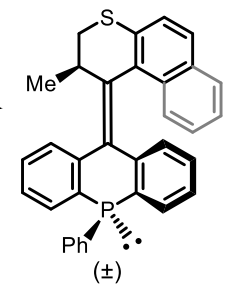

$( \pm)$
$1 b$

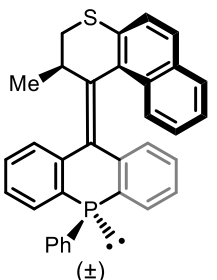

$( \pm)$

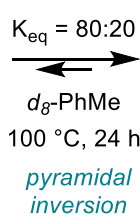

inversion

ermal helix inversion

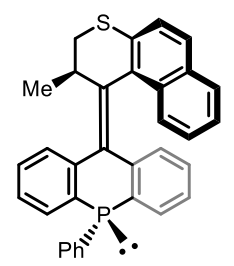

$( \pm)$

Procedure: A solution of $10.0 \mathrm{mg}(0.0206 \mathrm{mmol})$ of $\mathbf{1 a}$ in $0.50 \mathrm{~mL} d_{8}$-toluene was rigorously degassed in a J-Young NMR tube through 6 freeze-pump-thaw cycles (Caution: the solution should be frozen at $-115{ }^{\circ} \mathrm{C}$ in a liquid nitrogen/ethanol bath, because there is a high risk of the tube breaking if frozen in liquid nitrogen directly). Initial ${ }^{1} \mathrm{H}$ and ${ }^{31} \mathrm{P}$ NMR spectra were recorded (Figure $5 \mathrm{~A}$ in the main text).

The sample was then irradiated with a ThorLabs M365FP1 LED at room temperature for $11 \mathrm{~min}$, after which ${ }^{1} \mathrm{H}$ and ${ }^{31} \mathrm{P}$ NMR spectra were recorded (Figure $5 \mathrm{~B}$ in the main text).

The sample was then heated in an oil bath at $42{ }^{\circ} \mathrm{C}$ for $36 \mathrm{~h}$, after which ${ }^{1} \mathrm{H}$ and ${ }^{31} \mathrm{P}$ NMR spectra were recorded (Figure 5C in the main text).

Finally, the sample was heated in an oil bath at $100{ }^{\circ} \mathrm{C}$ for $24 \mathrm{~h}$, after which ${ }^{1} \mathrm{H}$ and ${ }^{31} \mathrm{P}$ NMR spectra were recorded (Figure 5D in the main text). 


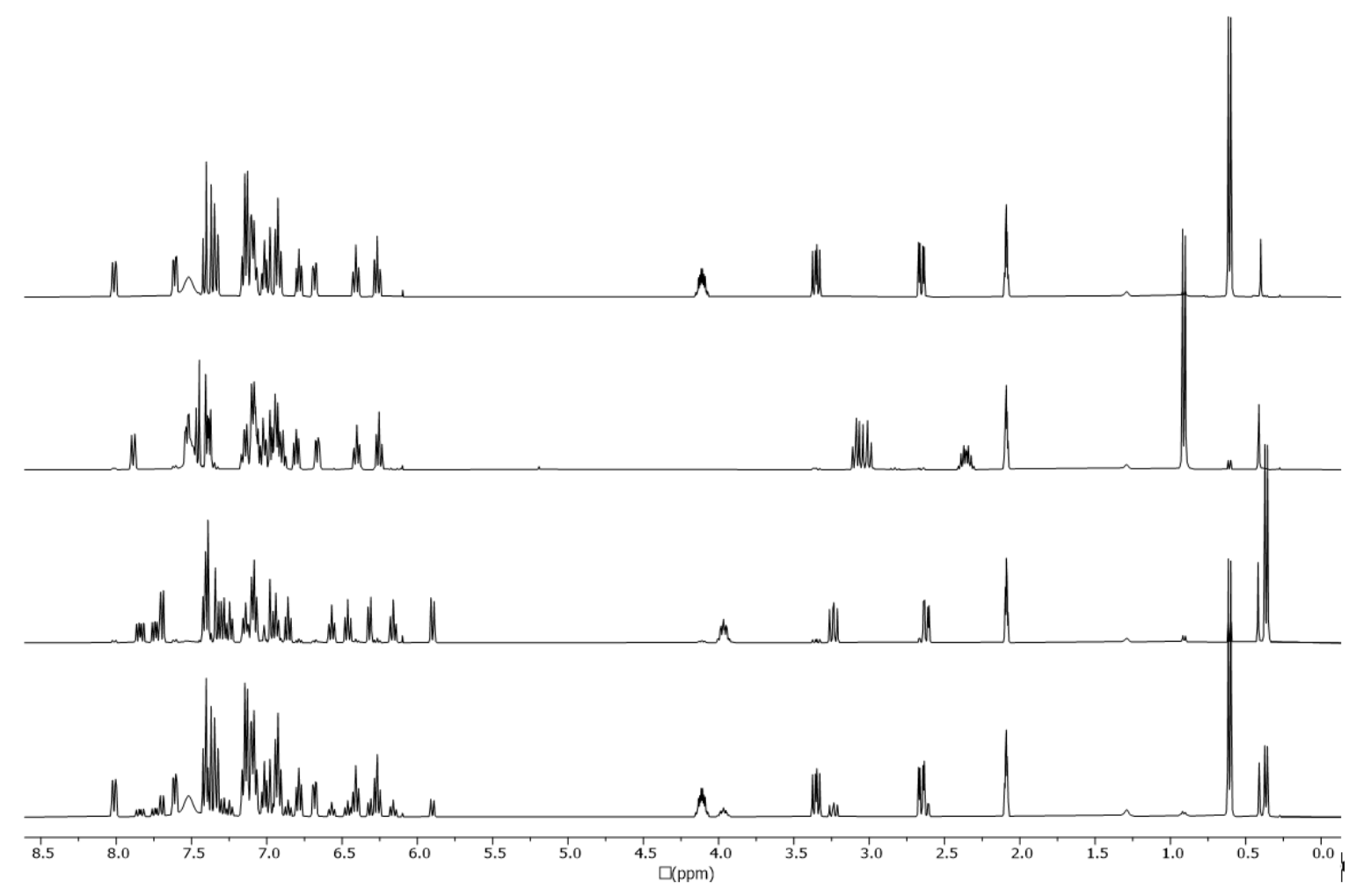

Figure S11. Transit through the "shortcut" cycle of motor 1, followed by ${ }^{1} \mathrm{H}$ NMR. (A) Pure 1a in $d_{8}$-PhMe. (B) After irradiating at $365 \mathrm{~nm}$ at room temperature. (C) After heating $36 \mathrm{~h}$ at $42{ }^{\circ} \mathrm{C}$. (D) After heating $24 \mathrm{~h}$ at $100{ }^{\circ} \mathrm{C}$.
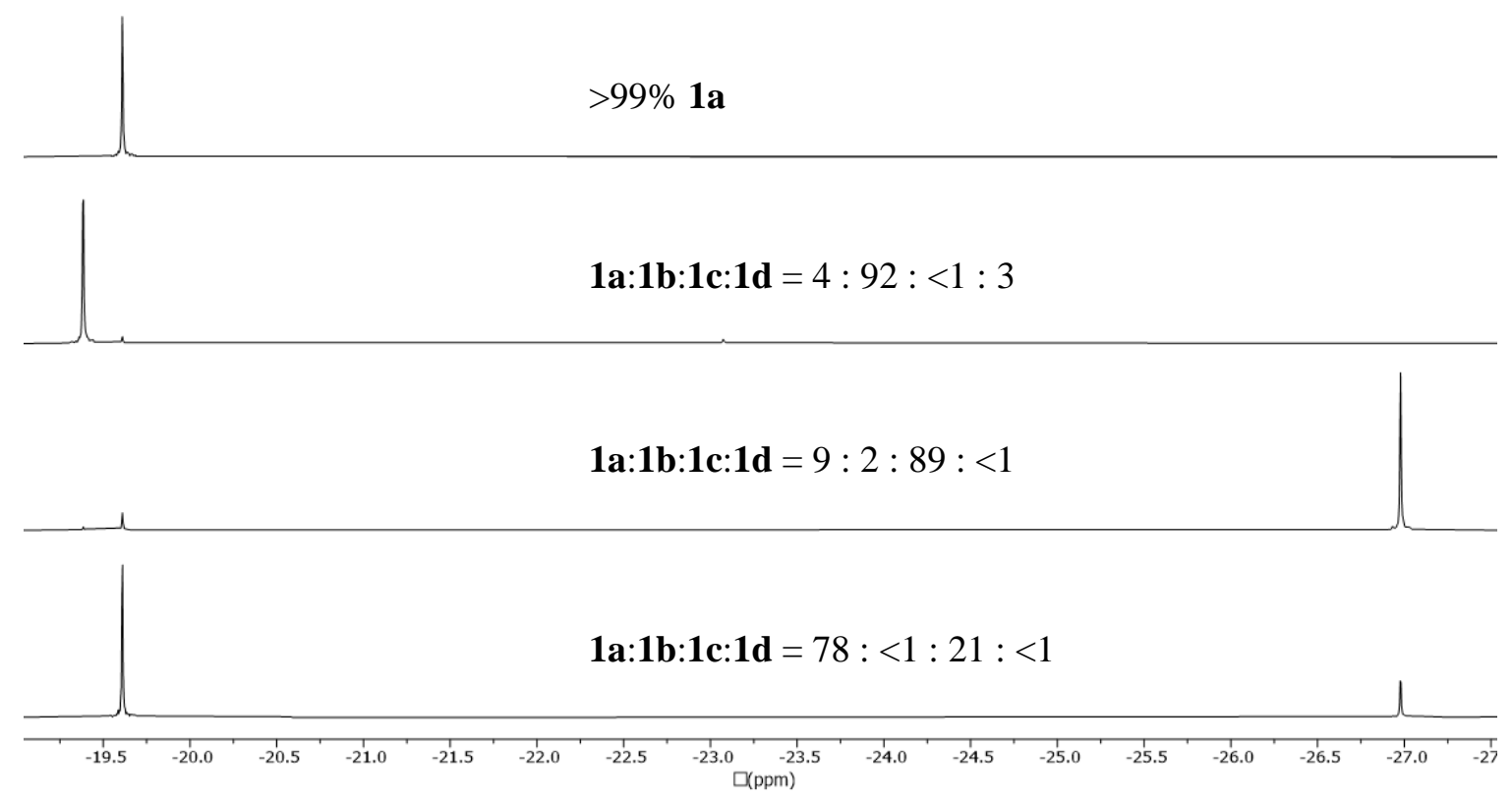

Figure S12. Transit through the "shortcut" cycle of motor 1, followed by ${ }^{31} \mathrm{P}$ NMR. (A) Pure 1a in $d_{8}$-PhMe. (B) After irradiating at $365 \mathrm{~nm}$ at room temperature. (C) After heating $36 \mathrm{~h}$ at $42{ }^{\circ} \mathrm{C}$. (D) After heating $24 \mathrm{~h}$ at $100{ }^{\circ} \mathrm{C}$. 


\section{Kinetic Modeling and Optimization via Data Fitting}

The model was first constructed by considering all the possible interconversions between the four diastereomers. Each such conversion was considered as a first order chemical reaction because under the current experimental conditions the photokinetic factor can be largely assumed to be constant. With this, the model is written as the following set of coupled ordinary differential equations (ODEs):

$$
\begin{aligned}
& \frac{d[\boldsymbol{a}]}{d t}=-k_{a b}[\boldsymbol{a}]+k_{b a}[\boldsymbol{b}]-k_{a c}[\boldsymbol{a}]+k_{c a}[\boldsymbol{c}]-k_{a d}[\boldsymbol{a}]+k_{d a}[\boldsymbol{d}] \\
& \frac{d[\boldsymbol{b}]}{d t}=+k_{a b}[\boldsymbol{a}]-k_{b a}[\boldsymbol{b}]-k_{b c}[\boldsymbol{b}]+k_{c b}[\boldsymbol{c}]-k_{b d}[\boldsymbol{b}]+k_{d b}[\boldsymbol{d}] \\
& \frac{d[\boldsymbol{c}]}{d t}=+k_{a c}[\boldsymbol{a}]-k_{c a}[\boldsymbol{c}]+k_{b c}[\boldsymbol{b}]-k_{c b}[\boldsymbol{c}]-k_{c d}[\boldsymbol{c}]+k_{d c}[\boldsymbol{d}] \\
& \frac{d[\boldsymbol{d}]}{d t}=+k_{a d}[\boldsymbol{a}]-k_{d a}[\boldsymbol{d}]+k_{b d}[\boldsymbol{b}]-k_{d b}[\boldsymbol{d}]+k_{c d}[\boldsymbol{c}]-k_{d c}[\boldsymbol{d}]
\end{aligned}
$$

where $\mathbf{a}, \mathbf{b}, \mathbf{c}$ and $\mathbf{d}$ are the different diastereomer and $k$ 's are the rate constants of the interconversions. The set of ODEs is then used to simulate the photokinetic profile via numerical integration using MATLAB's ode15s routine.

Data fitting between the measured photokinetic profile and the simulated one used a derivative-free routine fminsearch employing the Nelder-Mead simplex algorithm search method. ${ }^{5}$ The objective function that fminsearch minimized was the root-mean-square-difference (RMSD) between the model and the experiment:

$$
R M S D=\sqrt{\left\langle\sum_{i}\left(\sum_{t}\left[Y_{t}^{i}-S_{t}^{i}\right]^{2}\right)\right\rangle}
$$

Where for a diastereomer $\mathrm{i}(\mathrm{i}=\mathbf{a} . . \mathbf{d}), Y_{\mathrm{i}}^{\mathrm{t}}$ is its experimentally measured relative concentration at time $\mathrm{t}$ and $S_{t}^{i}$ is its modelled concentration at that time. $<0>$ denotes an average. This fitting procedure is similar to that reported in reference 6 .

Three variants of the model were considered for each motor ( 2 and $\mathbf{3}$ ): (i) the full model as described above, (ii) the model where the a-c and b-d interconversions are removed (which is equivalent to forcing $k_{\mathrm{ac}}=k_{\mathrm{ca}}=k_{\mathrm{bd}}=k_{\mathrm{db}}=0$ in the full model), and (iii) the model where a-c and $\mathbf{b}$-d interconversions are removed and only unidirectional rotations are allowed (which is equivalent to forcing $k_{\mathrm{ba}}=k_{\mathrm{cb}}=k_{\mathrm{dc}}=k_{\mathrm{ad}}=0$ ). These variants are respectively termed full, cyclic reversible and unidirectional.

The model that gave rise to the RMSD value is considered as the most appropriate one for each motor. After the fitting, the modelled relative concentrations of all the diastereomers are in excellent agreement with the experimentally measured ones (Figure S13). In order to test if other sets of $k$ 's could result in lower RMSD value, 10,000 data-fitting trials were executed for each of the model variants, each with a randomly picked set of initial guesses. We report the $k$ 's that gave the lowest RMSD (Table S1). 

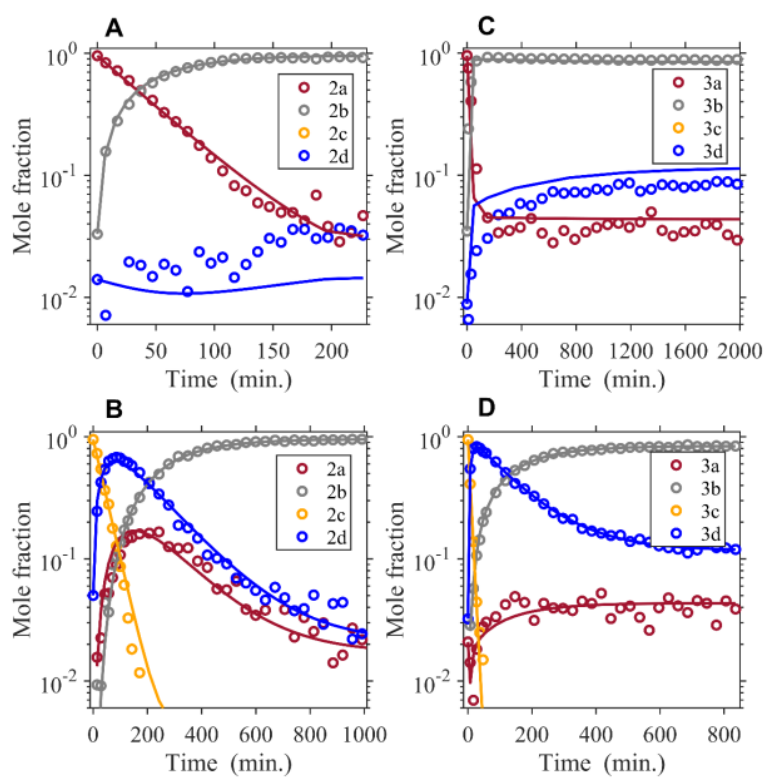

Figure S13. Photokinetic plots of the simulated cyclic reversible model (full lines) that best fits the experimental data (symbols) fitted to the two motors. (A) 2a irradiated with $395 \mathrm{~nm}$ at $-20{ }^{\circ} \mathrm{C}$.

(B) $2 \mathbf{c}$ irradiated with $395 \mathrm{~nm}$ at $-20{ }^{\circ} \mathrm{C}$. (C) 3a irradiated with 405 at $-50{ }^{\circ} \mathrm{C}$. (D) $3 \mathbf{c}$ irradiated with $405 \mathrm{~nm}$ at $-50{ }^{\circ} \mathrm{C}$. Fitted rate constants are given in Table S1. For brevity, not all data points shown. The simulated time courses in (A) and (C) converge slightly slower and faster than those in (B) and (D) due to unstandardized experiments (see main text). Figure is homologous to Figure 6 in the main text.

Table S1. Best fitted values of the rate constants, given in $1 / \mathrm{sec}$.

\begin{tabular}{|l|c|c|c|c|c|c|}
\hline & \multicolumn{3}{|c|}{ Motor 2 } & \multicolumn{3}{c|}{ Motor 3 } \\
\hline & Full & Cyc. rev. & Unidir. & Full & Cyc. rev. & Unidir. \\
\hline $\mathrm{k}_{\mathrm{ab}}$ & $2.77 \mathrm{E}-4$ & $2.91 \mathrm{E}-4$ & $2.79 \mathrm{E}-4$ & $7.17 \mathrm{E}-3$ & $5.77 \mathrm{E}-3$ & $1.17 \mathrm{E}-3$ \\
\hline $\mathrm{k}_{\mathrm{ba}}$ & $7.69 \mathrm{E}-6$ & $3.11 \mathrm{E}-6$ & N/A & $3.39 \mathrm{E}-4$ & $2.99 \mathrm{E}-4$ & N/A \\
\hline $\mathrm{k}_{\mathrm{ac}}$ & $2.98 \mathrm{E}-6$ & N/A & N/A & $2.33 \mathrm{E}-16$ & N/A & N/A \\
\hline $\mathrm{k}_{\mathrm{ca}}$ & $3.49 \mathrm{E}-9$ & N/A & N/A & $2.30 \mathrm{E}-16$ & N/A & N/A \\
\hline $\mathrm{k}_{\mathrm{ad}}$ & $4.22 \mathrm{E}-6$ & $3.71 \mathrm{E}-10$ & N/A & $3.71 \mathrm{E}-16$ & $3.01 \mathrm{E}-4$ & N/A \\
\hline $\mathrm{k}_{\mathrm{da}}$ & $8.41 \mathrm{E}-5$ & $9.35 \mathrm{E}-5$ & $2.64 \mathrm{E}-6$ & $1.05 \mathrm{E}-4$ & $1.12 \mathrm{E}-4$ & $1.08 \mathrm{E}-4$ \\
\hline $\mathrm{k}_{\mathrm{bc}}$ & $1.83 \mathrm{E}-10$ & $2.07 \mathrm{E}-6$ & $3.72 \mathrm{E}-4$ & $1.44 \mathrm{E}-5$ & $5.66 \mathrm{E}-10$ & $1.72 \mathrm{E}-5$ \\
\hline $\mathrm{k}_{\mathrm{cb}}$ & $1.30 \mathrm{E}-11$ & $1.13 \mathrm{E}-9$ & N/A & $1.24 \mathrm{E}-15$ & $5.32 \mathrm{E}-13$ & N/A \\
\hline $\mathrm{k}_{\mathrm{bd}}$ & $3.72 \mathrm{E}-8$ & N/A & N/A & $9.72 \mathrm{E}-16$ & N/A & N/A \\
\hline $\mathrm{k}_{\mathrm{db}}$ & $8.94 \mathrm{E}-6$ & N/A & N/A & $3.48 \mathrm{E}-16$ & N/A & N/A \\
\hline $\mathrm{k}_{\mathrm{cd}}$ & $3.73 \mathrm{E}-4$ & $3.72 \mathrm{E}-4$ & $9.39 \mathrm{E}-5$ & $1.92 \mathrm{E}-3$ & $1.93 \mathrm{E}-3$ & $1.94 \mathrm{E}-3$ \\
\hline $\mathrm{k}_{\mathrm{dc}}$ & $4.36 \mathrm{E}-10$ & $4.11 \mathrm{E}-7$ & N/A & $2.29 \mathrm{E}-16$ & $3.80 \mathrm{E}-7$ & N/A \\
\hline RMSD & 0.0175 & 0.0163 & 0.0168 & 0.00835 & 0.00771 & 0.0163 \\
\hline
\end{tabular}




\section{Analysis of Fully Constrained Networks for Motor 2}

The number of kinetic constants in a model equals the number of transitions considered, which can be at most 12 (see Sec. 6). We consider three types of features in the photokinetic data, which each yield a constraint that lowers the number of parameters that can be freely chosen by 1 .

i) Steady-state concentrations*, e.g. for $[\boldsymbol{a}]$ we obtain

$$
\left(\frac{d[\boldsymbol{a}]}{d t}\right)_{s s}=0=-k_{a b}[\boldsymbol{a}]_{s S}+k_{b a}[\boldsymbol{b}]_{s S}-k_{a c}[\boldsymbol{a}]_{s S}+k_{c a}[\boldsymbol{c}]_{s s}-k_{a d}[\boldsymbol{a}]_{s S}+k_{d a}[\boldsymbol{d}]_{s S}
$$

$*($ note: conservation of $[\boldsymbol{a}]+[\boldsymbol{b}]+[\boldsymbol{c}]+[\boldsymbol{d}]$ lowers the number of linearly independent constraints by 1$)$

ii) A local maximum. E.g. if $[\boldsymbol{a}]$ has a local maximum at time $t=\tau$, it follows that

$$
\left(\frac{d[\boldsymbol{a}]}{d t}\right)_{\max }=0=-k_{a b}[\boldsymbol{a}]_{\tau}+k_{b a}[\boldsymbol{b}]_{\tau}-k_{a c}[\boldsymbol{a}]_{\tau}+k_{c a}[\boldsymbol{c}]_{\tau}-k_{a d}[\boldsymbol{a}]_{\tau}+k_{d a}[\boldsymbol{d}]_{\tau}
$$

iii) Initial rate of consumption for a (nearly) pure species. E.g. pure $[\boldsymbol{a}]$ initially obeys

$$
\ln \frac{[\boldsymbol{a}]_{t}}{[\boldsymbol{a}]_{0}} \approx-k_{t o t, A} t=-\left(k_{a b}+k_{a c}+k_{a d}\right) t
$$

For a reaction network that has as many reactions as applicable constraints, all rate constants are directly obtained from the unique solution that satisfies these constraints for that network. We then use these rate constants to solve the kinetic equations (see sec. 6) for that network (using the odeint solver of the scipy library in Python). For each network, solutions were generated using the distinct initial concentrations in two kinetic datasets.

The solutions to constraints are network-specific. When a reaction network is not a good description of the underlying system, then its unique kinetic parameters will not allow it to capture the full behavior. By comparing networks with both datasets on linear scale and logarithmic scale (plotted in Fig. S12), we can then inspect if the model is self-consistent: a correct description should recover its parameters and subsequently reproduce the same data. A wrong description leads to a paradox and can be ruled out by visual inspection due to clear inconsistencies.

If $\mathbf{2}$ is a motor, then we should expect acyclic models to yield inconsistencies. There are three models left to evaluate, when the following considerations are taken into account:

i) Maintaining nonzero concentrations in an acyclic network requires species to react back-andforth (reactions must come in pairs, e.g. $\mathbf{a} \rightleftarrows \mathbf{b}$ ). $[\boldsymbol{a}]_{\mathrm{ss}},[\boldsymbol{b}]_{\mathrm{ss}},[\boldsymbol{d}]_{\mathrm{ss}}$ are detectably larger than zero and their concentrations change over time. Each species must thus be produced and consumed by at least one reaction.

ii) The consumption of $\mathbf{c}$ is constrained $\left(k_{t o t, c} \approx 0.025 \mathrm{~min}^{-1}\right)$ and $[\boldsymbol{c}]_{s s}$ is below the detection limit. The steady-state constraint for $c$ then imposes that consumption steps strongly outpace production steps for $\mathbf{c}$, i.e. $k_{t o t, c} \gg k_{a c}, k_{b c}, k_{d c}$.

iii) If $\mathbf{c}$ reacts back-and-forth with one species (e.g. $\mathbf{c} \rightleftarrows \mathbf{d}$ ), then production of $\boldsymbol{c}$ is slow. Starting with $[\boldsymbol{c}]_{s S}=0$, concentrations found for $\mathbf{a}, \mathbf{b}$ and $\mathbf{d}$ in time are virtually indistinguishable from a network without this reaction. If $\mathbf{c}$ reacts back-and-forth between species, e.g. $\mathbf{b} \rightleftarrows \mathbf{c} \rightleftarrows \mathbf{d}$, then its consumption is not rate-limiting and a model with $\mathbf{b} \rightleftarrows \mathbf{d}$ would yield quantitatively equivalent behavior. 
From the above, it follows that the photokinetic data for which $[\mathbf{C}]_{S S}$ is below the detection limit can be modeled using only the species $\mathbf{a}, \mathbf{b}$ and $\mathbf{d}$, as each model that includes $\mathbf{c}$ has an equivalent counterpart without $\mathbf{c}$, due to consideration iii). Since each of $\mathbf{a}, \mathbf{b}, \mathbf{d}$ must react back-and-forth without forming a cycle, only 3 acyclic networks remain:

$$
\mathrm{L} 1: \mathbf{b} \rightleftarrows \mathbf{a} \rightleftarrows \mathbf{d}, \quad \quad \mathrm{L} 2: \mathbf{a} \rightleftarrows \mathbf{b} \rightleftarrows \mathbf{d}, \quad \text { L3: } \mathbf{a} \rightleftarrows \mathbf{d} \rightleftarrows \mathbf{b} .
$$

Fig. S12 shows that each acyclic network deviates qualitatively and quantitatively from the pair of kinetic datasets, no acyclic network can thus account for the full data. However, L1 and L2 each show excellent agreement with one of the two datasets.

Moving to cylic models, the simplest fully constrained model, C1: $\mathbf{a} \rightarrow \mathbf{b} \rightarrow \mathbf{d} \rightarrow \mathbf{a}$, agrees with data where $\mathbf{a}$ is abundant, but otherwise production of $\mathbf{a}$, and $\mathbf{b}$ and consumption of $\mathbf{c}$ are too rapid. Cyclic model C2: $\mathbf{a} \rightleftarrows \mathbf{b} \rightarrow \mathbf{d} \rightarrow \mathbf{a}$ is still fully constrained, and yields quantitative agreement with the data without $\mathbf{c}$. Using the fully constrained $\mathrm{C} 3: \mathbf{a} \rightleftarrows \mathbf{b} \rightarrow \mathbf{c} \rightarrow \mathbf{d} \rightarrow \mathbf{a}$ for data including $\mathbf{c}$ yields qualitative agreement.

At this point all constraints have been used, and further improvement may be sought through models with more steps or refinement of the current parameters through fitting.
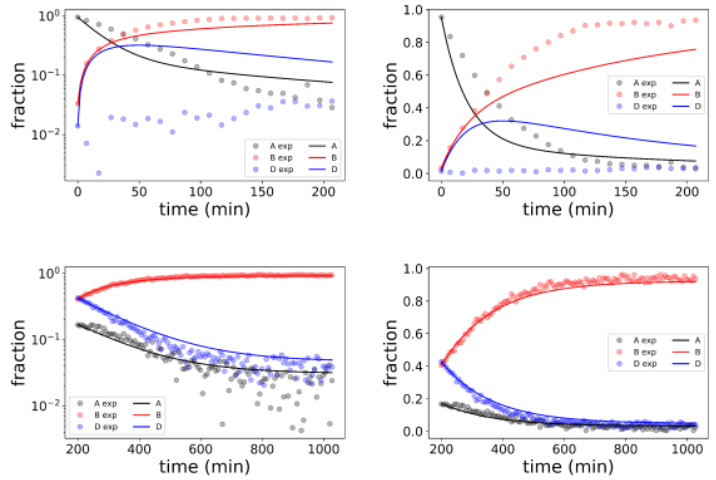

\section{$\mathrm{L} 1: \mathbf{b} \rightleftarrows \mathbf{a} \rightleftarrows \mathbf{d}$}
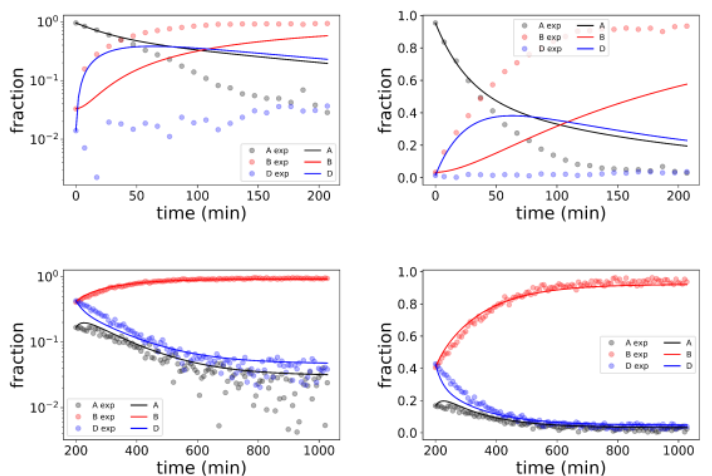

L3: $\mathbf{a} \rightleftarrows \mathbf{d} \rightleftarrows \mathbf{b}$
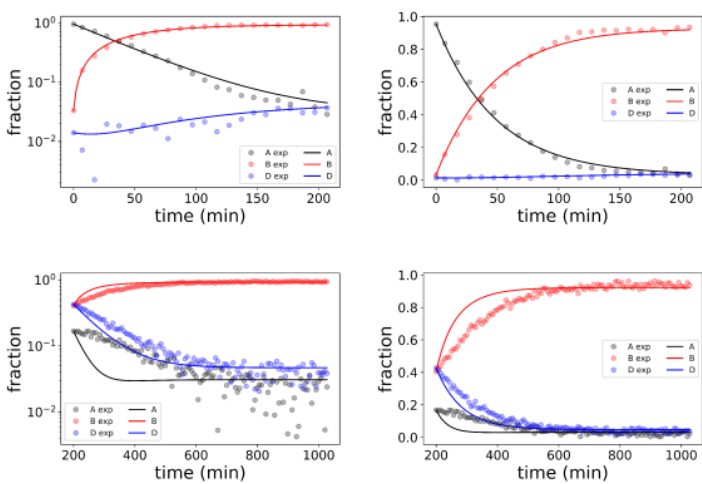

L2: $\mathbf{a} \rightleftarrows \mathbf{b} \rightleftarrows \mathbf{d}$
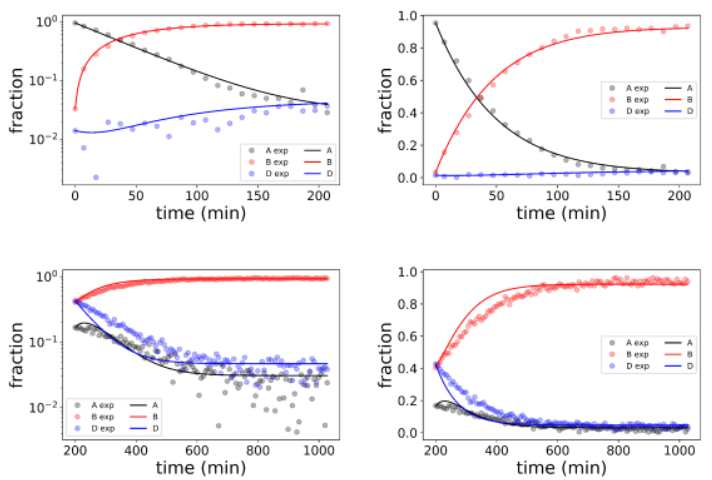

$\mathrm{C} 1: \mathbf{a} \rightarrow \mathbf{b} \rightarrow \mathbf{d} \rightarrow \mathbf{a}$ 

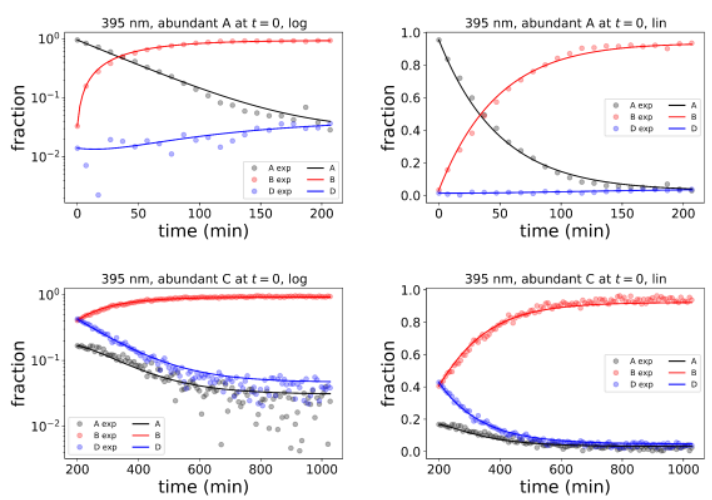

$\mathrm{C} 2: \mathbf{a} \rightleftarrows \mathbf{b} \rightarrow \mathbf{d} \rightarrow \mathbf{a}$
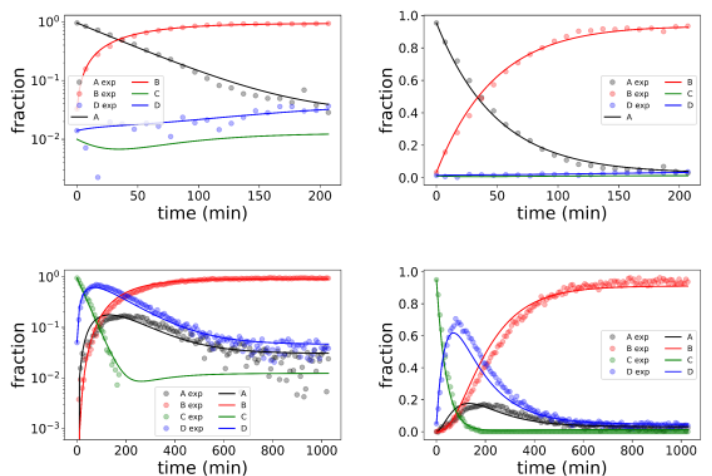

$\mathrm{C} 3: \mathbf{a} \rightleftarrows \mathbf{b} \rightarrow \mathbf{c} \rightarrow \mathbf{d} \rightarrow \mathbf{a}$

Figure S14 comparison of fully constrained acyclic models L1, L2, L3 and cyclic models C1, C2 using the data for $\mathbf{a}, \mathbf{b}, \mathbf{d}$ where $\mathbf{c}$ is not detectable, and cyclic model $\mathrm{C} 3$ for the full data. Kinetic constants for the models are the unique solutions of a linear system of constraints due to features in the kinetic data (slopes, maxima, steady-state concentrations). A correct network description for the data must reproduce that same data from these constraints for all conditions. Clear disagreement implies an incorrect network (L1,L2,L3,C1).

\section{Single-Crystal X-Ray Diffraction Measurements}

Single-crystals were mounted on a cryoloop and placed in the nitrogen stream (100 K) of a BrukerAXS D8 Venture diffractometer. Data collection and processing was carried out using the Bruker APEX3 software suite. ${ }^{7,8}$ A multi-scan absorption correction was applied, based on the intensities of symmetry-related reflections measured at different angular settings (SADABS). ${ }^{9}$ The structures were solved using SHELXT ${ }^{10}$ and refinement was performed using SHELXL. ${ }^{11}$ The hydrogen atoms were generated by geometrical considerations, constrained by idealized geometries and allowed to ride on their carrier atoms with an isotropic displacement parameter related to the equivalent displacement parameter of their carrier atoms. All analyzed crystals had been prepared from racemic samples with the exception of 3a, the enantiomers of which had been separated prior to crystallization. However, also in the case of $\mathbf{2 a}$ and $\mathbf{3} \mathbf{c}$ enantiomerically pure single-crystals were obtained. In both cases the structure was refined as an inversion twin with BASF refining to 0.056 and 0.030 , respectively. For 3a, anomalous dispersion effects were used to establish the absolute configuration of the enantiomer used for crystallization as S. No A- or B-level alerts were raised by CheckCIF for the fully refined structures. The structural parameters presented in Table 4 were generated using PLATON ${ }^{12}$ and OLEX $2^{13}$ software, and the structural depictions in Figure 7 were generated using ORTEP-III. ${ }^{14}$

\subsection{Crystallization Procedures}

All compounds with stable helix configuration (2a, 2c, 3a, 3c) were crystallized from dichloromethane solutions by vapor-diffusion of pentane.

Au motor $2 \mathbf{b}$. A solution of $2.0 \mathrm{mg}$ of Au motor $2 \mathbf{a}$ in $0.5 \mathrm{~mL} \mathrm{CD}_{2} \mathrm{Cl}_{2}$ was irradiated at $395 \mathrm{~nm}$ (ThorLabs M395F2 lamp) for $2 \mathrm{~h}$ at $6{ }^{\circ} \mathrm{C}$, after which ${ }^{1} \mathrm{H}$ NMR confirmed conversion to $\mathbf{2 b}$. X-Ray quality crystals of $\mathbf{2 b}$ were grown by vapor diffusion of pentane into this solution at $6{ }^{\circ} \mathrm{C}$.

Au motor 2d. A solution of $5.6 \mathrm{mg}$ Au motor $2 \mathrm{c}$ in $0.5 \mathrm{~mL} d_{8}$-THF was irradiated at room temperature at $395 \mathrm{~nm}$ (ThorLabs M395F2 lamp) within an NMR probe through a fiber optic cable. The reaction was followed by ${ }^{1} \mathrm{H}$ NMR, and suspended when isomer $\mathbf{2 d}$ reached its maximum concentration of $\sim 65 \%$. The sample was ejected, and the solvent was removed by rotary 
evaporation. The residue was redisolved in $0.4 \mathrm{~mL}$ dichloromethane, and the resulting solution was divided into portions which were then layered with pentane. X-Ray quality crystals were obtained from a solution in a $-20{ }^{\circ} \mathrm{C}$ freezer.

Oxide motor 3a. A solution of $6.2 \mathrm{mg}$ of phosphine oxide motor $3 \mathrm{a}$ in $1.0 \mathrm{~mL}$ THF was irradiated directly with a $405 \mathrm{~nm}$ (ThorLabs M405FP1) lamp for $1 \mathrm{~h}$ at $6{ }^{\circ} \mathrm{C}$. The solvent was removed by rotary evaporation. The residue was redissolved in $0.6 \mathrm{~mL}$ dichloromethane, and the resulting solution was divided into portions which were then layered with pentane. X-Ray quality crystals were obtained from a solution in a $-20{ }^{\circ} \mathrm{C}$ freezer.

Oxide motor 3d. A solution of $3.0 \mathrm{mg}$ oxide motor $3 \mathbf{c}$ in $0.4 \mathrm{~mL} d_{8}$-THF was irradiated at room temperature at $405 \mathrm{~nm}$ (ThorLabs M405FP1 lamp) within an NMR probe through a fiber optic cable. The reaction was followed by ${ }^{1} \mathrm{H}$ NMR, and suspended when isomer $\mathbf{3 d}$ reached its maximum concentration of $\sim 85 \%$. The sample was ejected, and the solvent was removed by rotary evaporation. The residue was redisolved in $0.4 \mathrm{~mL}$ dichloromethane, and the resulting solution was divided into portions which were then layered with pentane. X-Ray quality crystals were obtained from a solution in a $-20{ }^{\circ} \mathrm{C}$ freezer. 


\subsection{Au motor $2 a$}

CCDC Deposition Number

Name

Formula

Molecular Weight

Crystal System

$T$ [K]

Space Group

$a[\AA ̊]$

$b[\AA]$

$c[\AA]]$

$\alpha\left[^{\circ}\right]$

$b\left[^{\circ}\right]$

$V\left[^{\circ}\right]$

$V\left[\AA^{3}\right]$

Z

$D_{\text {calc }}\left[\mathrm{g} \cdot \mathrm{cm}^{-3}\right]$

$\mathrm{F}\left(\begin{array}{lll}0 & 0 & 0\end{array}\right)$

$h_{\min }, h_{\max }$

$k_{\min }, k_{\max }$

$I_{\min }, I_{\max }$

$\mu\left[\mathrm{mm}^{-1}\right]$

Crystal Size [mm]

Colour, Shape

$R_{\text {int }}$

$\vartheta_{\min }, \vartheta_{\max }\left[^{\circ}\right]$

Total Reflections (before merge)

Data (I>3 x sigma(I))

[Reflections,Parameters, Restraints]

$S$ (=GooF)

Min. Residual Density [e/ $\left.\AA^{3}\right]$

Max. Residual Density $\left[\mathrm{e} / \AA^{3}\right]$

Threshold Expression

$R_{1}$

$w R_{2}$

\subsection{Au motor $2 b$}

CCDC Deposition Number

Name

Formula

Molecular Weight

Crystal System

$T[\mathrm{~K}]$

Space Group

$a[\AA]$

$b[\AA]$

$c[\AA]$

$\alpha\left[^{\circ}\right]$

$B\left[^{\circ}\right]$

$V\left[{ }^{\circ}\right]$

$V\left[\AA^{3}\right]$

Z

$D_{\text {calc }}\left[\mathrm{g} \cdot \mathrm{cm}^{-3}\right]$

$\mathrm{F}\left(\begin{array}{lll}0 & 0 & 0\end{array}\right)$

$\mathrm{h}_{\text {min }}, \mathrm{h}_{\max }$

$k_{\min }, k_{\max }$

$I_{\min }, I_{\max }$

$\mu\left[\mathrm{mm}^{-1}\right]$

Crystal Size [mm]

Colour, Shape

$R_{\text {int }}$

$\vartheta_{\min }, \vartheta_{\max }\left[^{\circ}\right]$

Total Reflections (before merge)

Data (I>3 x sigma(I))

[Reflections,Parameters, Restraints]

$\mathrm{S}$ (=GooF)

Min. Residual Density $\left[e / \AA^{3}\right]$

Max. Residual Density [e/ $\left./ \AA^{3}\right]$

Threshold Expression

$R_{1}$

$w R_{2}$
CCDC 2019760

2a

$\mathrm{C}_{33} \mathrm{H}_{25} \mathrm{Au}_{1} \mathrm{Cl}_{1} \mathrm{P}_{1} \mathrm{~S}_{1}$

716.97

orthorhombic

100(2)

$P 22_{1} 2_{1} 2_{1}$

11.1778(4)

12.3835(4)

19.5149(6)

90

90

90

2701.26(15)

4

1.763

1400

$-13,13$

$-15,15$

$-24,24$

12.583

$0.12 \times 0.05 \times 0.04$

clear_pale_colourless needle

0.0433

4.228, 74.495

31031

$5392,336,0$

1.085

$-1.210$

0.568

I>2sigma(l)

0.0201

0.0436

CCDC 2019759

2b

$\mathrm{C}_{33} \mathrm{H}_{25} \mathrm{Au}_{1} \mathrm{Cl}_{1} \mathrm{P}_{1} \mathrm{~S}_{1}$

716.97

monoclinic

100(2)

$P 21 / c$

9.3566(4)

13.4693(6)

$21.3480(9)$

90

$94.6870(10)$

90

2681.4(2)

4

1.776

1400

$-11,11$

$-16,16$

$-26,26$

12.676

$0.16 \times 0.14 \times 0.14$

clear_light_yellow block

0.0328

$3.884,74.408$

45493

$5477,335,6$

1.082

$-1.056$

1.870

I $>2$ sigma(I)

0.0248

0.0575
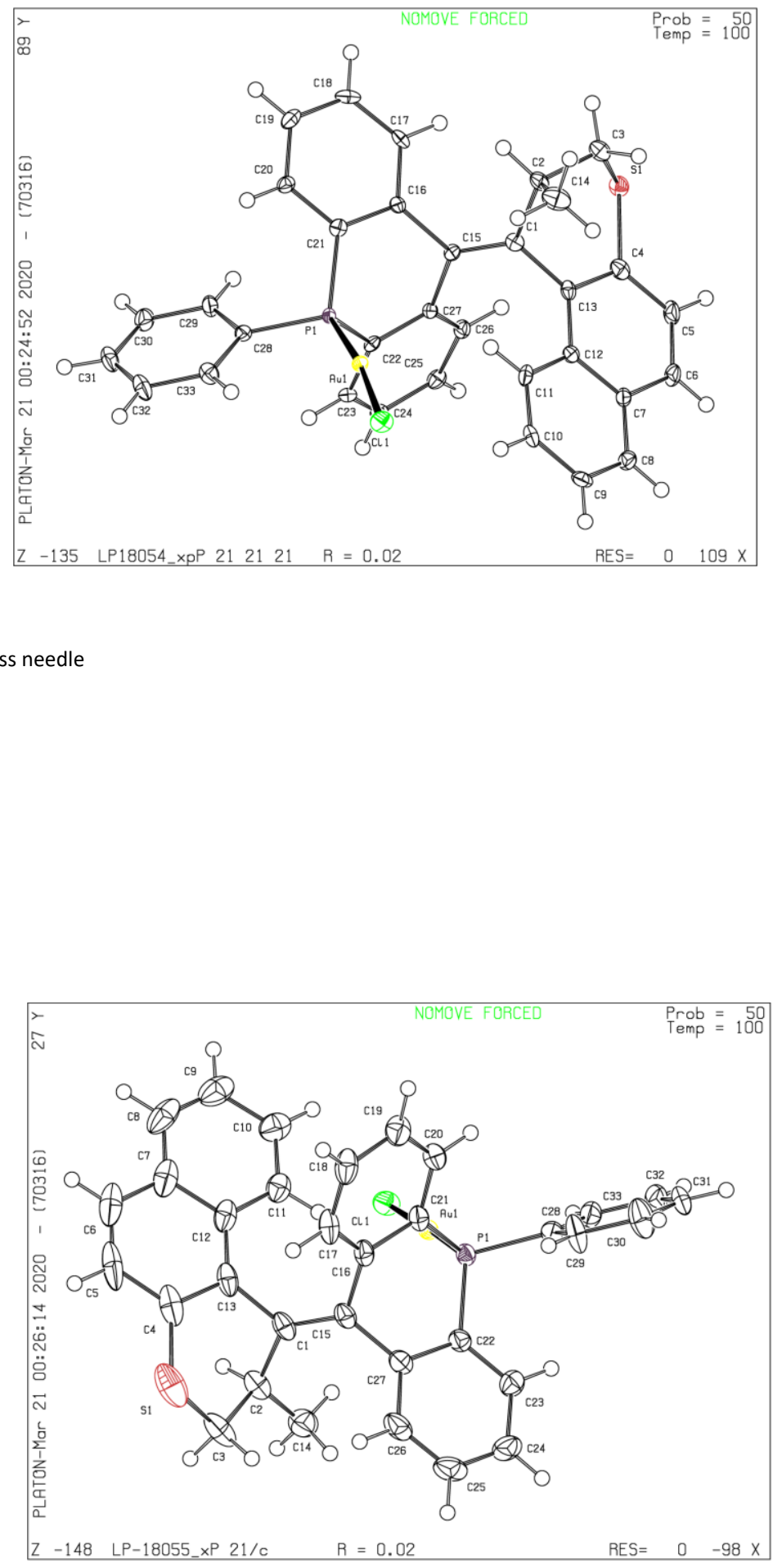


\section{$8.3 \mathrm{Au}$ motor $2 \mathrm{c}$}

CCDC Deposition Number

\section{Name}

Formula

Molecular Weight

Crystal System

$T[\mathrm{~K}]$

Space Group

$a[\AA]$

$b[\AA]$

$c[\AA ̊]$

$\alpha\left[^{\circ}\right]$

$B\left[^{\circ}\right]$

$V\left[^{\circ}\right]$

$V\left[\AA^{3}\right]$

Z

$D_{\text {calc }}\left[\mathrm{g} \cdot \mathrm{cm}^{-3}\right]$

$\mathrm{F}\left(\begin{array}{lll}0 & 0 & 0\end{array}\right)$

$h_{\min }, h_{\max }$

$k_{\min }, k_{\max }$

$I_{\min }, I_{\max }$

$\mu\left[\mathrm{mm}^{-1}\right]$

Crystal Size [mm]

Colour, Shape

$R_{\text {int }}$

$\vartheta_{\min }, \vartheta_{\max }\left[{ }^{\circ}\right]$

Total Reflections (before merge)

Data (I>3 x sigma(I))

[Reflections,Parameters, Restraints]

$\mathrm{S}$ (=GooF)

Min. Residual Density [e/ $\left.\AA^{3}\right]$

Max. Residual Density $\left[\mathrm{e} / \AA^{3}\right]$

Threshold Expression

$R_{1}$

$w R_{2}$

\subsection{Au motor $2 d$}

CCDC Deposition Number

Name

Formula

Molecular Weight

Crystal System

$T[\mathrm{~K}]$

Space Group

$a[\AA]$

$b[\AA]$

$c[\AA]$

$\alpha\left[^{\circ}\right]$

$B\left[^{\circ}\right]$

$V\left[^{\circ}\right]$

$V\left[\AA^{3}\right]$

$D_{\text {calc }}\left[\mathrm{g} \cdot \mathrm{cm}^{-3}\right]$

$\mathrm{F}\left(\begin{array}{lll}0 & 0 & 0\end{array}\right)$

$h_{\min }, h_{\max }$

$k_{\min }, k_{\max }$

$I_{\min } I_{\max }$

$\mu\left[\mathrm{mm}^{-1}\right]$

Crystal Size [mm]

Colour, Shape

$R_{\text {int }}$

$\vartheta_{\min }, \vartheta_{\max }\left[^{\circ}\right]$

Total Reflections (before merge)

Data (I>3 x sigma(I))

[Reflections,Parameters, Restraints]

$\mathrm{S}$ (=GooF)

Min. Residual Density [e/ $/ \AA^{3}$ ]

Max. Residual Density $\left[\mathrm{e} / \AA^{3}\right]$

Threshold Expression

$R_{1}$

$w R_{2}$
CCDC 2019757

2c

$\mathrm{C}_{33} \mathrm{H}_{25} \mathrm{Au}_{1} \mathrm{Cl}_{1} \mathrm{P}_{1} \mathrm{~S}_{1}$

716.97

triclinic

100(2)

$P-1$

9.3551(4)

$11.2801(5)$

14.0783(6)

$100.5460(10)$

98.5630(10)

$110.1280(10)$

1334.72(10)

2

1.784

700

$-11,11$

$-14,14$

$-17,17$

12.733

$0.18 \times 0.16 \times 0.14$

clear_pale_colourless block

0.0277

$3.281,74.457$

25627

5422, 335, 0

1.085

$-0.891$

1.202

I>2sigma(I)

0.0200

0.0466

CCDC 2019758

\section{2d}

$\mathrm{C}_{35} \mathrm{H}_{29} \mathrm{Au}_{1} \mathrm{Cl}_{5} \mathrm{P}_{1} \mathrm{~S}_{1}$

886.83

triclinic

100(2)

$P-1$

$11.6283(3)$

12.6205(4)

13.4772(4)

$76.4600(10)$

$69.8050(10)$

63.8510(10)

1658.36(9)

2

1.776

868

$-14,14$

$-15,16$

$-17,16$

13.280

$0.08 \times 0.08 \times 0.06$

clear_pale_colourless plank

0.0528

3.920, 79.993

77916

7171, 417, 9

1.026

$-0.533$

0.837

I>2sigma(I)

0.0227

0.0452
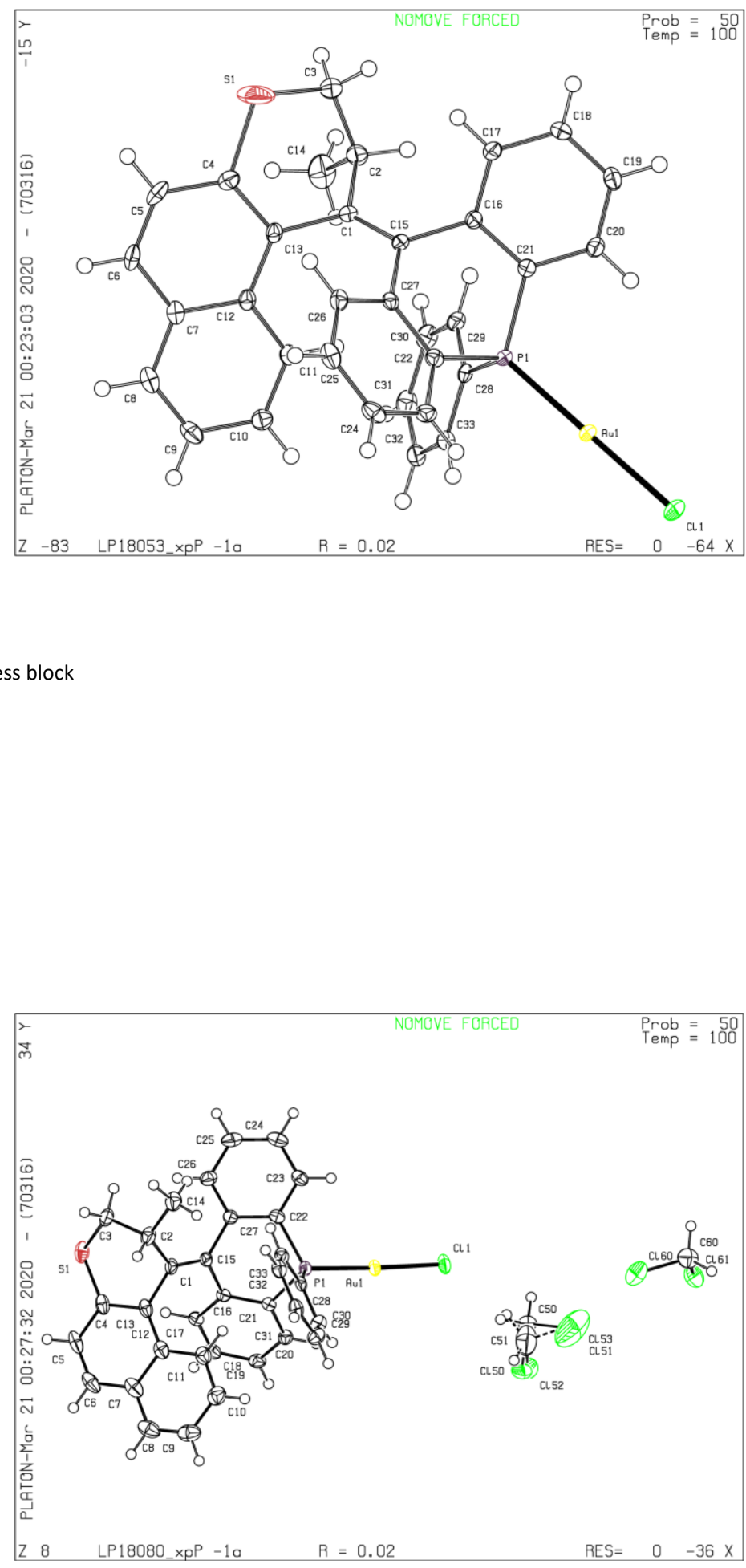


\subsection{Oxide motor $3 a$}

CCDC Deposition Number

Name

Formula

Molecular Weight

Crystal System

$T$ [K]

Space Group

$a[\AA ̊]$

$b[\AA]$

$c[\AA]]$

$\alpha\left[^{\circ}\right]$

$B\left[^{\circ}\right]$

$V\left[^{\circ}\right]$

$V\left[\AA^{3}\right]$

Z

$D_{\text {calc }}\left[\mathrm{g} \cdot \mathrm{cm}^{-3}\right]$

$\mathrm{F}\left(\begin{array}{lll}0 & 0 & 0\end{array}\right)$

$h_{\text {min }}, h_{\text {max }}$

$k_{\min }, k_{\max }$

$I_{\min }, I_{\max }$

$\mu\left[\mathrm{mm}^{-1}\right]$

Crystal Size [mm]

Colour, Shape

$R_{\text {int }}$

$\vartheta_{\min }, \vartheta_{\max }\left[^{\circ}\right]$

Total Reflections (before merge)

Data (I>3 x sigma(I))

[Reflections,Parameters, Restraints]

$S$ (=GooF)

Min. Residual Density [e/ $\left.\AA^{3}\right]$

Max. Residual Density $\left[\mathrm{e} / \AA^{3}\right]$

Threshold Expression

$R_{1}$

$w R_{2}$

\subsection{Oxide motor $3 b$}

CCDC Deposition Number

Name

Formula

Molecular Weight

Crystal System

$T[\mathrm{~K}]$

Space Group

$a[\AA]$

$b[\AA]$

$c[\AA]$

$\alpha\left[^{\circ}\right]$

$B\left[^{\circ}\right]$

$V\left[^{\circ}\right]$

$V\left[\AA^{3}\right]$

Z

$D_{\text {calc }}\left[\mathrm{g} \cdot \mathrm{cm}^{-3}\right]$

$\mathrm{F}\left(\begin{array}{lll}0 & 0 & 0\end{array}\right)$

$\mathrm{h}_{\text {min }}, \mathrm{h}_{\max }$

$k_{\min }, k_{\max }$

$I_{\min }, I_{\max }$

$\mu\left[\mathrm{mm}^{-1}\right]$

Crystal Size [mm]

Colour, Shape

$R_{\text {int }}$

$\vartheta_{\min }, \vartheta_{\max }\left[{ }^{\circ}\right]$

Total Reflections (before merge)

Data (I>3 x sigma(I))

[Reflections,Parameters, Restraints]

$\mathrm{S}$ (=GooF)

Min. Residual Density $\left[e / \AA^{3}\right]$

Max. Residual Density [e/ $\left./ \AA^{3}\right]$

Threshold Expression

$R_{1}$

$w R_{2}$
CCDC 2019763

3a

$\mathrm{C}_{33} \mathrm{H}_{27} \mathrm{O}_{2} \mathrm{P}_{1} \mathrm{~S}_{1}$

518.57

orthorhombic

100(2)

$P 2{ }_{1} 2{ }_{1} 2_{1}$

10.4297(3)

$12.6136(4)$

19.5411(5)

90

90

90

2570.75(13)

4

1.340

1088

$-13,13$

$-16,16$

$-24,24$

1.936

$0.14 \times 0.06 \times 0.04$

clear_pale_colourless needle

0.1041

4.171, 79.994

108401

$5585,352,0$

1.038

$-0.301$

0.217

I>2sigma(I)

0.0316

0.0735

CCDC 2019762

3b

$\mathrm{C}_{33} \mathrm{H}_{26} \mathrm{O}_{1.50} \mathrm{P}_{1} \mathrm{~S}_{1}$

509.57

triclinic

100(2)

$P-1$

9.2730(3)

10.7399(3)

$13.1737(4)$

$71.9230(10)$

84.920(2)

$84.355(2)$

1238.84(7)

2

1.366

534

$-11,11$

$-13,13$

$-16,16$

1.984

$0.16 \times 0.10 \times 0.08$

clear_pale_colourless block

0.0690

$3.536,80.057$

58127

$5370,343,0$

1.048

$-0.378$

0.601

I>2sigma(I)

0.0512

0.1154
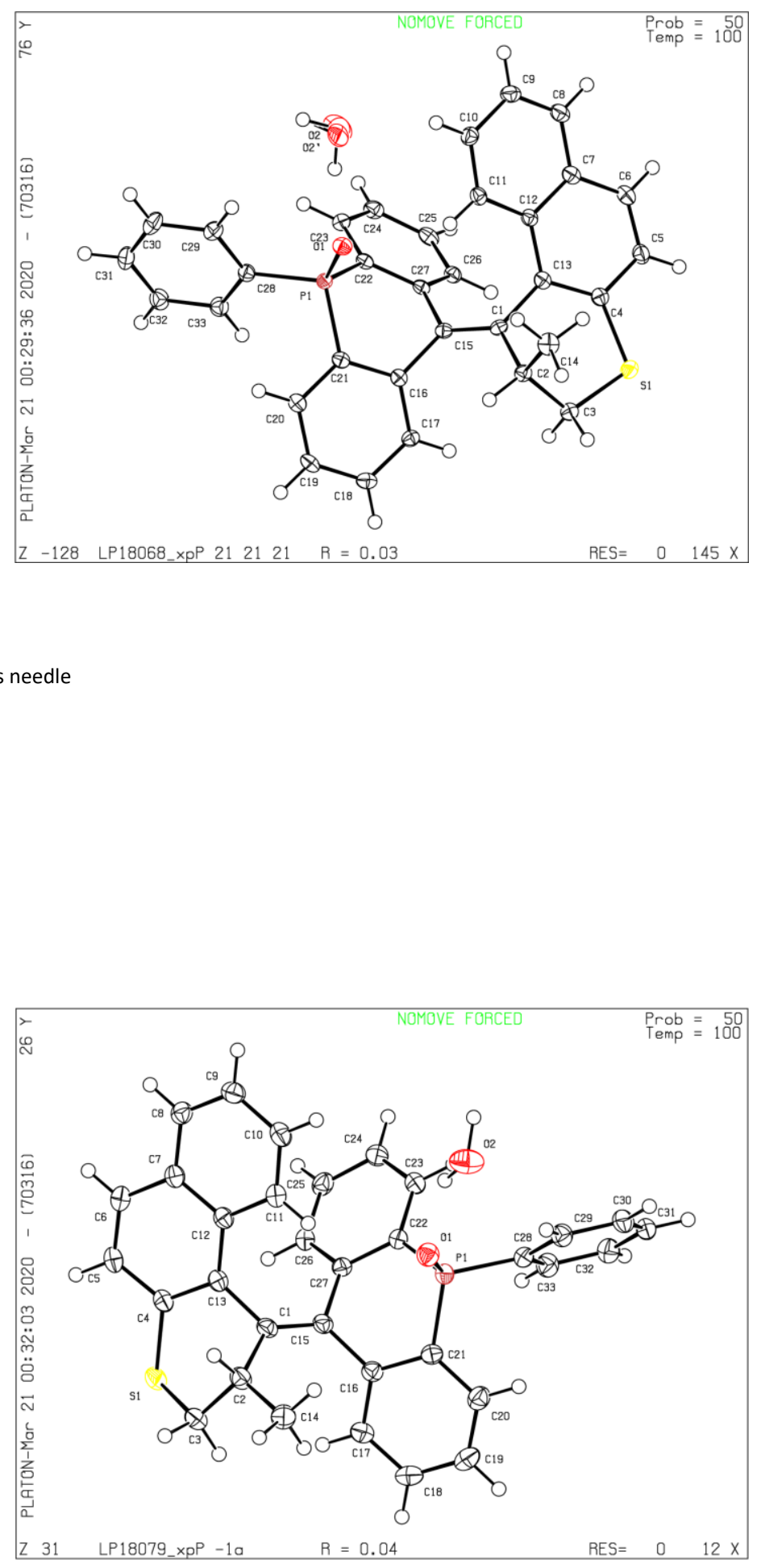


\subsection{Oxide motor $3 \mathrm{c}$}

CCDC Deposition Number

Name

Formula

Molecular Weight

Crystal System

$T[\mathrm{~K}]$

Space Group

$a[\AA ̊]$

$b[\AA]$

$c[\AA]]$

$\alpha\left[^{\circ}\right]$

$b\left[^{\circ}\right]$

$\gamma\left[{ }^{\circ}\right]$

$V\left[\AA^{3}\right]$

Z

$D_{\text {calc }}\left[\mathrm{g} \cdot \mathrm{cm}^{-3}\right]$

$\mathrm{F}\left(\begin{array}{lll}0 & 0 & 0\end{array}\right)$

$h_{\text {min }}, h_{\text {max }}$

$k_{\min }, k_{\max }$

$I_{\min }, I_{\text {max }}$

$\mu\left[\mathrm{mm}^{-1}\right]$

Crystal Size [mm]

Colour, Shape

$R_{\text {int }}$

$\vartheta_{\text {min, }} \vartheta_{\max }\left[{ }^{\circ}\right]$

Total Reflections (before merge)

Data (I>3 x sigma(I))

[Reflections,Parameters, Restraints]

$\mathrm{S}$ (=GooF)

Min. Residual Density [e/ $\left./ \AA^{3}\right]$

Max. Residual Density $\left[\mathrm{e} / \AA^{3}\right]$

Threshold Expression

$R_{1}$

$w R_{2}$

\subsection{Oxide motor $3 d$}

CCDC Deposition Number

Name

Formula

Molecular Weight

Crystal System

$T[\mathrm{~K}]$

Space Group

$a[\AA]$

$b[\AA ̊]$

$c[\AA]$

$\alpha\left[^{\circ}\right]$

$B\left[^{\circ}\right]$

$V\left[^{\circ}\right]$

$V\left[\AA^{3}\right]$

Z

$D_{\text {calc }}\left[\mathrm{g} \cdot \mathrm{cm}^{-3}\right]$

$\mathrm{F}\left(\begin{array}{lll}0 & 0 & 0\end{array}\right)$

$\mathrm{h}_{\text {min }}, \mathrm{h}_{\max }$

$k_{\min }, k_{\max }$

$I_{\min }, I_{\max }$

$\mu\left[\mathrm{mm}^{-1}\right]$

Crystal Size [mm]

Colour, Shape

$R_{\text {int }}$

$\vartheta_{\min }, \vartheta_{\max }\left[{ }^{\circ}\right]$

Total Reflections (before merge)

Data (I>3 x sigma(I))

[Reflections,Parameters, Restraints]

$\mathrm{S}$ (=GooF)

Min. Residual Density [e/ $\AA^{3}$ ]

Max. Residual Density $\left[\mathrm{e} / \AA^{3}\right]$

Threshold Expression

$R_{1}$

$w R_{2}$
CCDC 2019764

$3 c$

$\mathrm{C}_{33} \mathrm{H}_{25} \mathrm{O}_{1} \mathrm{P}_{1} \mathrm{~S}_{1}$

500.56

monoclinic

100(2)

$P 2_{1}$

$8.6081(2)$

$14.7650(3)$

$10.4290(2)$

90

106.5820(10)

90

1270.39(5)

2

1.309

524

$-10,10$

$-18,18$

$-13,13$

1.911

$0.12 \times 0.12 \times 0.08$

clear_pale_colourless block

0.0501

4.423, 80.002

24656

5289, 327, 1

1.039

$-0.197$

0.387

I>2sigma(I)

0.0308

0.0724

CCDC 2019761

3d

$\mathrm{C}_{33} \mathrm{H}_{25} \mathrm{O}_{1} \mathrm{P}_{1} \mathrm{~S}_{1}$

500.56

monoclinic

100(2)

$P 21 / n$

10.7006(3)

14.7825(4)

$15.9996(5)$

90

102.7310(10)

90

2468.62(12)

4

1.347

1048

$-13,13$

$-18,18$

$-20,20$

1.967

$0.18 \times 0.12 \times 0.02$

clear_pale_colourless plate

0.0593

$4.119,80.281$

55156

$5360,326,0$

1.025

$-0.347$

0.383

1>2sigma(I)

0.0416

0.0857
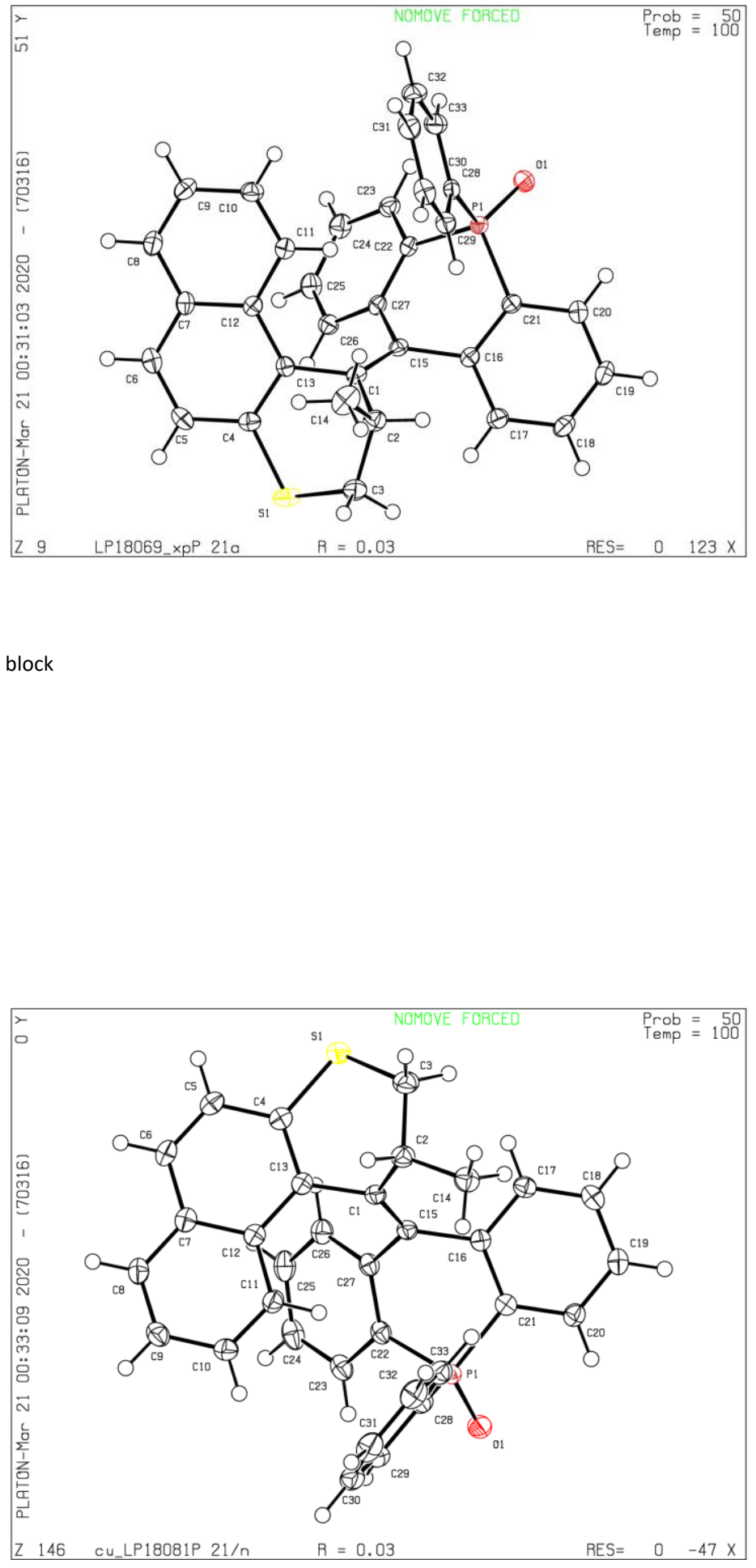
9. Characterization Data for New Compounds

Thioketone 4

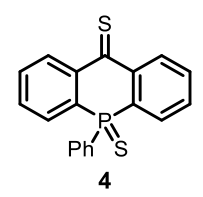

${ }^{1} \mathrm{H}$ NMR $\left(\mathrm{CDCl}_{3}, 500 \mathrm{MHz}, 25^{\circ} \mathrm{C}\right)$

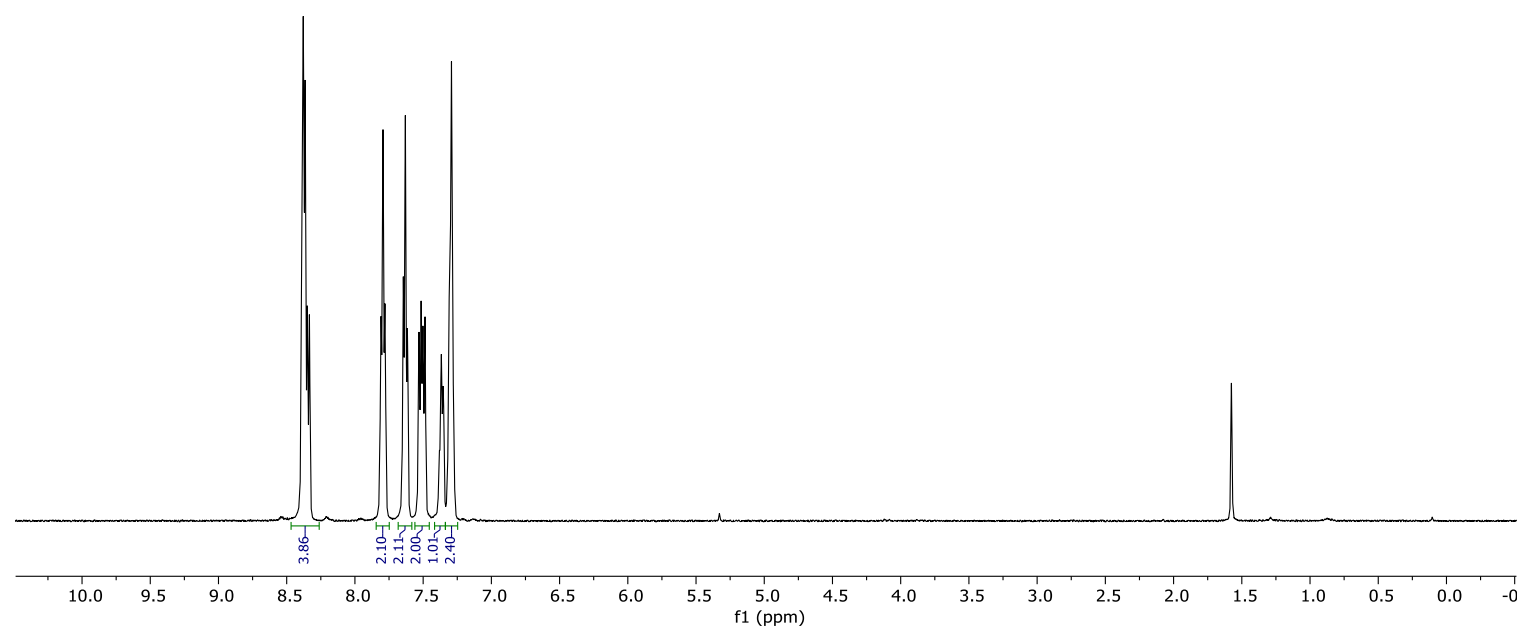

${ }^{13} \mathrm{C}$ NMR $\left(\mathrm{CDCl}_{3}, 126 \mathrm{MHz}, 25^{\circ} \mathrm{C}\right)$

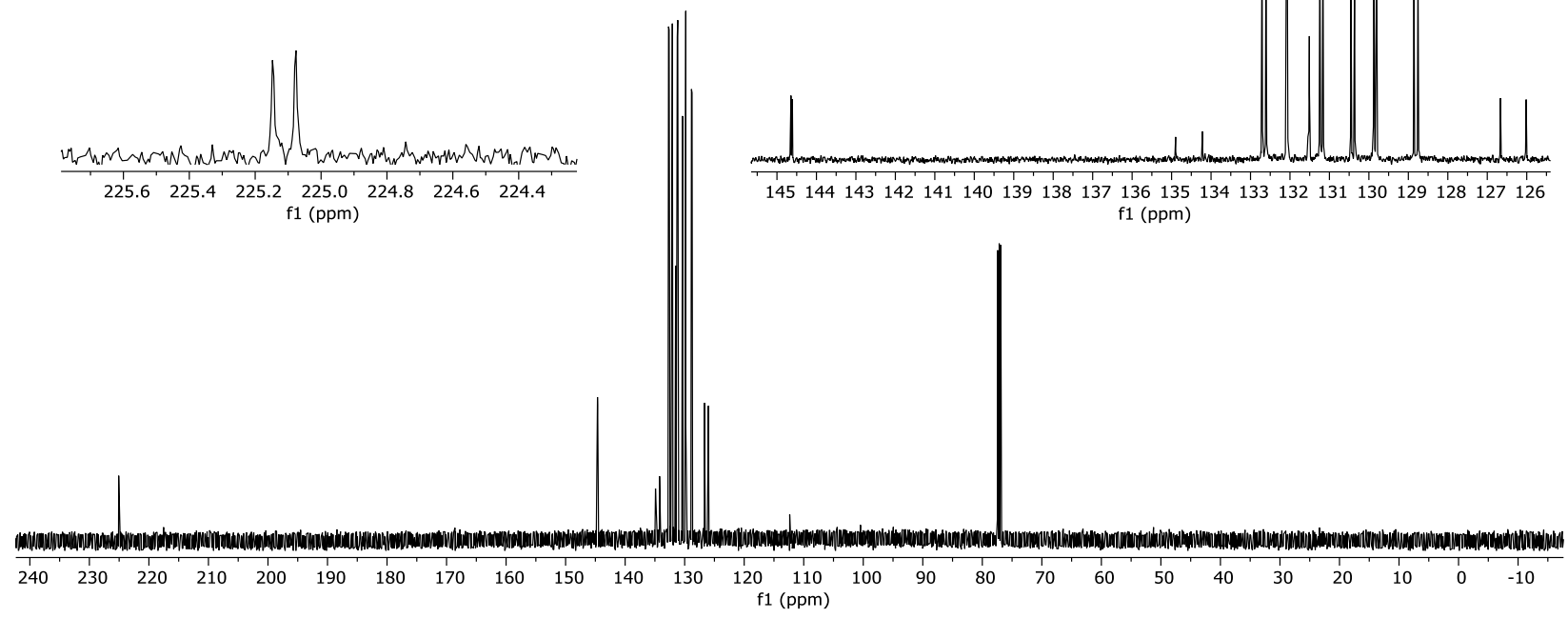

S40 
${ }^{31} \mathrm{P}$ NMR $\left(\mathrm{CDCl}_{3}, 162 \mathrm{MHz}, 25^{\circ} \mathrm{C}\right)$

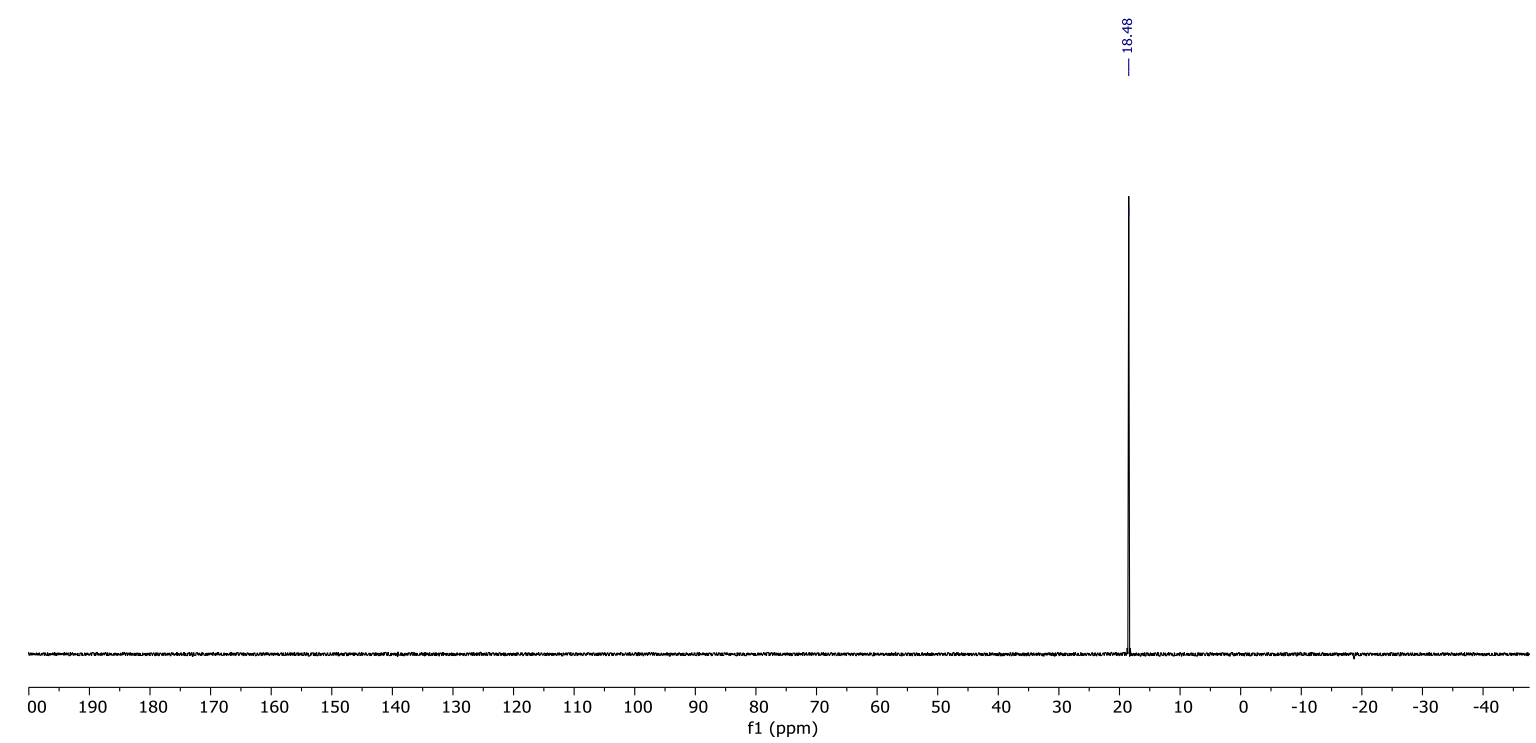

\section{HRMS (ESI+)}

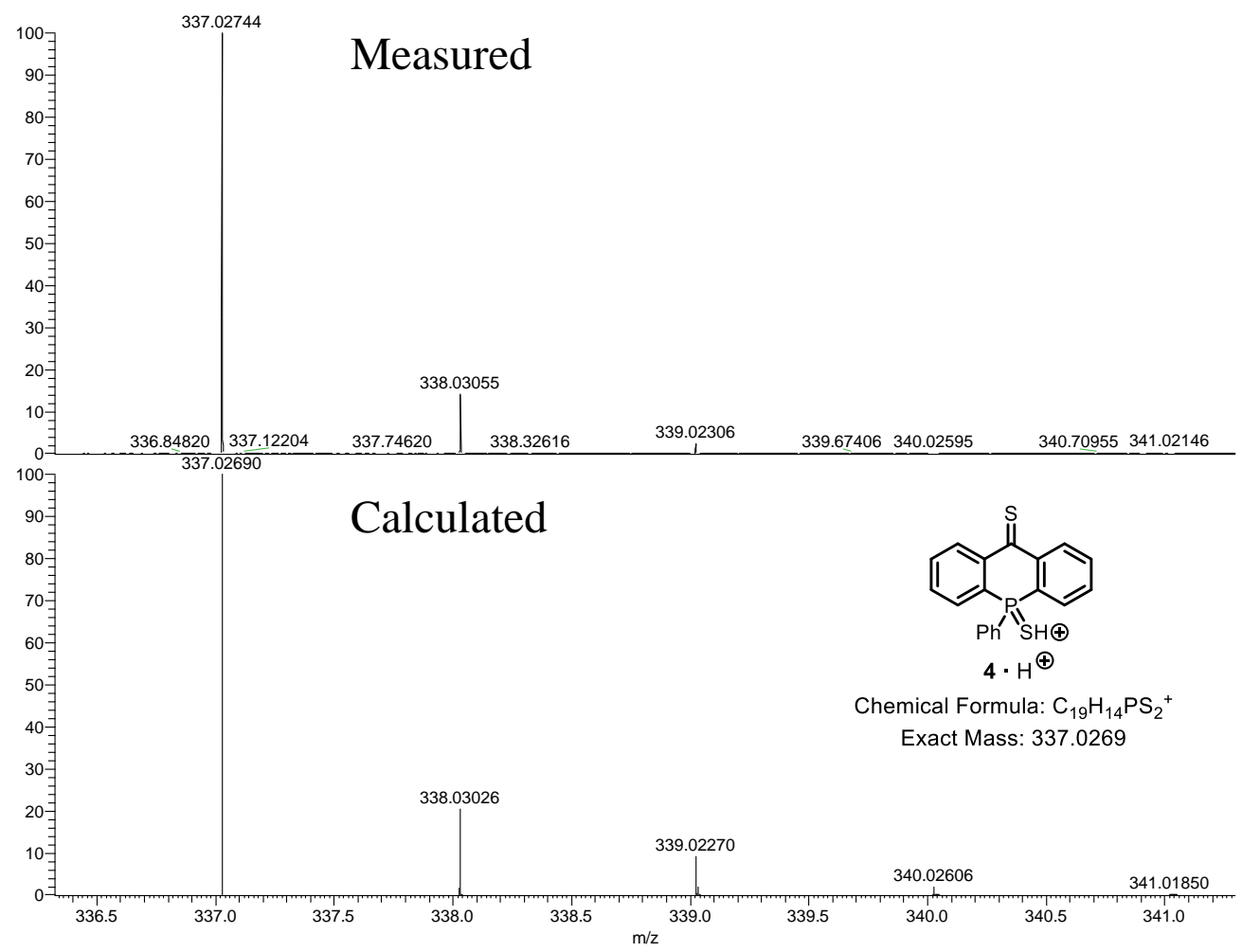


Phosphine motor 1a

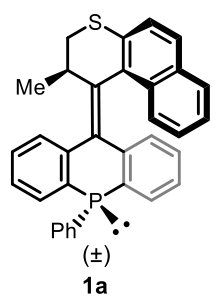

${ }^{1} \mathrm{H} \mathrm{NMR}\left(\mathrm{CDCl}_{3}, 400 \mathrm{MHz}, 25{ }^{\circ} \mathrm{C}\right)$

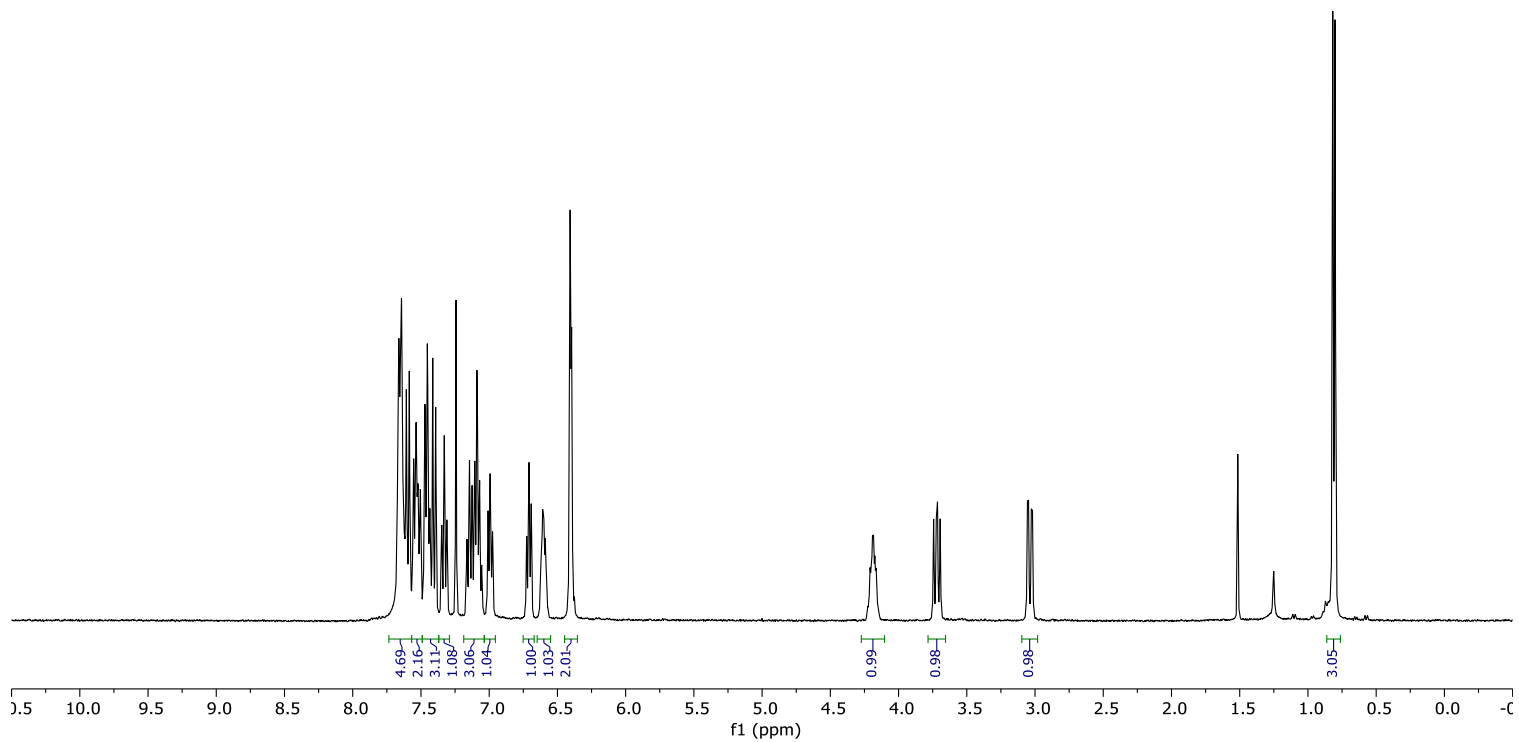

${ }^{13} \mathrm{C} \mathrm{NMR}\left(\mathrm{CDCl}_{3}, 101 \mathrm{MHz}, 25{ }^{\circ} \mathrm{C}\right)$

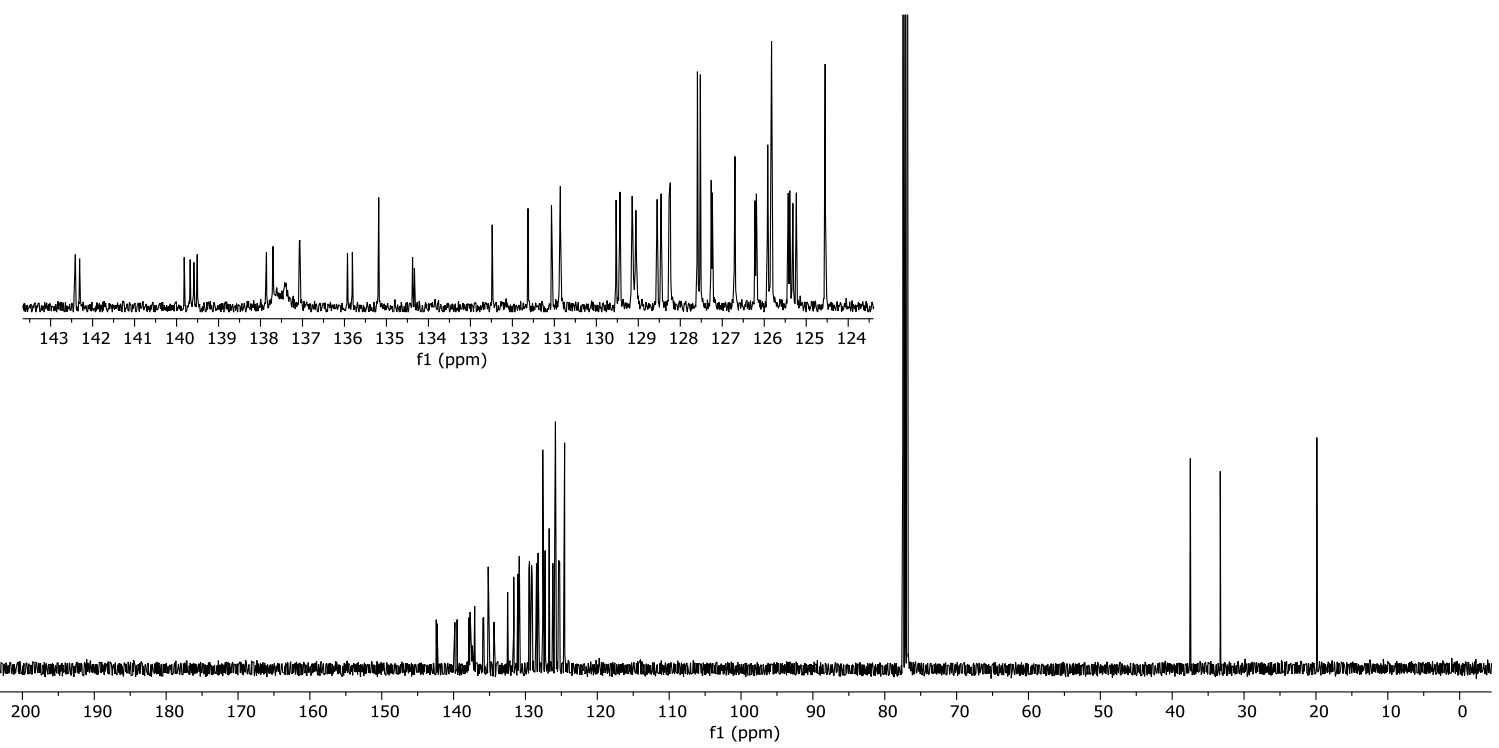


${ }^{31} \mathrm{P}$ NMR $\left(\mathrm{CDCl}_{3}, 162 \mathrm{MHz}, 25^{\circ} \mathrm{C}\right)$
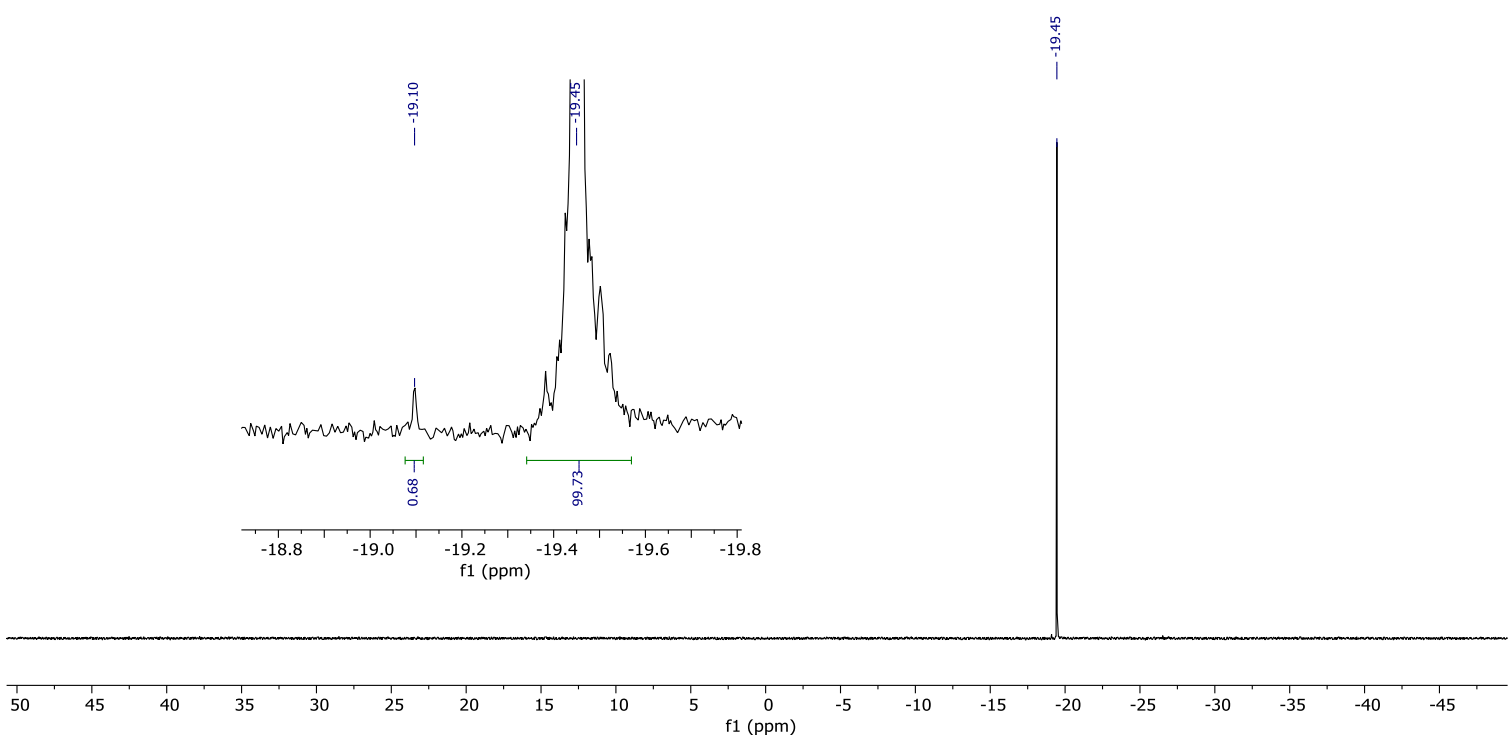

\section{HRMS (ESI+)}

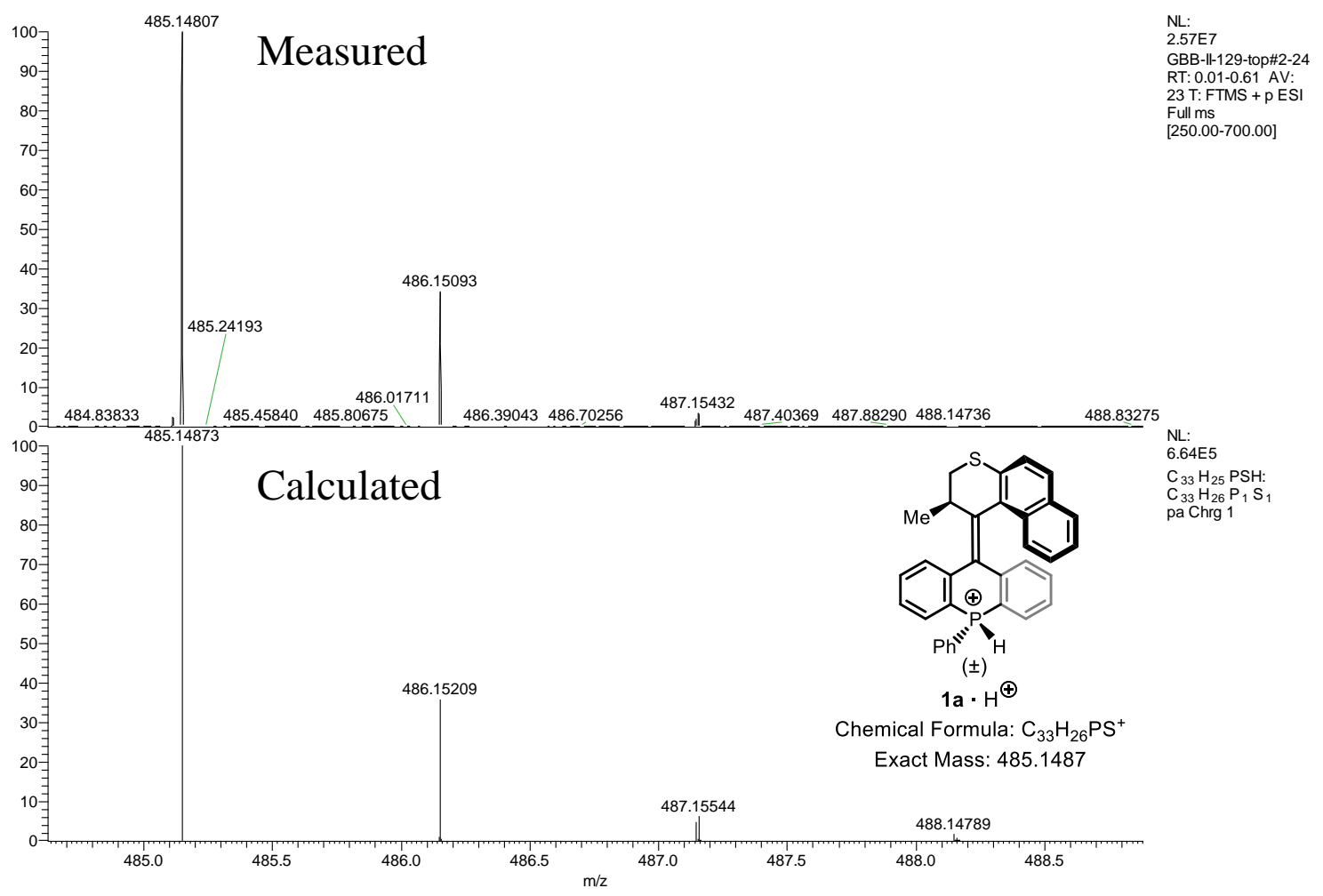


Phosphine Motor 1c

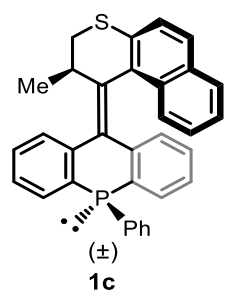

${ }^{1} \mathrm{H} \mathrm{NMR}\left(\mathrm{CDCl}_{3}, 400 \mathrm{MHz}, 25{ }^{\circ} \mathrm{C}\right)$

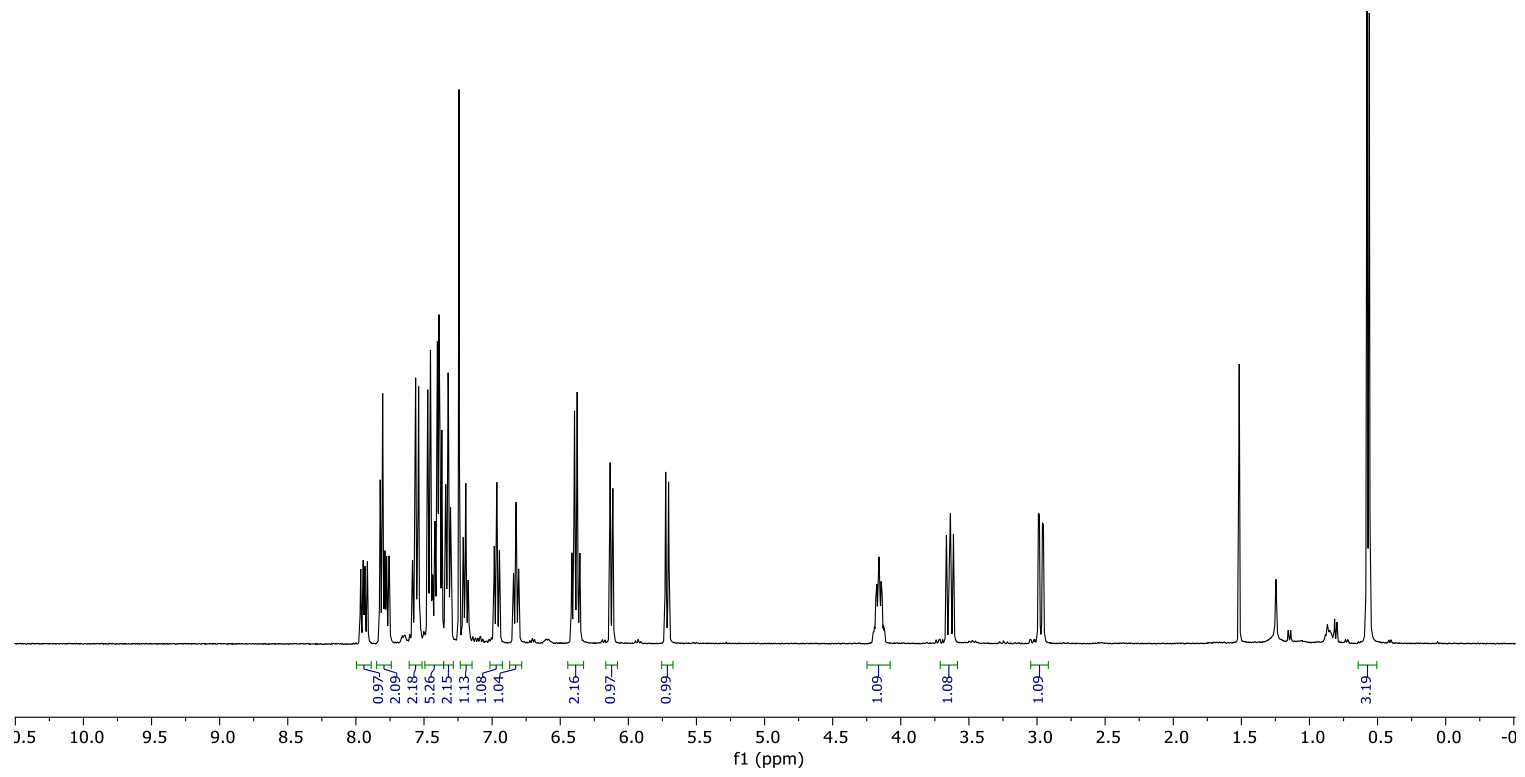

${ }^{13} \mathrm{C}$ NMR $\left(\mathrm{CDCl}_{3}, 101 \mathrm{MHz}, 25{ }^{\circ} \mathrm{C}\right)$
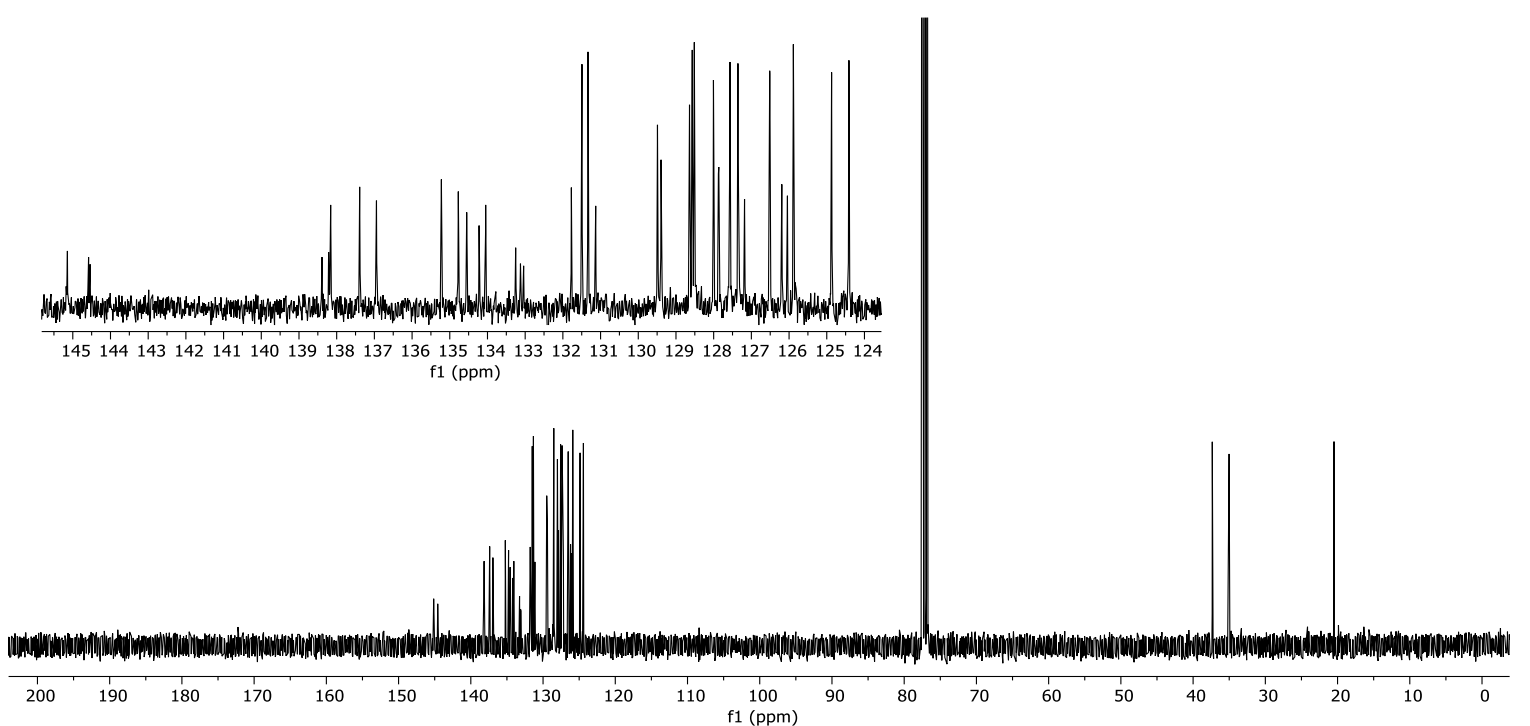
${ }^{31} \mathrm{P}$ NMR $\left(\mathrm{CDCl}_{3}, 162 \mathrm{MHz}, 25^{\circ} \mathrm{C}\right)$

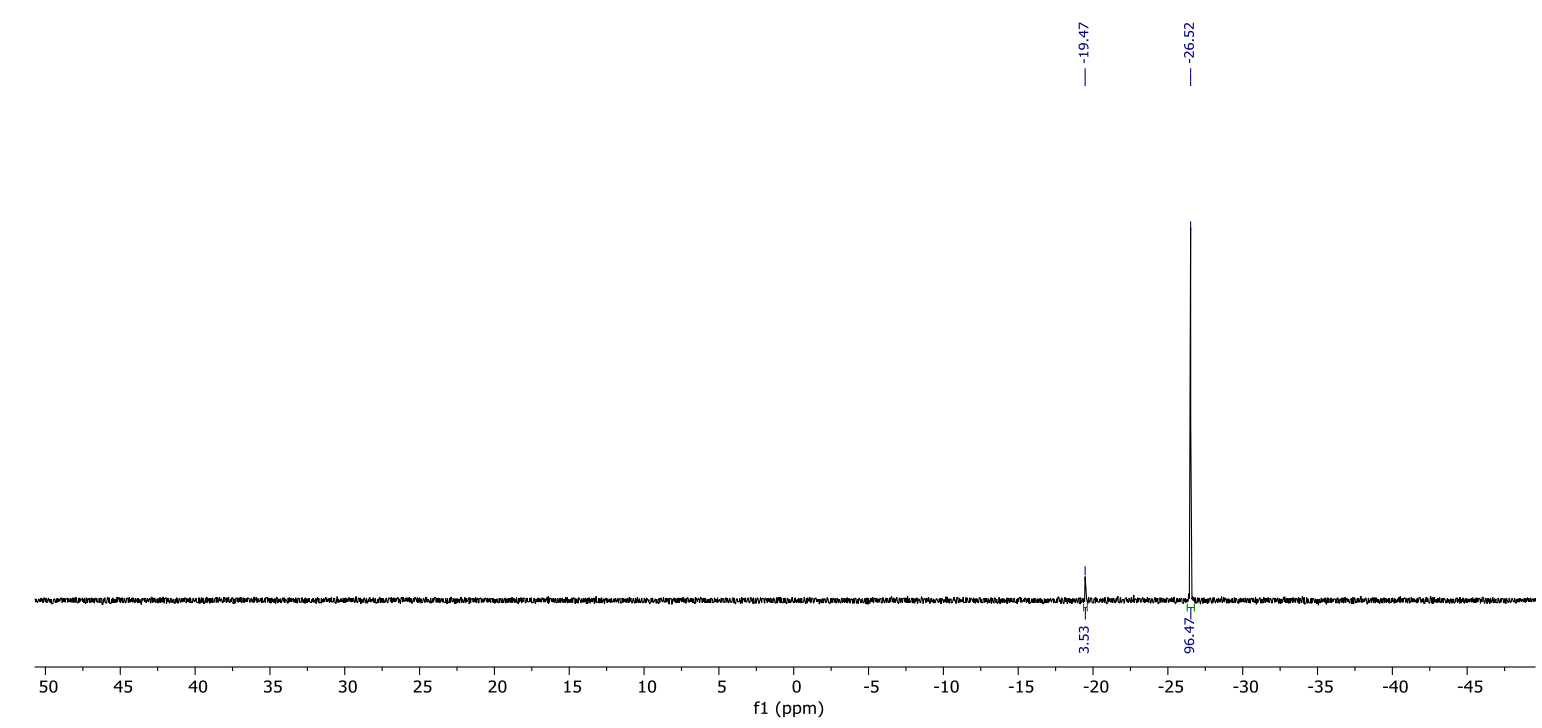

\section{HRMS (ESI+)}

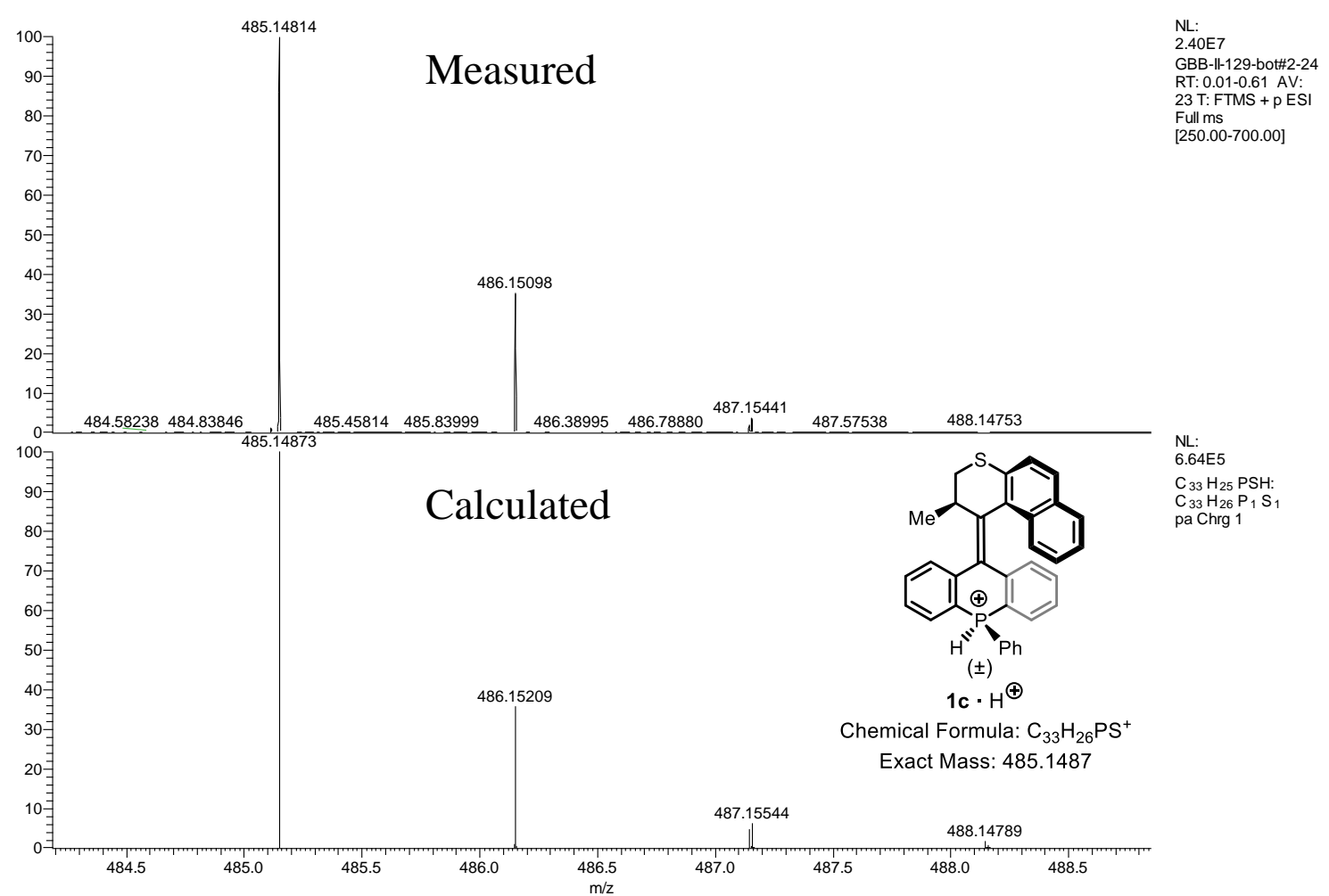


Au Motor 2a

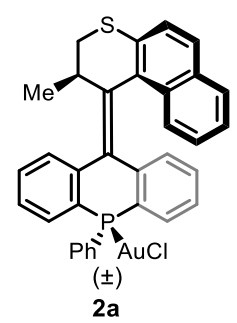

${ }^{1} \mathrm{H}$ NMR $\left(\mathrm{CDCl}_{3}, 600 \mathrm{MHz}, 25^{\circ} \mathrm{C}\right)$

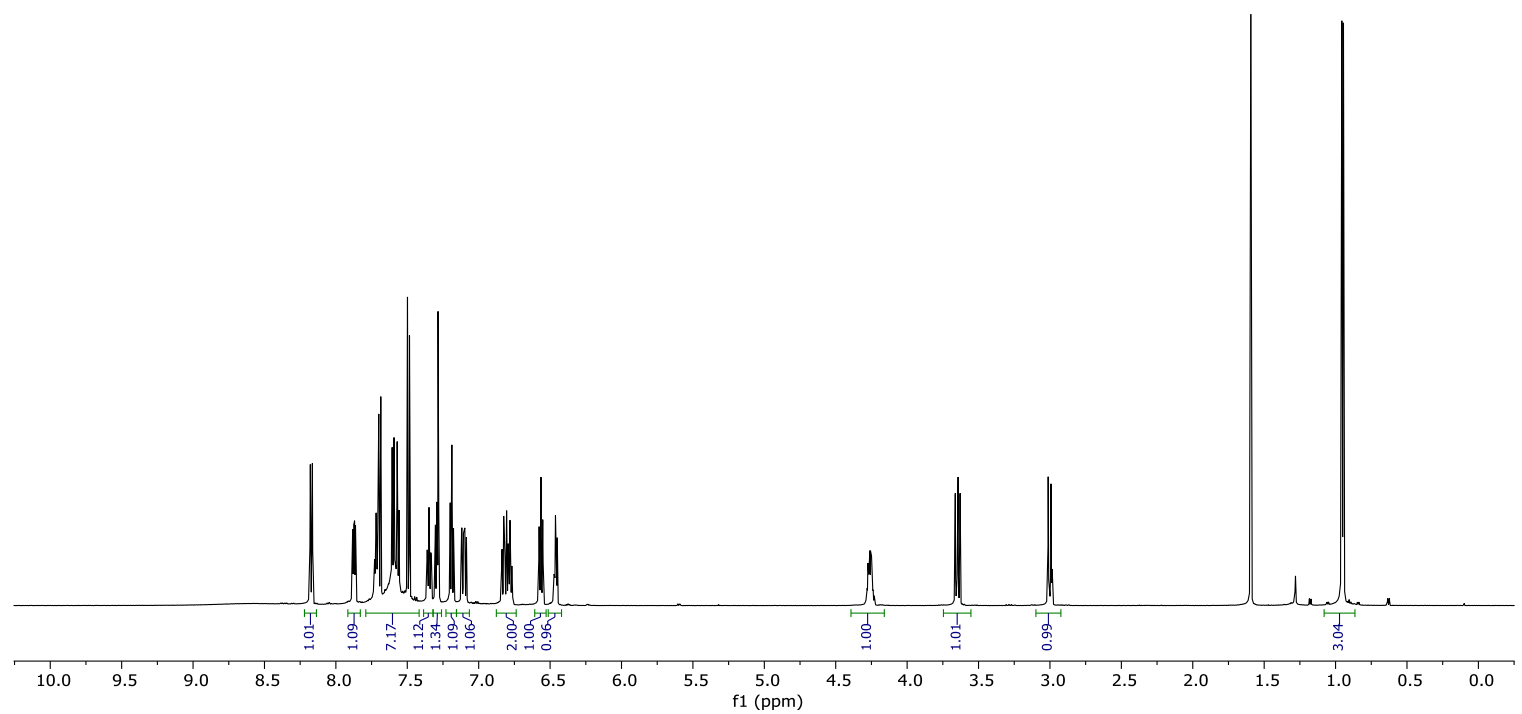

${ }^{1} \mathrm{H} \mathrm{NMR}\left(\mathrm{CDCl}_{3}, 500 \mathrm{MHz}\right.$, various temperatures)

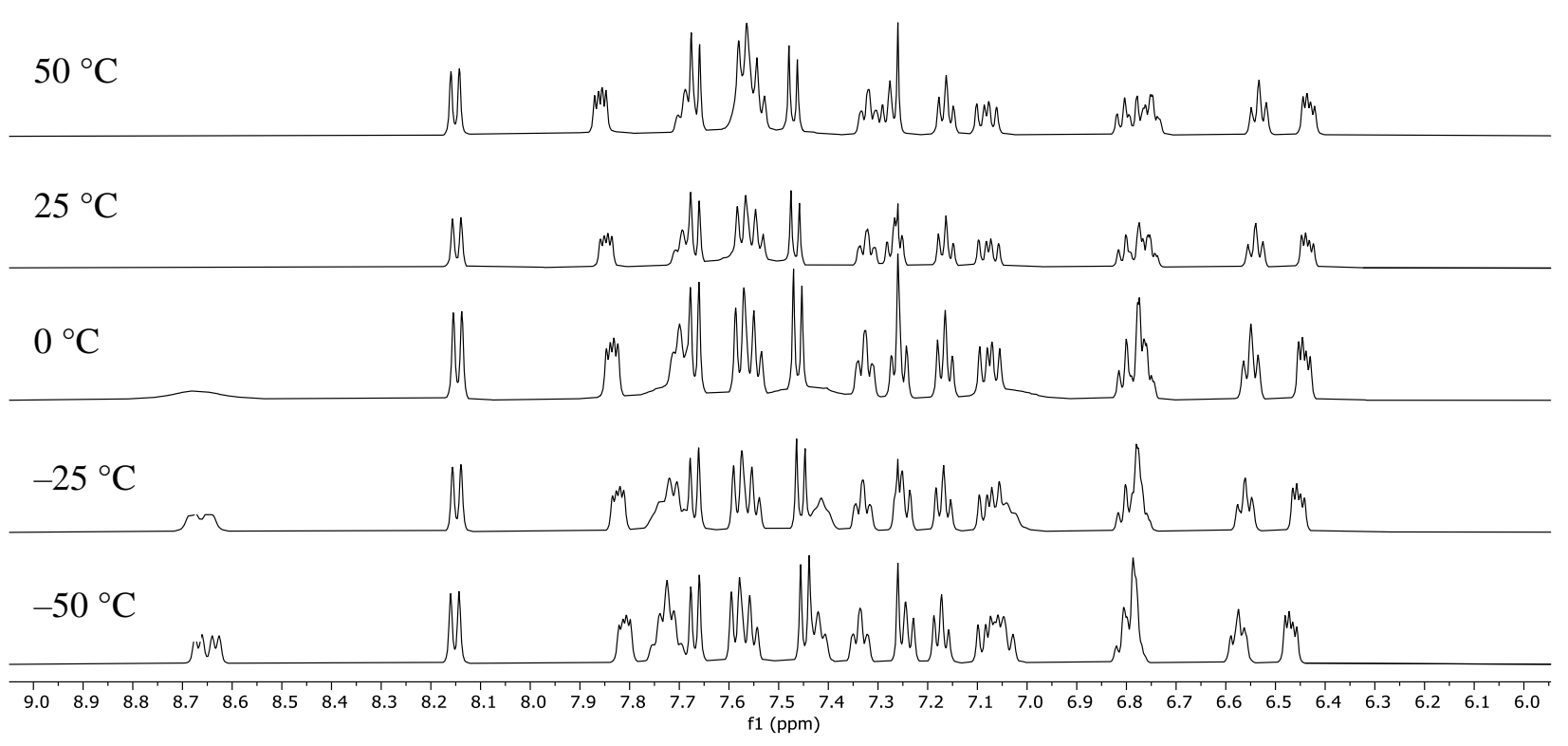




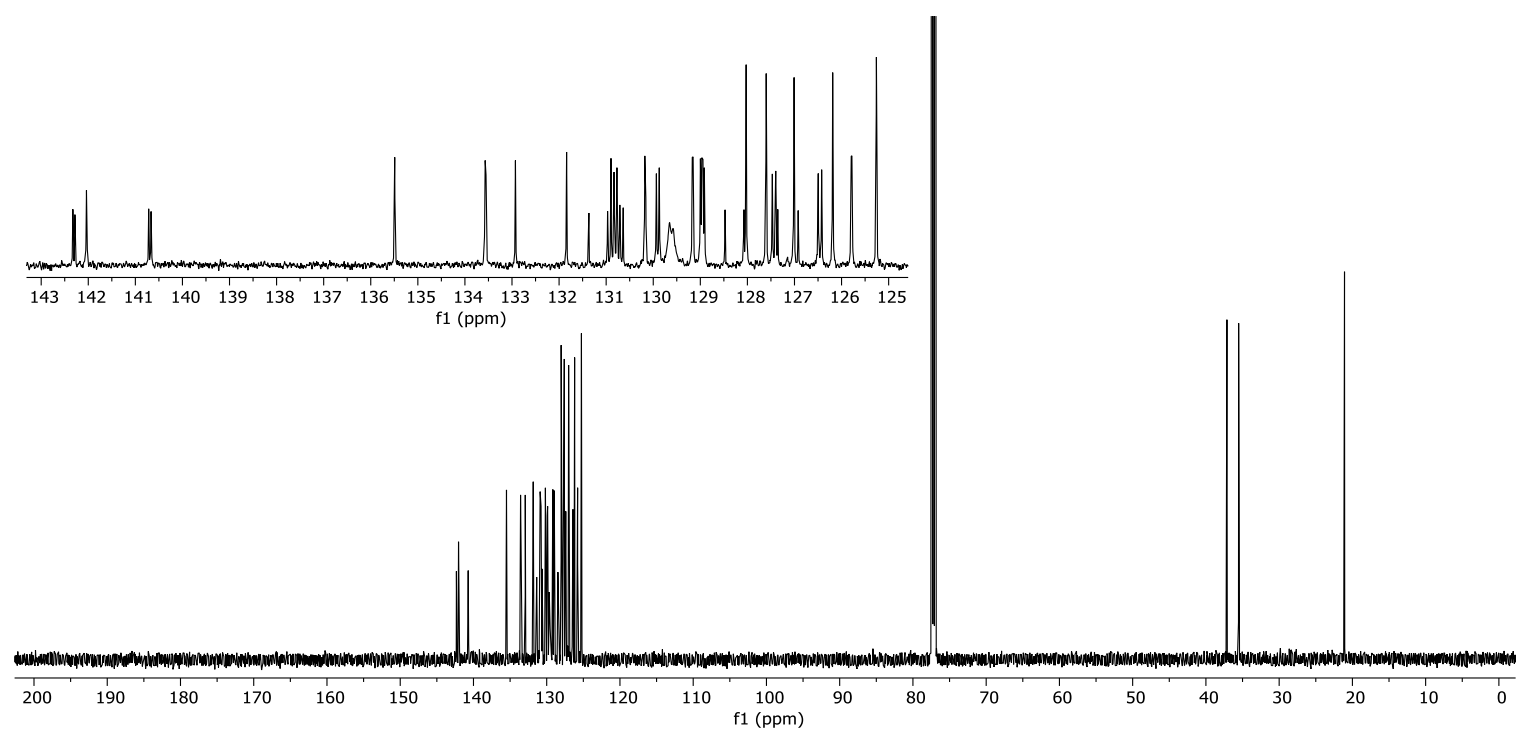

${ }^{31} \mathrm{P} \mathrm{NMR}\left(\mathrm{CDCl}_{3}, 162 \mathrm{MHz}, 25^{\circ} \mathrm{C}\right)$

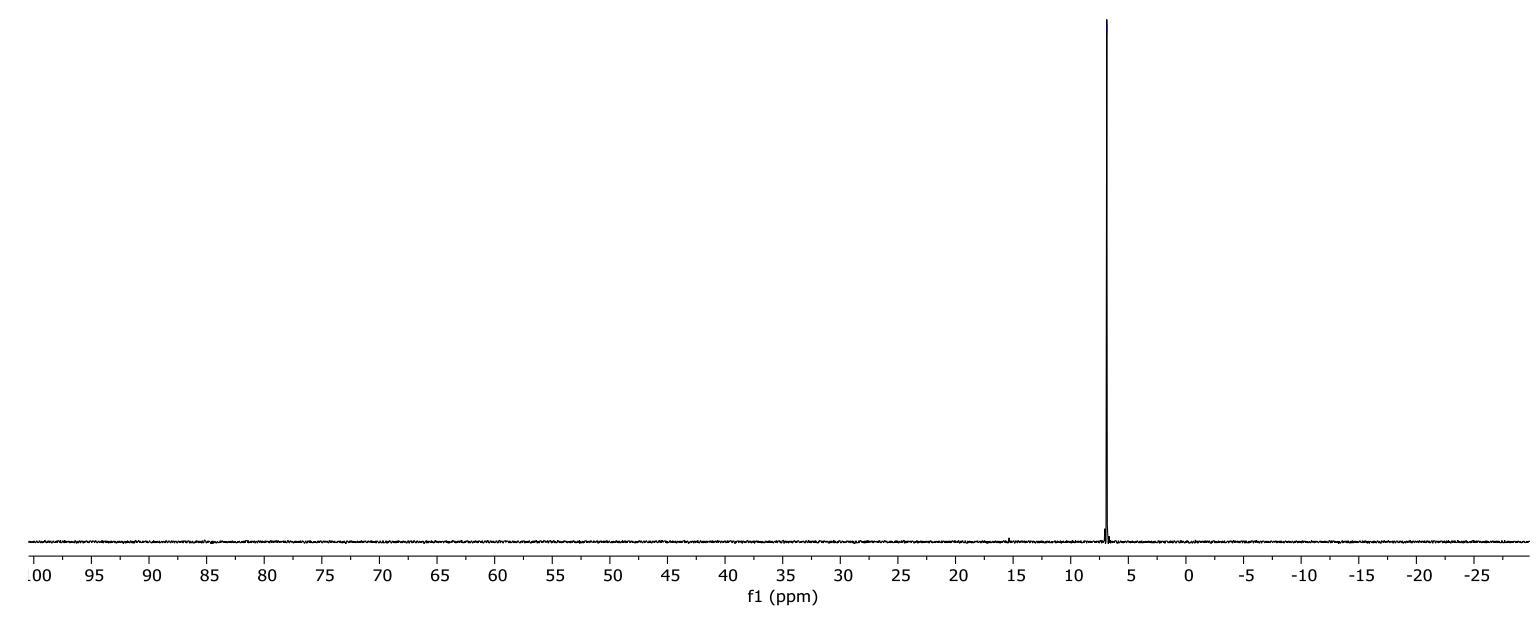

HRMS (ESI+)

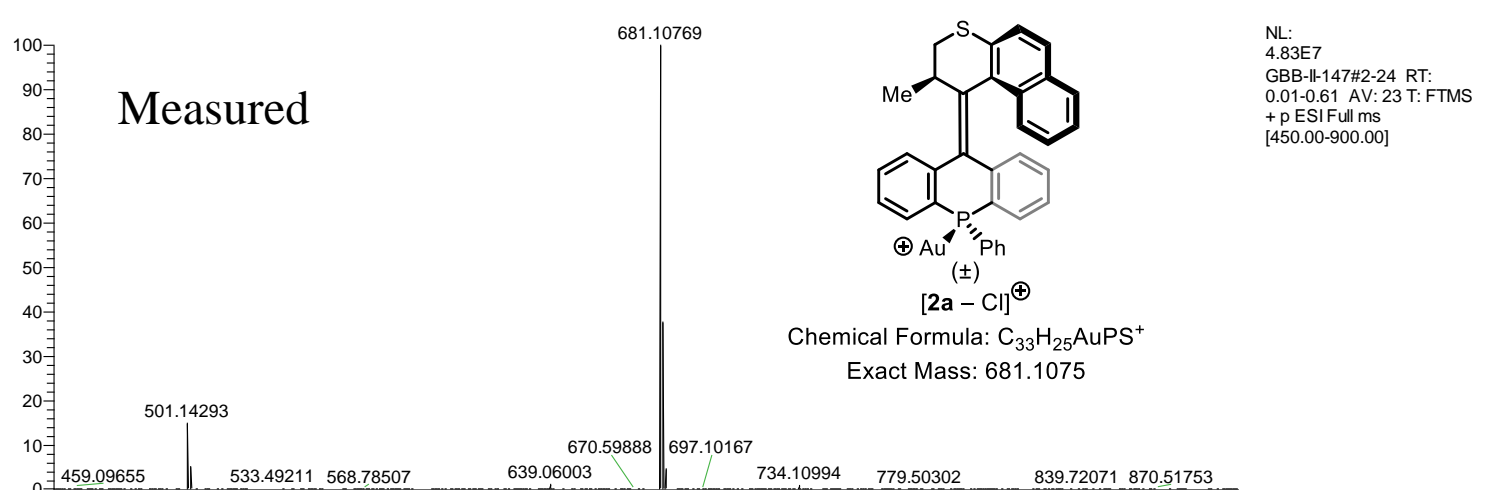


Au Motor 2c<smiles>[2H][PH]1(Cl)c2ccccc2C(=C2c3c(ccc4ccccc34)SC[C@@H]2C)c2ccccc21</smiles>

$( \pm)$

${ }^{1} \mathrm{H} \mathrm{NMR}\left(\mathrm{CDCl}_{3}, 600 \mathrm{MHz}, 25^{\circ} \mathrm{C}\right)$

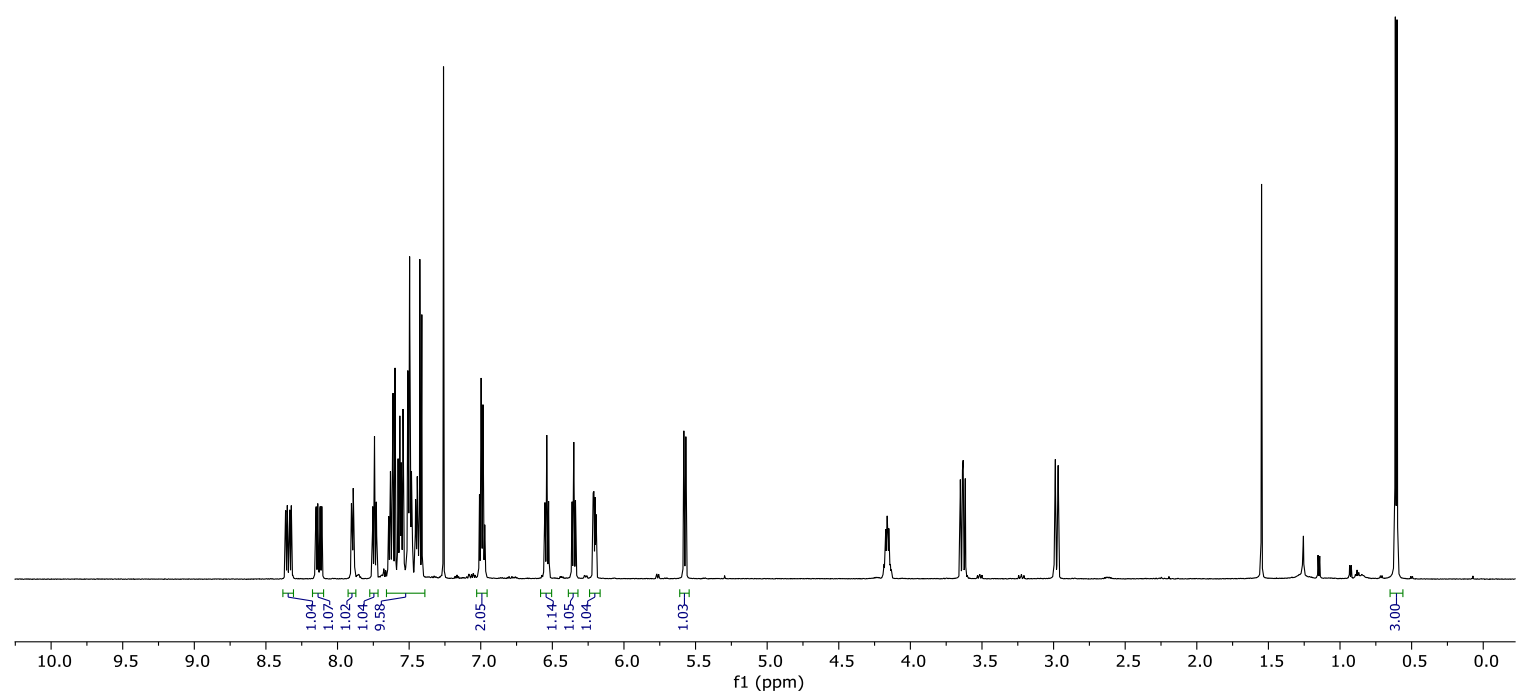

${ }^{13} \mathrm{C} \mathrm{NMR}\left(\mathrm{CDCl}_{3}, 151 \mathrm{MHz}, 25{ }^{\circ} \mathrm{C}\right)$
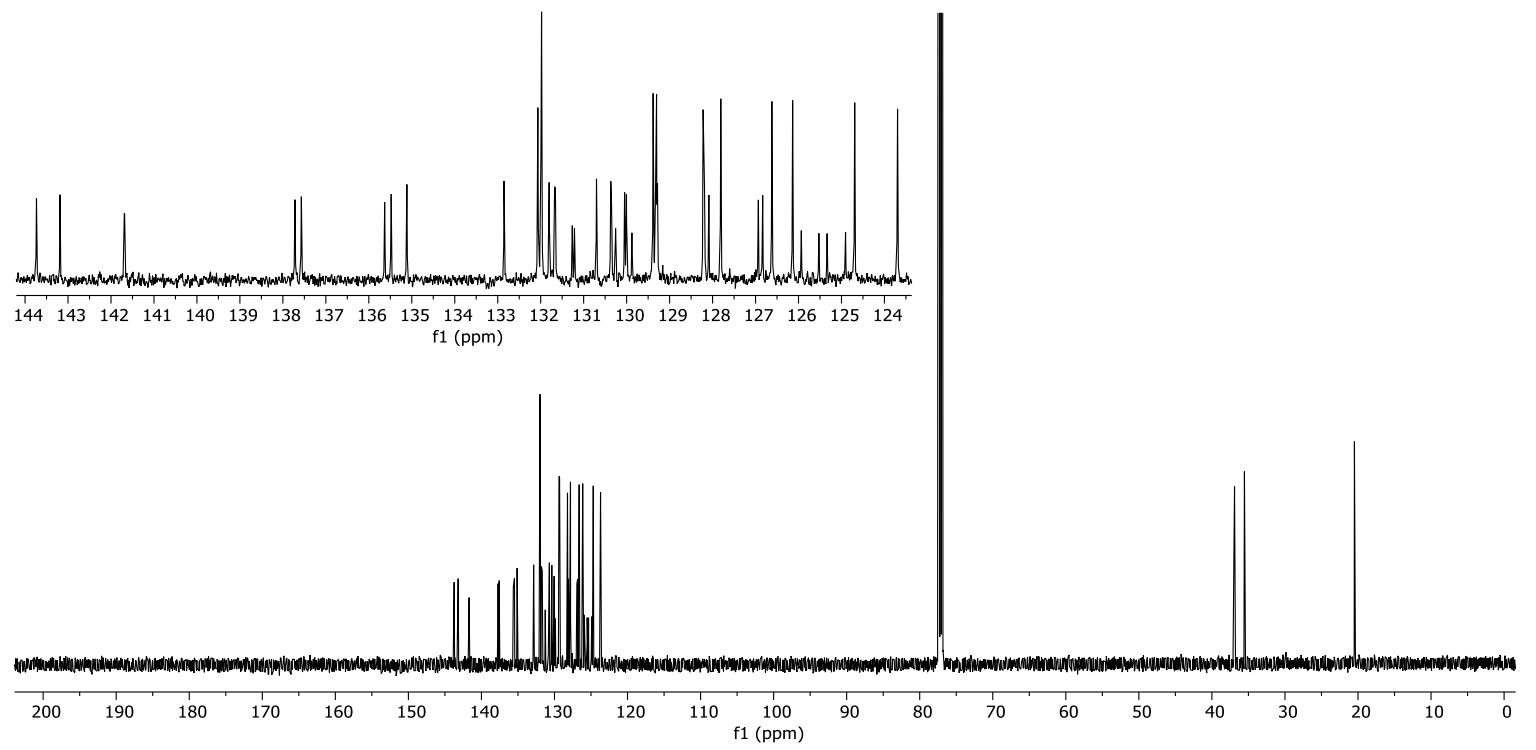
${ }^{31} \mathrm{P}$ NMR $\left(\mathrm{CDCl}_{3}, 243 \mathrm{MHz}, 25^{\circ} \mathrm{C}\right)$

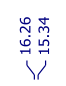

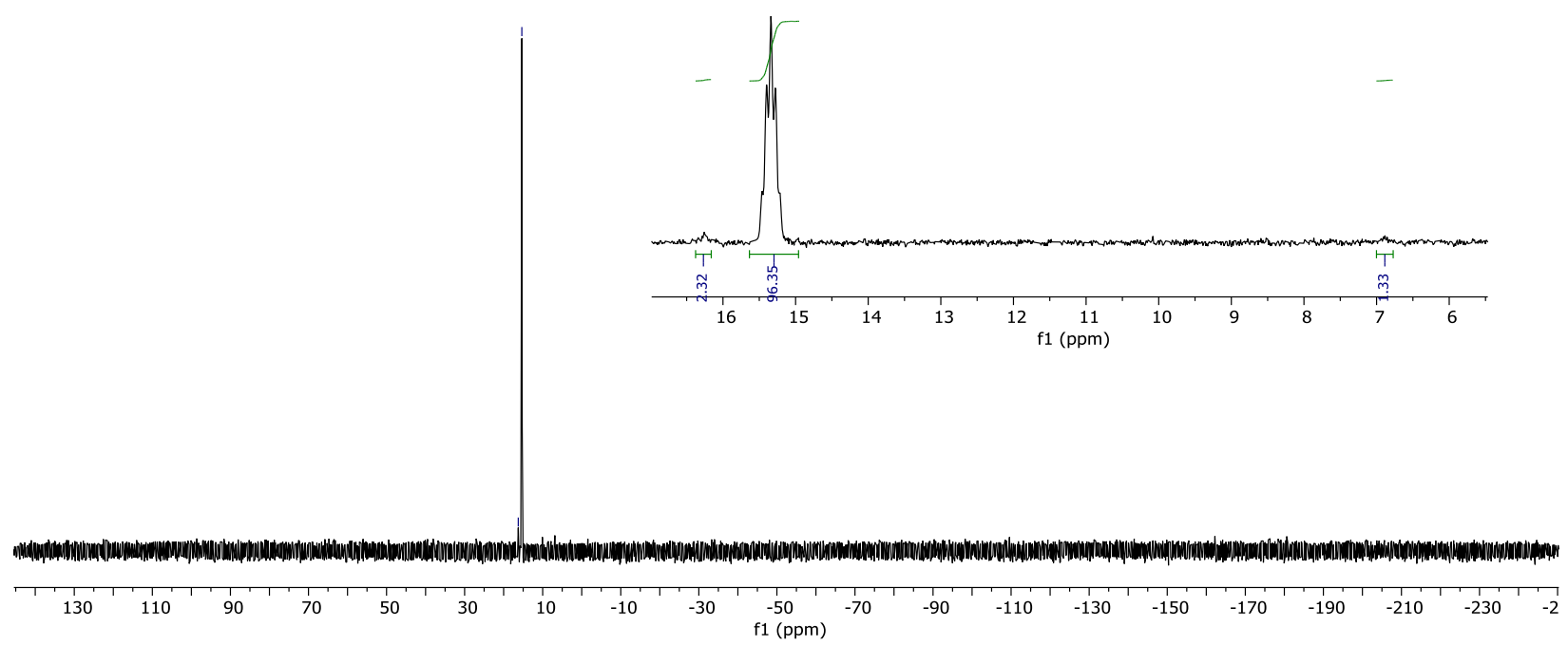

HRMS (ESI+)

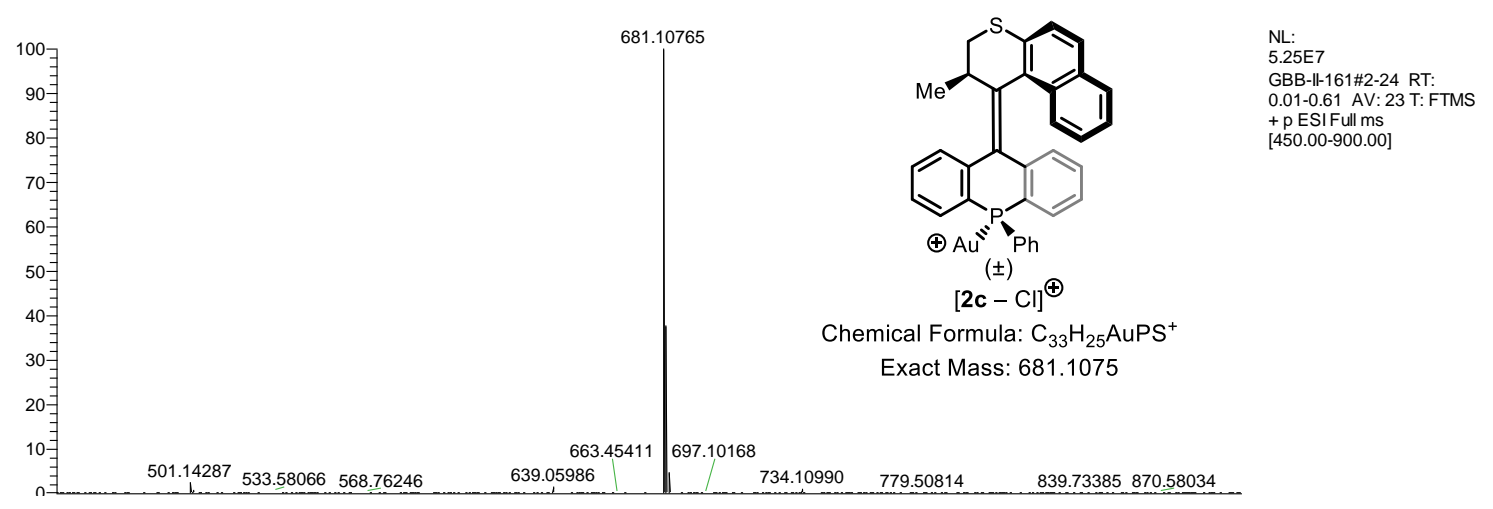


Oxide Motor 3a

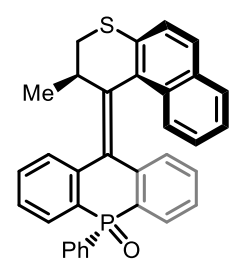

( $)$

${ }^{1} \mathrm{H}$ NMR $\left(\mathrm{CDCl}_{3}, 600 \mathrm{MHz}, 25^{\circ} \mathrm{C}\right)$

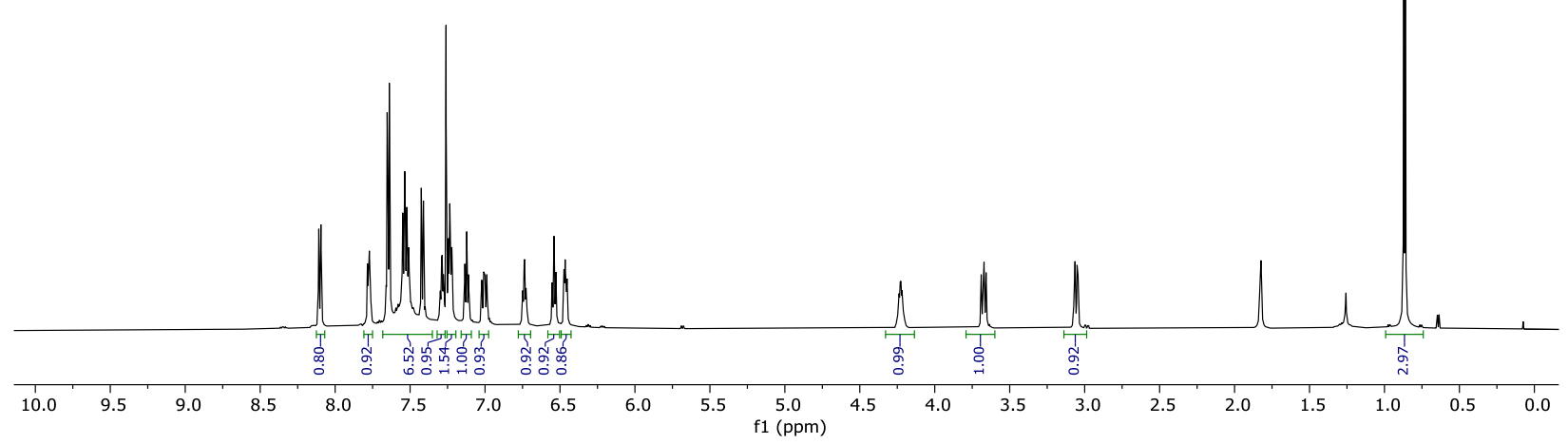

${ }^{1} \mathrm{H} \mathrm{NMR}\left(\mathrm{CDCl}_{3}, 500 \mathrm{MHz}\right.$, various temperatures)

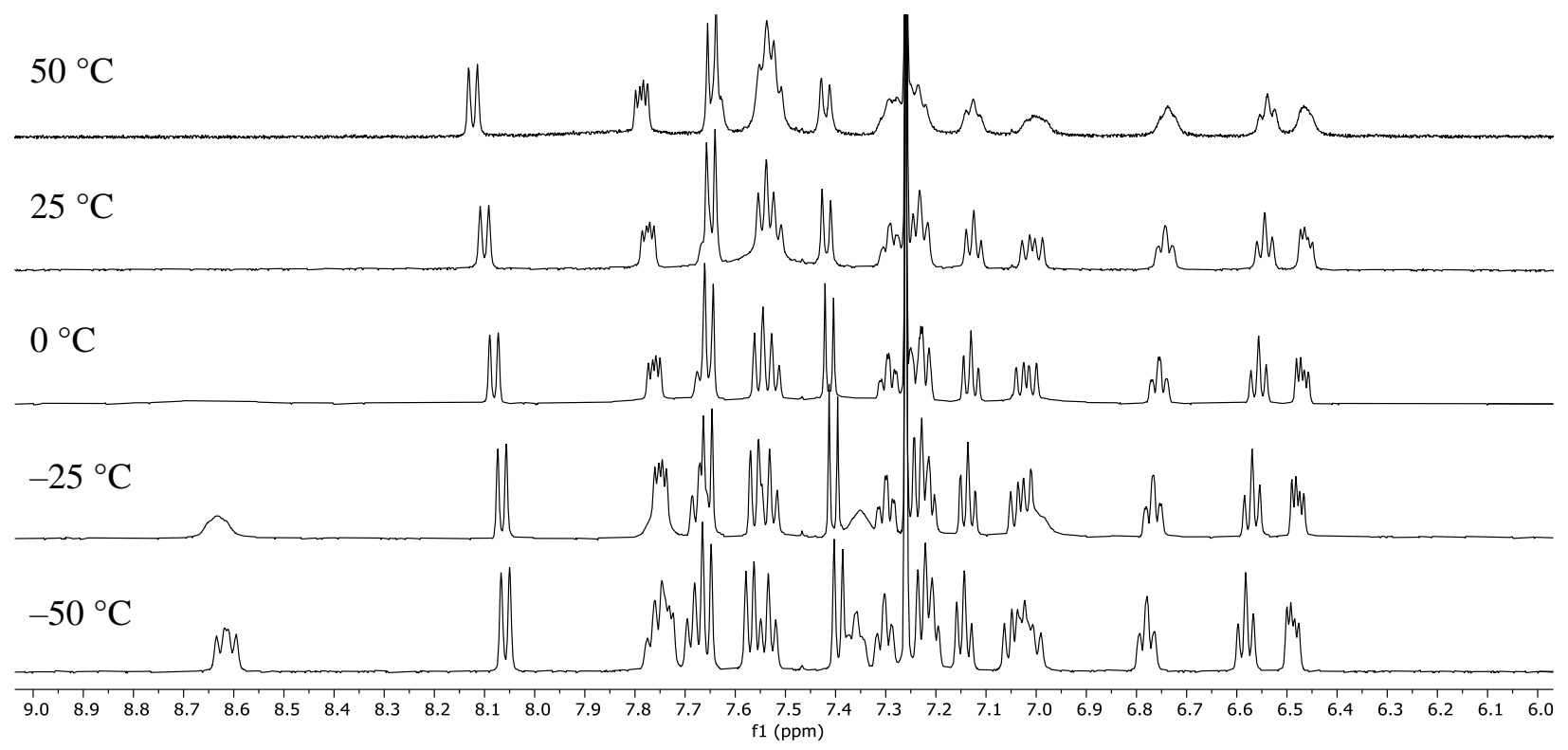


${ }^{13} \mathrm{C} \mathrm{NMR}\left(\mathrm{CDCl}_{3}, 151 \mathrm{MHz}, 25{ }^{\circ} \mathrm{C}\right)$

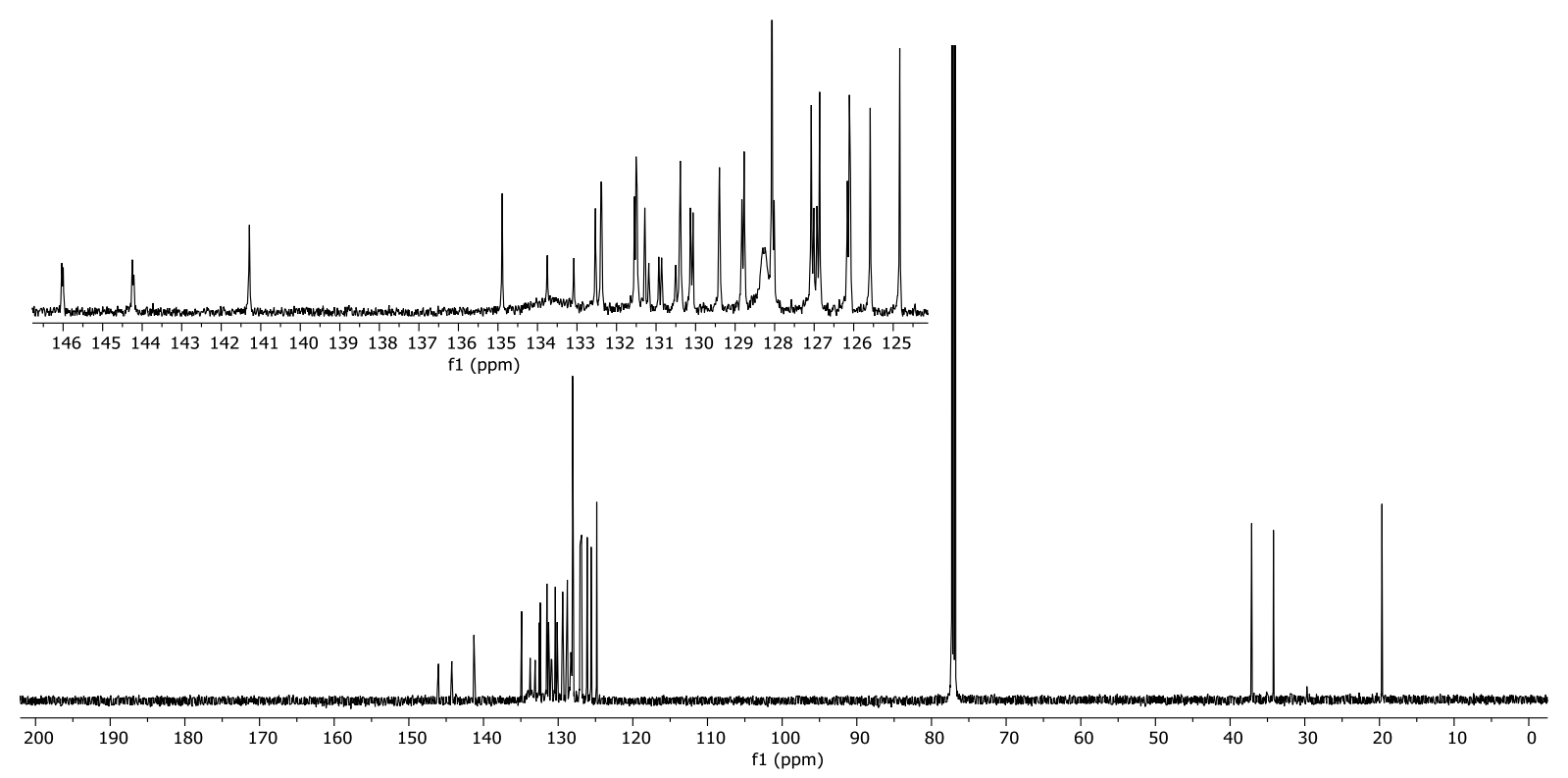

${ }^{31} \mathrm{P}$ NMR $\left(\mathrm{CDCl}_{3}, 243 \mathrm{MHz}, 25^{\circ} \mathrm{C}\right)$

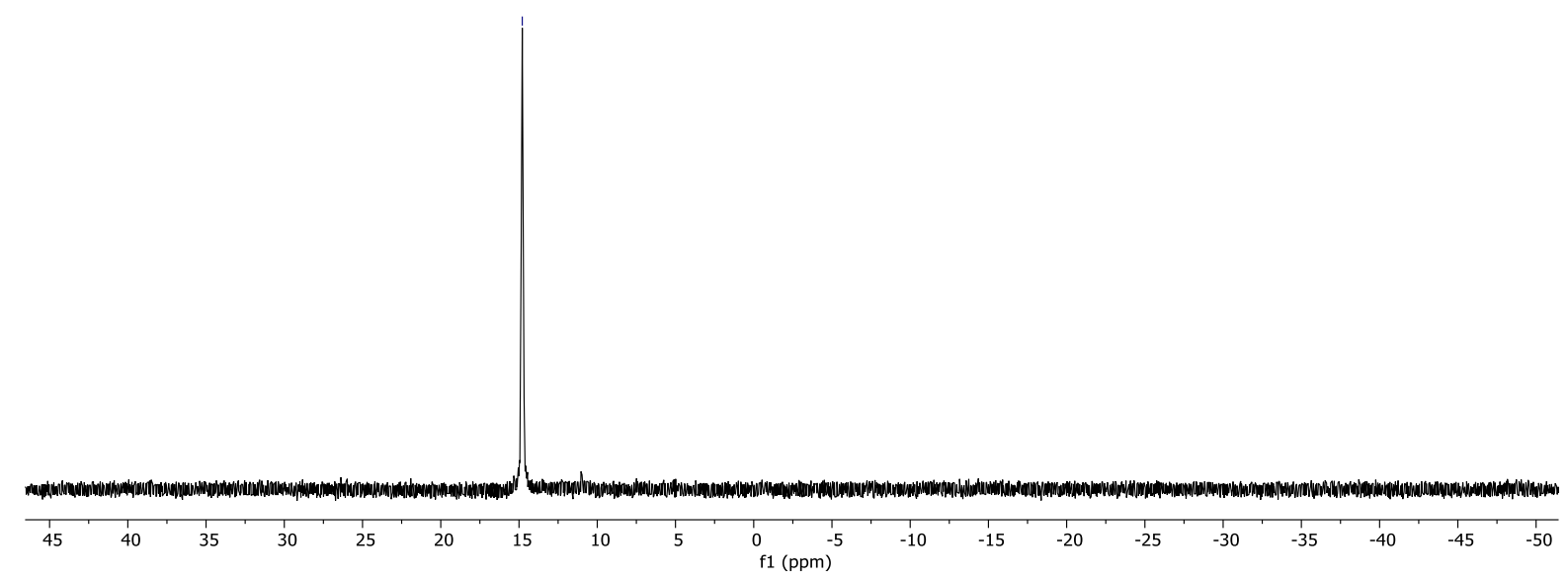

HRMS (ESI+)

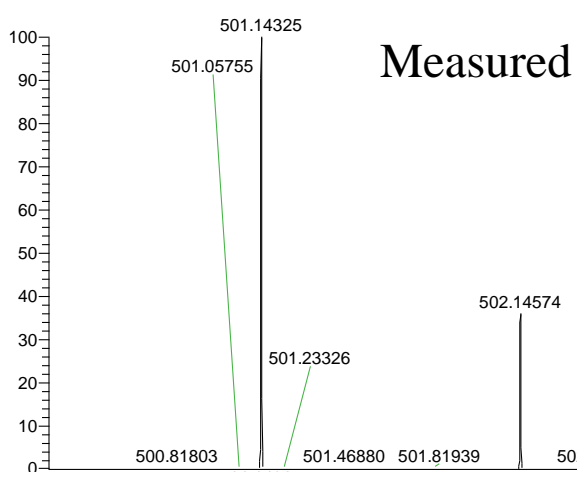

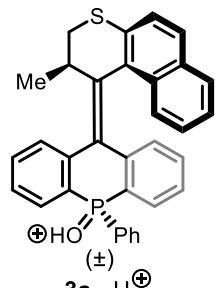

$3 a \cdot H^{\oplus}$

Chemical Formula: $\mathrm{C}_{33} \mathrm{H}_{26} \mathrm{OPS}^{+}$

Exact Mass: 501.1436

503.14830
NL:
$1.48 \mathrm{E} 8$

GBB-II-145\#2-24

RT: $0.01-0.61$ AV:

Full $\mathrm{ms}$
$[250.00-700.00]$ 
Oxide Motor 3c<smiles>[B]P1(=O)c2ccccc2C(=C2[CH]CSc3ccc4ccccc4c32)c2ccccc21</smiles>

$3 c$

${ }^{1} \mathrm{H} \mathrm{NMR}\left(\mathrm{CDCl}_{3}, 500 \mathrm{MHz}, 25^{\circ} \mathrm{C}\right)$

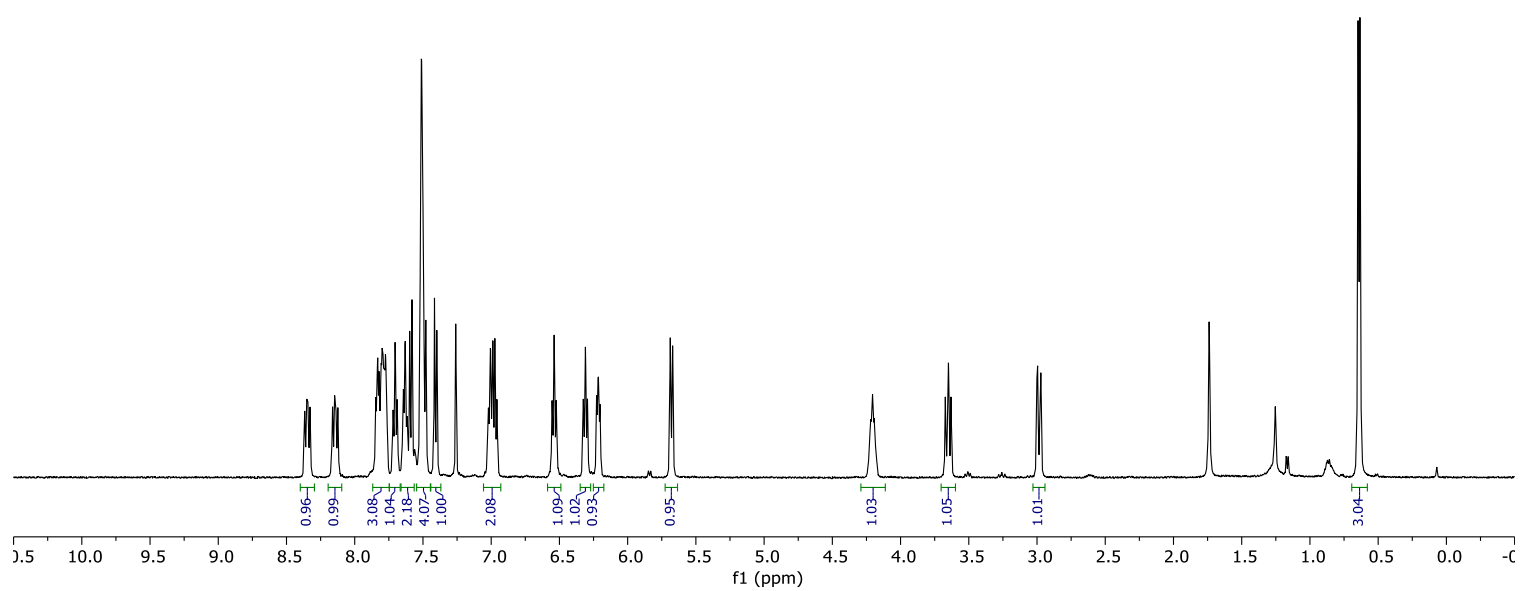

${ }^{13} \mathrm{C}$ NMR $\left(\mathrm{CDCl}_{3}, 126 \mathrm{MHz}, 25{ }^{\circ} \mathrm{C}\right)$

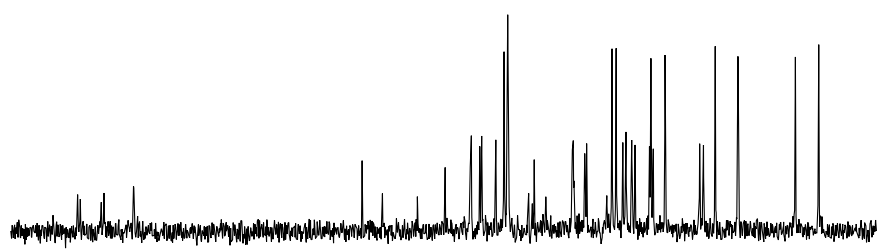

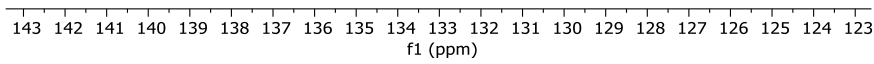

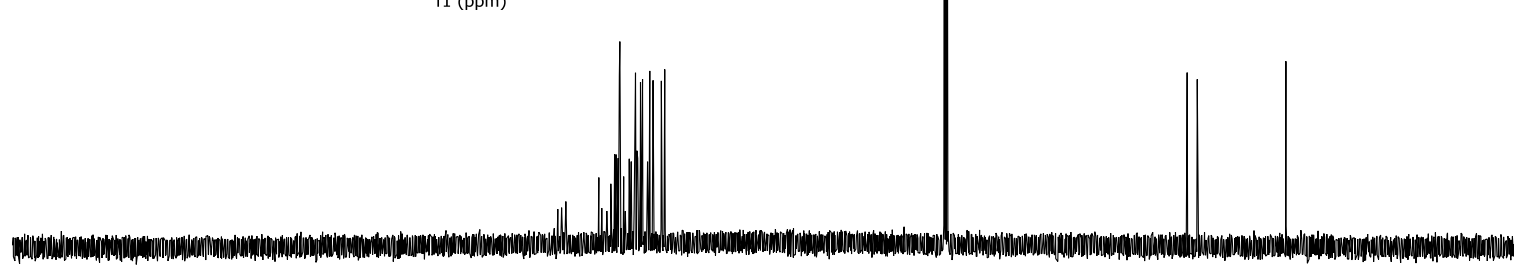

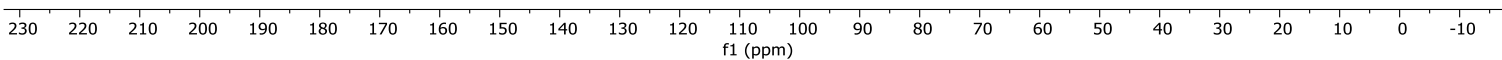


${ }^{31} \mathrm{P}$ NMR $\left(\mathrm{CDCl}_{3}, 162 \mathrm{MHz}, 25^{\circ} \mathrm{C}\right)$

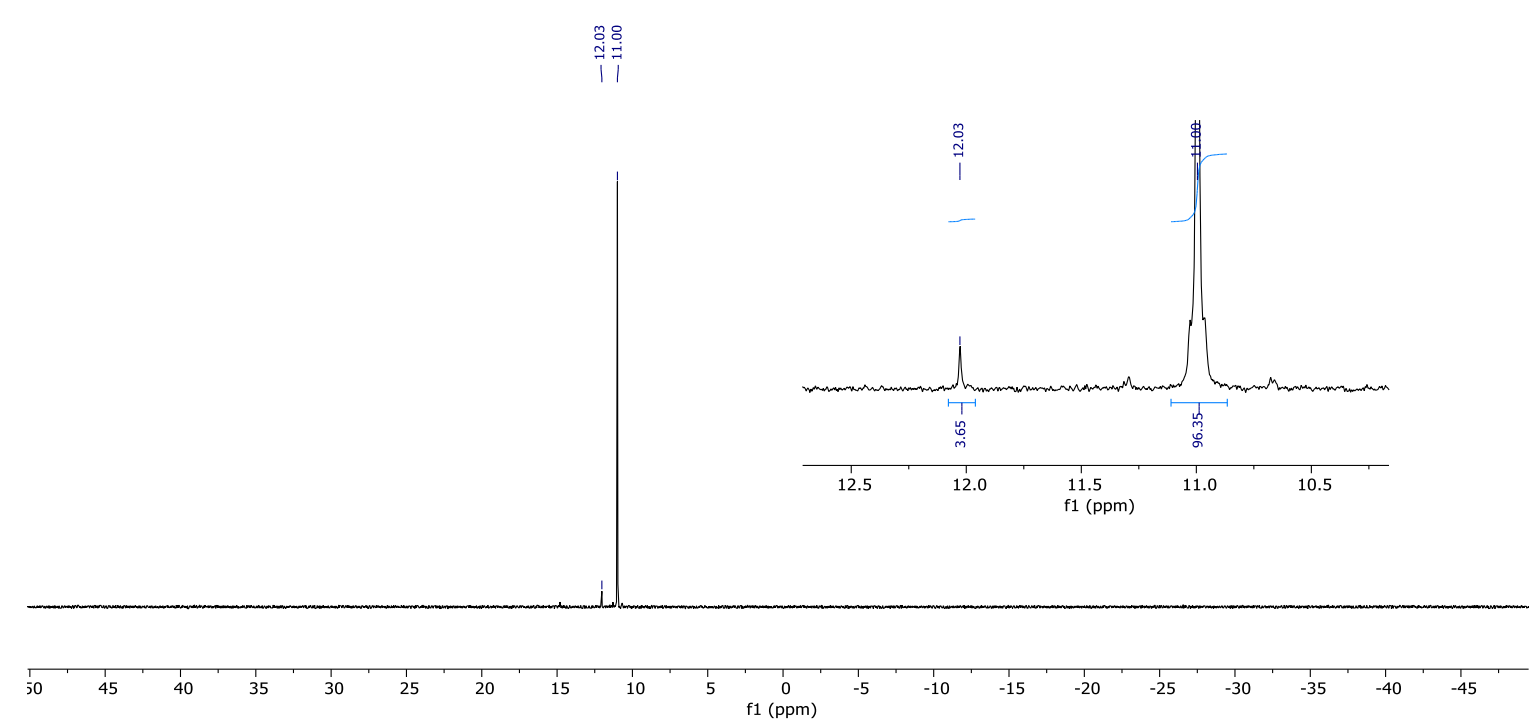

\section{HRMS (ESI+)}

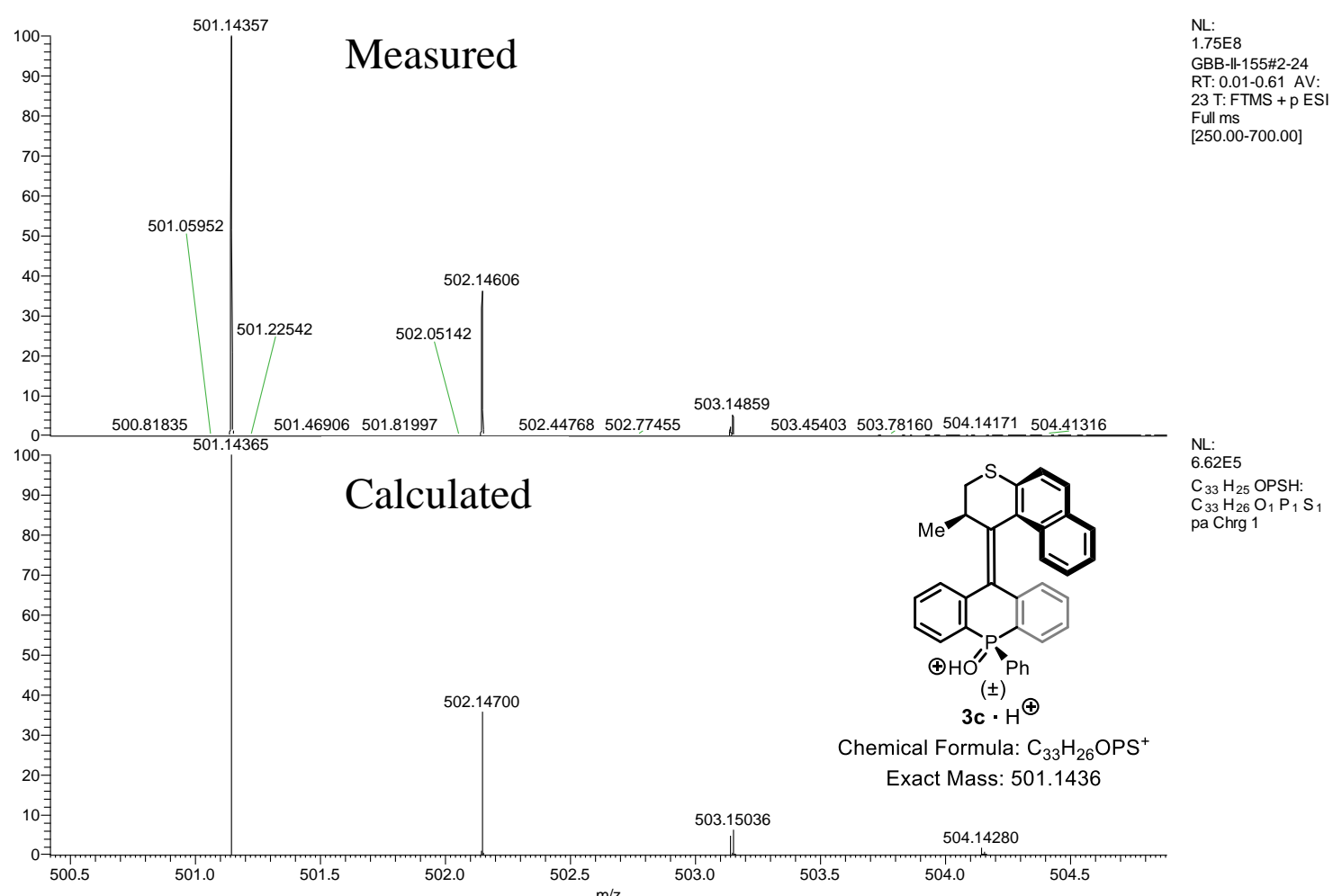




\section{References}

${ }^{1}$ https://www.thorlabs.com/newgrouppage9.cfm?objectgroup_id $=5206$

${ }^{2}$ Schaub, T. A.; Brülls, S. M.; Dral, P. O.; Hampel, F.; Maid, H.; Kivala, M. Chem. Eur. J. 2017, 23, 6988-6992.

${ }^{3}$ Berger, S.; Braun, S. 200 and More NMR Experiments; Wiley-VCH, Germany, 2004; pp 145-148.

${ }^{4}$ Perrin, C. L.; J. Chem. Ed. 2017, 94, 669-672.

${ }^{5}$ Lagarias, J. C. et al: Convergence Properties of the Nelder-Mead Simplex Method in Low Dimensions; SIAM J. Optim. 1998, 9, 112.

${ }^{6}$ Maity, S. et al; Caught in the Act: Mechanistic Insight into Supramolecular Polymerization-Driven SelfReplication from Real-Time Visualization; J. Am. Chem. Soc. 2020, 142, 13709-13717.

${ }^{7}$ Bruker, (2016). APEX3 (V2016.1-0), SAINT (Version 8.37A) and SADABS (Version 2014/5). Bruker AXS Inc., Madison, Wisconsin, USA.

${ }^{8}$ Bruker, (2019). APEX3 (V2019.1-0), SAINT (Version 8.40A) and SADABS (Version 2016/1). Bruker AXS Inc., Madison, Wisconsin, USA.

${ }^{9}$ Krause, L., Herbst-Irmer, R., Sheldrick, G. M. \& Stalke, D. Comparison of silver and molybdenum microfocus X-ray sources for single-crystal structure determination. J. Appl. Crystallogr. 2015, 48, 3-10.

${ }^{10}$ Sheldrick, G. M. \& IUCr. SHELXT - Integrated space-group and crystal-structure determination. Acta Crystallogr. Sect. A Found. Adv. 2015, 71, 3-8.

${ }^{11}$ Sheldrick, G. M. A short history of SHELX. Acta Crystallogr Sect. A 2008, A64, 112-122.

${ }^{12}$ A.L.Spek, J. Appl. Cryst. 2003, 36, 7-11

${ }^{13}$ O. V. Dolomanov, L. J. Bourhis, R. J. Gildea, J. A. K. Howard and H. Puschmann J. Appl. Cryst. (2009). 42, 339-341.

${ }^{14}$ L. J. Farrugia, J. Appl. Cryst. 2012, 45, 849-854. 